\title{
Improving Heavy-Duty Diesel Truck Ergonomics to Reduce Fatigue and Improve Driver Health and Performance
}



U.S. Department of Transportation 


\section{FOREWORD}

In this study sponsored by the Federal Motor Carrier Safety Administration, noise levels, wholebody vibration from the driver and passenger seats, and the in-cab air quality of heavy-duty diesel trucks were measured while the vehicles were parked with the engine idling at a truck stop rest area and while they were driven over a prescribed route. The air quality was determined by measuring in-cab concentrations of carbon monoxide, oxides of nitrogen, and particulate matter less than $2.5 \mu \mathrm{m}$ in aerodynamic diameter. These factors were selected because they are suspected to have some influence on the health and performance of drivers. Also the intention was that the data sets will serve as baseline data from which future similar studies may determine if (new) truck designs have changed the existing state of these conditions for the drivers. Twenty-seven trucks from four manufacturers were tested. Model years of the trucks were between 2006 and 2008.

This final report would be of interest to health and wellness professionals: occupational safety and health management, researchers, and academicians; commercial motor vehicle industry: drivers, carriers, manufacturers, and truck travel centers.

\section{NOTICE}

This document is disseminated under the sponsorship of the U.S. Department of Transportation in the interest of information exchange. The United States Government assumes no liability for its contents or the use thereof.

The contents of this Report reflect the views of the contractor, who is responsible for the accuracy of the data presented herein. The contents do not necessarily reflect the official policy of the U.S. Department of Transportation.

This Report does not constitute a standard, specification, or regulation.

The United States Government does not endorse products or manufacturers named herein. Trade or manufacturers' names appear herein solely because they are considered essential to the object of this report. 


\section{Technical Report Documentation Page}

\begin{tabular}{|c|c|c|c|c|}
\hline $\begin{array}{l}\text { 1. Report No. } \\
\text { FMCSA-RRR-10-010 }\end{array}$ & \multicolumn{2}{|c|}{ 2. Government Accession No. } & \multicolumn{2}{|c|}{ 3. Recipient's Catalog No. } \\
\hline \multirow{2}{*}{\multicolumn{3}{|c|}{$\begin{array}{l}\text { 4. Title and Subtitle } \\
\text { IMPROVING HEAVY DUTY DIESEL TRUCK ERGONOMICS TO } \\
\text { REDUCE FATIGUE AND IMPROVE DRIVER HEALTH AND } \\
\text { PERFORMANCE }\end{array}$}} & \multicolumn{2}{|l|}{$\begin{array}{l}\text { 5. Report Date } \\
\text { December } 2010\end{array}$} \\
\hline & & & \multicolumn{2}{|c|}{ 6. Performing Organization Code } \\
\hline \multicolumn{3}{|c|}{$\begin{array}{l}\text { 7. Author(s) } \\
\text { Joshua S. Fu, James A. Calcagno III, Wayne T. Davis, J.A.M Boulet, and } \\
\text { Jack F. Wasserman }\end{array}$} & \multicolumn{2}{|c|}{ 8. Performing Organization Report No. } \\
\hline \multirow{2}{*}{\multicolumn{3}{|c|}{$\begin{array}{l}\text { 9. Performing Organization Name and Address } \\
\text { The University of Tennessee } \\
\text { Dept. of Civil \& Environmental Engineering } \\
1506 \text { Middle Drive; } 223 \text { Perkins Hall } \\
\text { Knoxville, TN } 37996\end{array}$}} & \multicolumn{2}{|c|}{ 10. Work Unit No. (TRAIS) } \\
\hline & & & \multicolumn{2}{|c|}{ 11. Contract or Grant No. } \\
\hline \multirow{2}{*}{\multicolumn{3}{|c|}{$\begin{array}{l}\text { 12. Sponsoring Agency Name and Address } \\
\text { Department of Transportation } \\
\text { Federal Motor Carrier Safety Administration } \\
1200 \text { New Jersey Ave SE } \\
\text { Washington, DC } 20590\end{array}$}} & \multicolumn{2}{|l|}{$\begin{array}{l}\text { 13. Type of Report } \\
\text { Final Report }\end{array}$} \\
\hline & & & \multicolumn{2}{|c|}{ 14. Sponsoring Agency Code } \\
\hline \multicolumn{5}{|c|}{$\begin{array}{l}\text { 15. Supplementary Notes } \\
\text { This research was sponsored by the Federal Motor Carrier Safety Administration. } \\
\text { Contracting Officer's Technical Representative was Albert Alvarez. }\end{array}$} \\
\hline \multicolumn{5}{|c|}{  } \\
\hline $\begin{array}{l}\text { 17. Key Words } \\
\text { Air quality, diesel, diesel truc } \\
\text { in-, noise, noise level, seats, vi }\end{array}$ & $\begin{array}{l}\text { sonomics, heavy duty, } \\
\text { on, whole- }\end{array}$ & $\begin{array}{l}\text { 18. Distributic } \\
\text { No restricti }\end{array}$ & tement & \\
\hline $\begin{array}{l}\text { 19. Security Classif. (of this report) } \\
\text { Unclassified }\end{array}$ & $\begin{array}{l}\text { 20. Security Classif } \\
\text { Unclassified }\end{array}$ & f this page) & $\begin{array}{l}\text { 21. No. of Pages } \\
129\end{array}$ & 22. Price \\
\hline
\end{tabular}

Form DOT F 1700.7 (8-72) 


\section{SI* (MODERN METRIC) CONVERSION FACTORS}

Table of APPROXIMATE CONVERSIONS TO SI UNITS

\begin{tabular}{|c|c|c|c|c|}
\hline Symbol & When You Know & Multiply By & To Find & Symbol \\
\hline \multicolumn{5}{|c|}{ LENGTH } \\
\hline In & Inches & 25.4 & Millimeters & $\mathrm{mm}$ \\
\hline $\mathrm{Ft}$ & Feet & 0.305 & Meters & $\mathrm{m}$ \\
\hline Yd & Yards & 0.914 & Meters & $\mathrm{m}$ \\
\hline Mi & Miles & 1.61 & Kilometers & $\mathrm{km}$ \\
\hline \multicolumn{5}{|c|}{ AREA } \\
\hline $\mathrm{in}^{2}$ & square inches & 645.2 & square millimeters & $\mathrm{mm}^{2}$ \\
\hline $\mathrm{ft}^{2}$ & square feet & 0.093 & square meters & $\mathrm{m}^{2}$ \\
\hline $\mathrm{yd}^{2}$ & square yards & 0.836 & square meters & $m^{2}$ \\
\hline$A c$ & Acres & 0.405 & Hectares & ha \\
\hline $\mathrm{mi}^{2}$ & square miles & 2.59 & square kilometers & $\mathrm{km}^{2}$ \\
\hline & & VOLUME & $1000 \mathrm{~L}$ shall be shown in $\mathrm{m}^{3}$ & \\
\hline $\mathrm{fl} \mathrm{oz}$ & fluid ounces & 29.57 & Milliliters & $\mathrm{mL}$ \\
\hline Gal & Gallons & 3.785 & Liters & L \\
\hline $\mathrm{ft}^{3}$ & cubic feet & 0.028 & cubic meters & $\mathrm{m}^{3}$ \\
\hline $\mathrm{yd}^{3}$ & cubic yards & 0.765 & cubic meters & $m^{3}$ \\
\hline \multicolumn{5}{|c|}{ MASS } \\
\hline $\mathrm{Oz}$ & Ounces & 28.35 & Grams & $\mathrm{g}$ \\
\hline $\mathrm{Lb}$ & Pounds & 0.454 & Kilograms & $\mathrm{kg}$ \\
\hline $\mathrm{T}$ & short tons $(2000 \mathrm{lb})$ & 0.907 & megagrams (or "metric ton") & $\mathrm{Mg}$ (or "t") \\
\hline & & TEMPERATURE & Temperature is in exact degrees & \\
\hline${ }^{\circ} \mathrm{F}$ & Fahrenheit & $\begin{array}{l}5 \times(F-32) \div 9 \\
\text { or }(F-32) \div 1.8\end{array}$ & Celsius & ${ }^{\circ} \mathrm{C}$ \\
\hline \multicolumn{5}{|c|}{ ILLUMINATION } \\
\hline fc & foot-candles & 10.76 & Lux & \\
\hline $\mathrm{fl}$ & foot-Lamberts & 3.426 & candela $/ \mathrm{m}^{2}$ & $\mathrm{~cd} / \mathrm{m}^{2}$ \\
\hline \multicolumn{5}{|c|}{ Force and Pressure or Stress } \\
\hline & Poundforce & 4.45 & Newtons & $\mathrm{N}$ \\
\hline lbf/in ${ }^{2}$ & poundforce per square inch & 6.89 & Kilopascals & $\mathrm{kPa}$ \\
\hline \multicolumn{5}{|c|}{ Table of APPROXIMATE CONVERSIONS FROM SI UNITS } \\
\hline Symbol & When You Know & Multiply By & To Find & Symbol \\
\hline \multicolumn{5}{|c|}{ LENGTH } \\
\hline $\mathrm{Mm}$ & Millimeters & 0.039 & inches & in \\
\hline M & Meters & 3.28 & feet & $\mathrm{ft}$ \\
\hline $\mathrm{m}$ & Meters & 1.09 & yards & yd \\
\hline $\mathrm{km}$ & Kilometers & 0.621 & miles & mi \\
\hline \multicolumn{5}{|c|}{ AREA } \\
\hline $\mathrm{mm}^{2}$ & square millimeters & 0.0016 & square inches & $\mathrm{in}^{2}$ \\
\hline $\mathrm{m}^{2}$ & square meters & 10.764 & square feet & $\mathrm{ft}^{2}$ \\
\hline$m^{2}$ & square meters & 1.195 & square yards & $\mathrm{yd}^{2}$ \\
\hline ha & Hectares & 2.47 & acres & ac \\
\hline $\mathrm{km}^{2}$ & square kilometers & 0.386 & square miles & $\mathrm{mi}^{2}$ \\
\hline \multicolumn{5}{|c|}{ VOLUME } \\
\hline $\mathrm{mL}$ & Milliliters & 0.034 & fluid ounces & $\mathrm{fl} \mathrm{oz}$ \\
\hline $\mathrm{L}$ & Liters & 0.264 & gallons & gal \\
\hline $\mathrm{m}^{3}$ & cubic meters & 35.314 & cubic feet & $\mathrm{ft}^{3}$ \\
\hline$m^{3}$ & cubic meters & 1.307 & cubic yards & $y d^{3}$ \\
\hline \multicolumn{5}{|c|}{ MASS } \\
\hline g & Grams & 0.035 & ounces & $\mathrm{Oz}$ \\
\hline $\mathrm{kg}$ & Kilograms & 2.202 & pounds & lb \\
\hline Mg (or "t") & megagrams (or "metric ton") & 1.103 & short tons (2000 lb) & $\mathrm{T}$ \\
\hline${ }^{\circ} \mathrm{C}$ & Celsius & $\begin{array}{l}\text { TEMPERATURE } \\
1.8 \mathrm{c}+32\end{array}$ & $\begin{array}{l}\text { Temperature is in exact degrees } \\
\text { Fahrenheit }\end{array}$ & ${ }^{\circ} \mathrm{F}$ \\
\hline \multicolumn{5}{|c|}{ ILLUMINATION } \\
\hline Ix & Lux & 0.0929 & foot-candles & fc \\
\hline $\mathrm{cd} / \mathrm{m}^{2}$ & candela $/ \mathrm{m}^{2}$ & 0.2919 & foot-Lamberts & $\mathrm{fl}$ \\
\hline \multicolumn{5}{|c|}{ Force \& Pressure Or Stress } \\
\hline $\mathrm{N}$ & Newtons & 0.225 & poundforce & lbf \\
\hline $\mathrm{kPa}$ & Kilopascals & 0.145 & poundforce per square inch & $\mathrm{lbf} / \mathrm{in}^{2}$ \\
\hline
\end{tabular}

* $\mathrm{SI}$ is the symbol for the International System of Units. Appropriate rounding should be made to comply with Section 4 of ASTM E380.

(Revised March 2003, Section 508-accessible version September 2009) 


\section{TABLE OF CONTENTS}

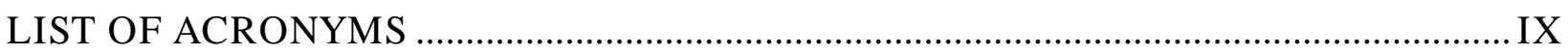



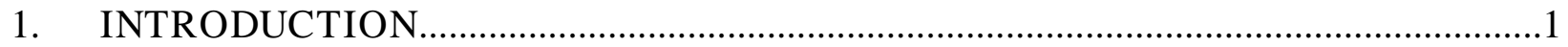

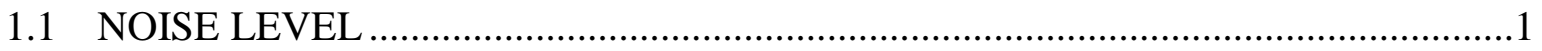

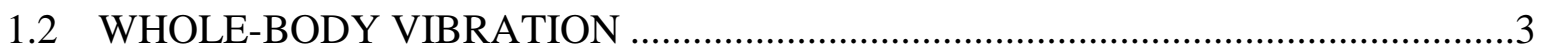

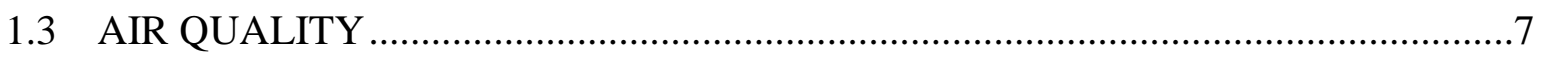

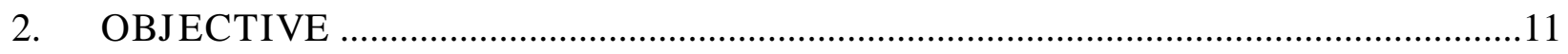



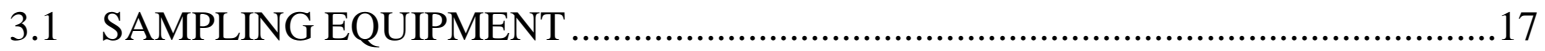



3.1.2 Whole-Body Vibration.............................................................................. 17

3.1.3 Air Quality …………………………………….................................. 18



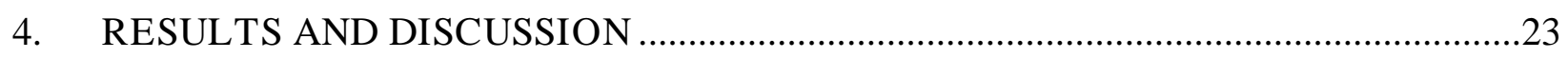



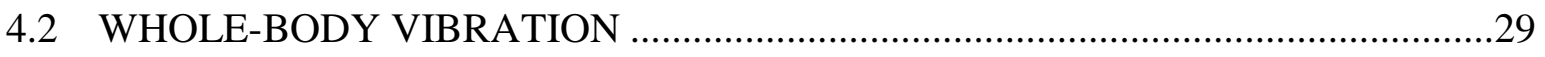

4.3 DRIVER'S SEAT CUSHION MONITORING ............................................................30



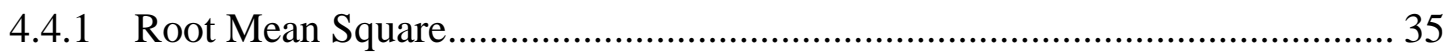



4.4.3 Vibration Dose Values................................................................................ 41





4.5.1 Calibration of Measured Concentrations …………….................................... 42

4.5.2 Truck Air Exchange Rates .......................................................................... 44

4.5.3 Parked-Idling Test................................................................................ 45



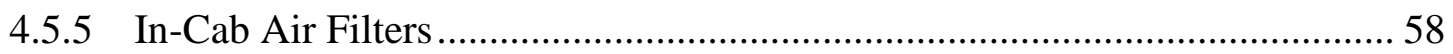

4.5.6 Chemical Analysis of Particulate Matter ........................................................ 60






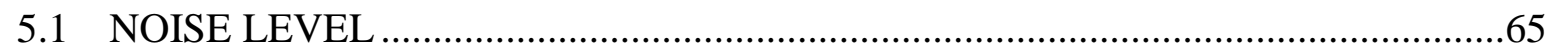



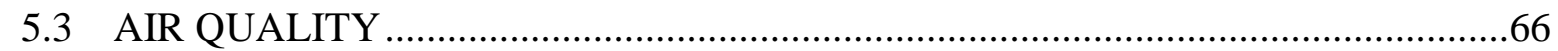

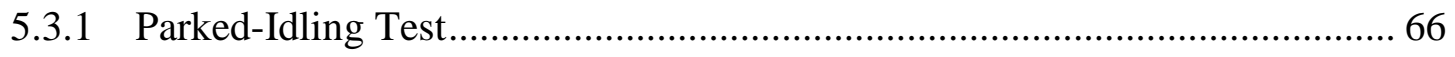

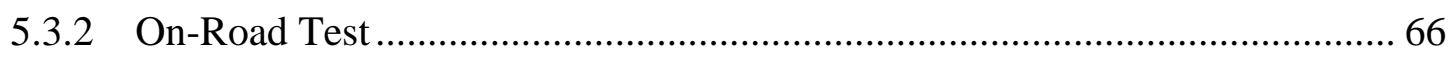

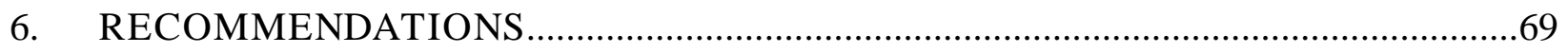

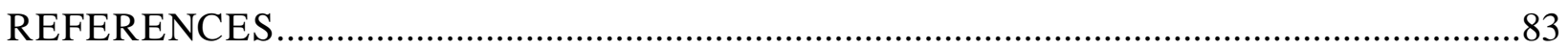




\section{LIST OF APPENDICES}

APPENDIX A-EXPOSURE STANDARDS OR RECOMMENDED VALUES ................71

APPENDIX B—ON-ROAD IN-CAB AVERAGE NOISE LEVELS PER TRUCK .............72

APPENDIX C—DRIVER SEAT CUSHION RMS VALUES PER ROADWAY ................73

APPENDIX D_DRIVER SEAT CUSHION RMS VALUES PER ROADWAY ................74

APPENDIX E-DRIVER BACK REST RMS VALUES PER ROADWAY .......................75

APPENDIX F_PASSENGER SEAT CUSHION RMS VALUES PER ROADWAY ..........76

APPENDIX G_DRIVER SEAT CUSHION VDV PER ROADWAY ...............................77

APPENDIX H-DRIVER BACK REST VDV PER ROADWAY ....................................79

APPENDIX I-PASSENGER SEAT CUSHION VDV PER ROADWAY ..........................81 


\section{LIST OF FIGURES (AND FORMULAS)}

Figure 1. Equation. Instantaneous sound pressure level equation ..................................................1

Figure 2. Equation. Average sound level equation for discrete sound-level measurements ...........2

Figure 3. Diagram. Vibration measurement coordinate system for the seated person ......................4

Figure 4. Equation. Weighted root mean square acceleration equation .........................................5

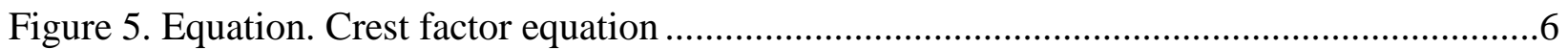

Figure 6. Equation. Fourth-power vibration dose method equation .................................................

Figure 7. Photo. Trucks parked at a study-selected travel center rest area ....................................13

Figure 8. Map. Map showing the driving route along I-40, US-27 \& TN-68, and I-75 ................14

Figure 9. Map. Relief map showing terrain contrast along the driving route..............................15

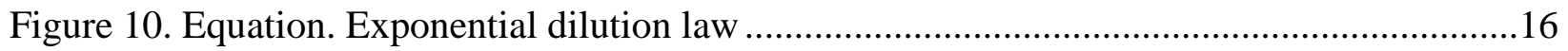

Figure 11. Diagram. Transducer placement for each HDDV .......................................................18

Figure 12. Photo. Assorted equipment located in sleeper berth area of truck .................................20

Figure 13. Graph. LS means peak noise level vs. truck manufacturer ...........................................24

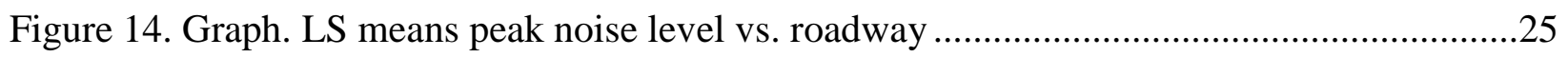

Figure 15. Graph. LS means peak noise level vs. roadway and manufacturer ...............................25

Figure 16. Graph. LS means maximum equivalent noise level vs. truck manufacturer ..................26

Figure 17. Graph. LS means maximum equivalent noise level vs. roadway .................................26

Figure 18. Graph. LS means max equivalent noise level vs. roadway and manufacturer ..............26

Figure 19. Graph. LS means $L_{\text {eq }}$ from Integrator-1 vs. truck manufacturer ....................................27

Figure 20. Graph. LS means $L_{\text {eq }}$ from Integrator-1 vs. roadway ..................................................27

Figure 21. Graph. LS means $L_{\text {eq }}$ from Integrator-1 vs. roadway and manufacturer .......................28

Figure 22. Graph. LS means Leq from Integrator-3 vs. truck manufacturer .................................28

Figure 23. Graph. LS means Leq from Integrator-3 vs. roadway ..................................................29

Figure 24. Graph. LS means Leq from Integrator-3 vs. roadway and manufacturer.......................29

Figure 25. Graph. LS means x-axis vibration vs. truck manufacturer ............................................30

Figure 26. Graph. LS means x-axis vibration vs. roadway...........................................................

Figure 27. Graph. LS means $x$-axis vibration vs. roadway and manufacturer.................................31

Figure 28. Graph. LS means y-axis vibration vs. truck manufacturer ...........................................31

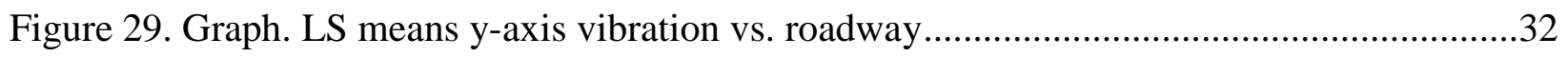

Figure 30. Graph. LS means y-axis vibration vs. roadway and manufacturer................................32

Figure 31. Graph. LS means z-axis vibration vs. truck manufacturer .............................................33

Figure 32. Graph. LS means z-axis vibration vs. roadway ..........................................................33

Figure 33. Graph. LS means z-axis vibration vs. roadway and manufacturer................................33

Figure 34. Graph. LS means $\Sigma$ (comfort) value vs. truck manufacturer..........................................34

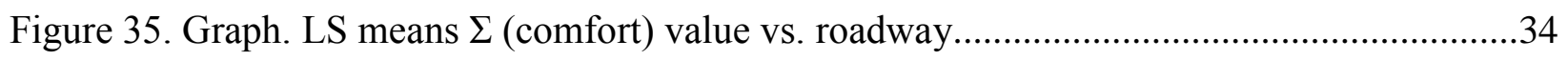

Figure 36. Graph. LS means $\Sigma$ (comfort) value vs. roadway and manufacturer ............................34

Figure 37. Graph. LS means comfort value (driver cushion) vs. truck manufacturer .....................36

Figure 38. Graph. LS means comfort value (driver cushion) vs. roadway ...................................36

Figure 39. Graph. LS means comfort value (driver cushion) vs. roadway and manufacturer........36 
Figure 40. Graph. LS means comfort value (driver back) vs. truck manufacturer .......................37

Figure 41. Graph. LS means comfort value (driver back) vs. roadway ...................................37

Figure 42. Graph. LS means comfort value (driver back) vs. roadway and manufacturer............37

Figure 43. Graph. LS means comfort value (passenger cushion) vs. truck manufacturer .............38

Figure 44. Graph. LS means comfort value (passenger cushion) vs. roadway............................38

Figure 45. Graph. LS means comfort value (passenger cushion) vs. roadway and manufacturer.38

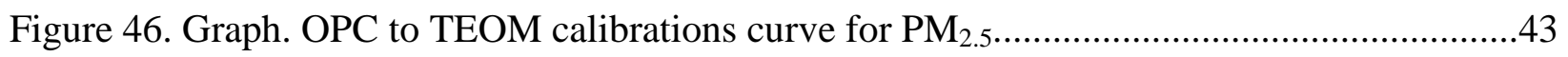

Figure 47. Graph. DRam to TEOM calibration curve for $\mathrm{PM}_{2.5}$..............................................43

Figure 48. Graph. TEOM corrected DRam vs. OPC calibration data for $\mathrm{PM}_{2.5}$..........................43

Figure 49. Graph. Decay curve for $\mathrm{CO}_{2}$ recirculaton air shifting to fresh-air mode ...................45

Figure 50. Graph. Overall average 1-h $\mathrm{CO}$ and $\mathrm{NO}_{\mathrm{X}}$ concentrations from parked-idling test ......46

Figure 51. Graph. Overall average 1-h $\mathrm{PM}_{2.5}$ concentrations from parked-idling test.................46

Figure 52. Graph. LS means CO concentration vs. truck manufacturer ....................................47

Figure 53. Graph. LS means CO concentration vs. engine/HVAC condition ............................47

Figure 54. Graph. LS means CO concentration vs. engine/HVAC and manufacturer ..................48

Figure 55. Graph. LS means NOX concentration vs. truck manufacturer..................................48

Figure 56. Graph. LS means $\mathrm{NO}_{\mathrm{X}}$ concentration vs. engine/HVAC condition ............................49

Figure 57. Graph. LS means NOX concentration vs. engine/HVAC and manufacturer ...............49

Figure 58. Graph. LS means PM2.5 (OPC) concentration vs. truck manufacturer .......................50

Figure 59. Graph. LS means $\mathrm{PM}_{2.5}$ (OPC) concentration vs. engine/HVAC condition ................50

Figure 60. Graph. LS means PM2.5 (OPC) concentration vs. engine/HVAC and manufacturer .50

Figure 61. Graph. LS means PM2.5 (DRam) concentration vs. truck manufacturer ...................51

Figure 62. Graph. LS means $\mathrm{PM}_{2.5}$ (DRam) concentration vs. engine/HVAC condition .............51

Figure 63. Graph. LS means PM2.5 (DRam) concentration vs. engine/HVAC and manufacturer51

Figure 64. Graph. Overall average 15-min $\mathrm{CO}$ and $\mathrm{NO}_{\mathrm{X}}$ concentrations from on-road test .........53

Figure 65. Graph. Overall average 15-min $\mathrm{PM}_{2.5}$ concentrations from on-road test.....................53

Figure 66. Graph. LS means CO concentration vs. truck manufacturer .....................................54

Figure 67. Graph. LS means CO concentration vs. roadway.................................................54

Figure 68. Graph. LS means CO concentration vs. roadway and truck manufacturer .................54

Figure 69. Graph. LS means $\mathrm{NO}_{\mathrm{X}}$ concentration vs. truck manufacturer...................................55

Figure 70. Graph. LS means $\mathrm{NO}_{\mathrm{X}}$ concentration vs. roadway ..............................................55

Figure 71. Graph. LS means $\mathrm{NO}_{\mathrm{X}}$ concentration vs. roadway and truck manufacturer ................55

Figure 72. Graph. LS means $\mathrm{PM}_{2.5}$ (OPC) concentration vs. truck manufacturer........................56

Figure 73. Graph. LS means $\mathrm{PM}_{2.5}$ (OPC) concentration vs. roadway.....................................56

Figure 74. Graph. LS means $\mathrm{PM}_{2.5}$ (OPC) concentration vs. roadway and truck manufacturer ...56

Figure 75. Graph. LS means $\mathrm{PM}_{2.5}$ (DRam) concentration vs. truck manufacturer ......................57

Figure 76. Graph. LS means $\mathrm{PM}_{2.5}$ (DRam) concentration vs. roadway ...................................57

Figure 77. Graph. LS means $\mathrm{PM}_{2.5}$ (DRam) concentration vs. roadway and truck manufacturer.57

Figure 78. Photo. Outside HVAC pre-filter accessible from the engine compartment ................58

Figure 79. Photo. Auxiliary air filtration system located under passenger seat ..........................59

Figure 80. Photo. Auxiliary HVAC system located under sleeper berth not filtered ....................59 
Figure 81. Photo. Internal air-filter removed from auxiliary HVAC unit. .59

Figure 82. Photo. TEM micrograph of PM during parked-idling test (0.2- $\mu \mathrm{m}$ scale)...................60

Figure 83. Photo. TEM micrograph of PM during parked-idling test (0.1- $\mu \mathrm{m}$ scale)....................61

Figure 84. Photo. TEM micrograph of PM during on-road test (0.2- $\mu \mathrm{m}$ scale) .............................61

Figure 85. Photo. TEM micrograph of PM during on-road test (0.1- $\mu \mathrm{m}$ scale) .............................62

\section{LIST OF TABLES}

Table 1. Comfort Reactions to a Vibration Environment (Seating Position) ....................................5

Table 2. Multivariate Correlations between Driver and Passenger Seating ..................................39

Table 3. Range of Values for Crest Factor from Driver and Passenger Seats .................................40

Table 4. Total Number of Trucks with CF Values Greater than 9 ..............................................40

Table 5. Range of Values for Jerk from Driver and Passenger Seats .............................................41

Table 6. Air Exchange Rates for a Subset of Trucks .....................................................................4

Table 7. Overall Average 1-h Concentrations from Parked-Idling Test...........................................45

Table 8. Overall Average 15-min Concentrations from On-Road Test...........................................52

Table 9: Exposure Standards or Recommended Values ...............................................................

Table 10: On-Road In-Cab Average Noise Levels Per Truck Manufacturer, and OSHA and ISO Integrator Measurements .............................................................................................72

Table 11. Driver Seat Cushion RMS Values Axis of Translation or $\mathrm{m} / \mathrm{s}^{2}$ Comfort vs. Roadway 73 Table 12. Driver Seat Cushion RMS Values Axis of Translation $\mathrm{m} / \mathrm{s}^{2}$ or Comfort vs. Roadway 74 Table 13. Driver Back Rest RMS Values Axis of Translation $\mathrm{m} / \mathrm{s}^{2}$ or Comfort vs. Roadway ......75 Table 14. Passenger Seat Cushion RMS Values Axis of Translation $\mathrm{m} / \mathrm{s}^{2}$ or Comfort vs.

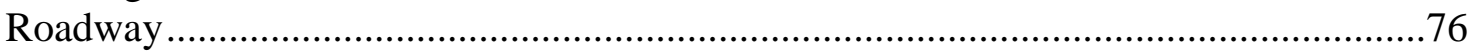

Table 15. Driver Seat Cushion VDV Axis of Translation $\mathrm{m} / \mathrm{s}^{2}$ or Comfort vs. Roadway .............77

Table 16. Driver Back Rest VDV Axis of Translation $\mathrm{m} / \mathrm{s}^{1.75}$ and Roadway................................79

Table 17. Passenger Seat Cushion VDV Axis of Translation $\mathrm{m} / \mathrm{s}^{1.75}$ and Roadway ......................81 


\section{LIST OF ACRONYMS}

AC

$\mathrm{A} / \mathrm{C}$

ACGIH

AER

AL

ANSI

$\mathrm{a}_{\mathrm{v}}$

$\mathrm{a}_{\mathrm{w}}$

$a_{\text {WRMS }}$

C

$\mathrm{C}_{0}$

$\mathrm{CF}$

CL

CMV

$\mathrm{CO}$

$\mathrm{CO}_{2}$

Conc

$\mathrm{dB}$

dBA

dBC

DC

Deg

DEWE

DOF

Dram

EAV

EC alternating current

air conditioning

American Conference of Governmental Industrial Hygienists

air exchange rate

action level

American National Standards Institute

acceleration total value

acceleration weighted value

acceleration weighted root mean square

Concentration of gas at measurement interval

concentration of gas at time zero

correction factor or crest factor

criterion level

commercial motor vehicle

carbon monoxide

carbon dioxide

Concentration

decibel scale

decibel scale using the A-filter weighting

decibel using the C-filter weighting

direct current

Degree

Dewetron

degrees of freedom

DataRAM

exposure action value

elemental carbon 
ELV

EPA

EU

FEA

$\operatorname{Exp}$

FMCSA

G

HDDV

HEPA

HOS

$\mathrm{Hp}$

HVAC

HVM

$\mathrm{H}$

HSD

I

Id

ID

ISO

K

$\mathrm{Km} / \mathrm{h}$

$\mathrm{LA}_{\mathrm{eq}}$

$\mathrm{LA}_{\text {Max }}$

$\mathrm{LA}_{\mathrm{Min}}$

$\mathrm{L}_{\text {Ave }}$

LBP

$\mathrm{L}_{\mathrm{eq}}$

$\mathrm{L}_{\mathrm{p}}$

exposure limit value

Environmental Protection Agency

European Union

finite element analysis

exponential function

Federal Motor Carrier Safety Administration

Gram

heavy-duty diesel vehicle

High-Efficiency Particulate Air filter

hours of service

Horsepower

heating, ventilation, and air-conditioning

human vibration meter

Hour

honest significant difference

measurement interval

Identification

inside diameter

International Organization for Standardization

correction factor constant

kilometer per hour

equivalent continuous sound level, A-weighted

maximum recorded sound level, A-weighted

minimum recorded sound level, A-weighted

average measured sound level

lower back pain

equivalent continuous sound level

sound pressure level 


\begin{tabular}{|c|c|}
\hline LS & least-square \\
\hline M & Meter \\
\hline Max & Maximum \\
\hline MBS & multi-body simulation \\
\hline Mfr & Manufacturer \\
\hline Min & Minute \\
\hline $\mathrm{mi} / \mathrm{h}$ & miles per hour \\
\hline $\mathrm{N}$ & sample count \\
\hline $\mathrm{N}$ & number of intervals \\
\hline NA & not available \\
\hline NAAQS & National Ambient Air Quality Standards \\
\hline NIHL & noise-induced hearing loss \\
\hline NIOSH & National Institute for Occupational Safety and Health \\
\hline NO & nitrogen monoxide or nitric oxide \\
\hline $\mathrm{NO}_{2}$ & nitrogen dioxide \\
\hline $\mathrm{NO}_{\mathrm{X}}$ & oxides of nitrogen or nitrogen oxides \\
\hline OC & organic carbon \\
\hline OPC & optical particle counter \\
\hline OSHA & Occupational Safety and Health Administration \\
\hline $\mathrm{P}$ & sound pressure \\
\hline PA & instantaneous sound pressure level, A-weighted \\
\hline PB-PAH & particulate bound polycyclic aromatic hydrocarbons \\
\hline PEL & permissible exposure limit \\
\hline $\mathrm{PM}_{2.5}$ and $\mathrm{PM}_{10}$ & particulate matter less than 2.5 and $10 \mu \mathrm{m}$ in aerodynamic diameter \\
\hline Ppb & parts per billion by volume \\
\hline Ppm & parts per million by volume \\
\hline $\mathrm{P}_{\text {ref }}$ & reference sound pressure level \\
\hline Q & specific or actual exchange rate \\
\hline
\end{tabular}


Q

REL

REML

RMS

Rpm

$\mathrm{S}$

SEM/EDS

SPL

Stdev

STEL

$\mathrm{T}$

TEM

TEOM

TC

$t_{i}$

TLV

TruckId

TruckMfr

TWA

VDV

VIN

WBV

WHO

$\mu$

$\mu g$

$\mu \mathrm{m}$

$\Sigma$

$\mathrm{P}$ exchange rate

recommended exposure limit

residual (or restricted) maximum likelihood estimation

root mean square

revolutions per minute

Second

scanning electron microscopy with energy dispersive $\mathrm{x}$-ray spectrometry

sound pressure level

standard deviation

short-term exposure limit

total measurement time period

transmission electron microscopy

tapered element oscillating microbalance

total carbon

time period at measurement interval

threshold limit value

truck identification

truck manufacturer

time-weighted average

vibration dose value

vehicle identification number

whole-body vibration

World Health Organization

Greek letter $m u$ for micro

Microgram

Micrometer

Greek letter sigma for summation symbol or comfort index

probability or significance level 


\section{EXECUTIVE SUMMARY}

\section{PURPOSE}

This study focused on measuring several factors that may influence the health and performance of long-haul freight truck drivers. The data sets will serve as baseline data for future similar studies that may determine whether new truck designs may have changed these factors.

\section{PROCESS}

The evaluated factors were noise level, whole-body vibration (WBV) from driver and passenger seats, and the air quality inside the cabin. Noise data were collected continuously during the onroad driving test using an integrating, averaging sound-level meter. Vibration data were collected using transducer pads installed on the driver and passenger seats. For computer modeling purposes, vibration transducers also were installed on the cab and truck frame. However, computer modeling results will not be discussed in this report. The in-cab air quality was evaluated using emission analyzers for carbon monoxide (CO), oxides of nitrogen ( $\mathrm{NO}_{\mathrm{X}}$ ), and particulate matter less than 2.5- $\mu \mathrm{m}$ in aerodynamic diameter $\left(\mathrm{PM}_{2.5}\right)$. The sample of heavy-duty diesel trucks included the latest-model-year vehicles available at the time of the study from four different truck manufacturers. Measurements were conducted while the trucks were parked with the engines idling at a truck-stop rest area and during an actual on-road driving episode that included interstates and State highways, over moderately steep and relatively flat terrains. The parked engine-idling test involved measuring in-cab air quality under several engine and heating, ventilation, and air-conditioning (HVAC) modes of operation.

\section{STUDY FINDINGS}

Noise Level: Overall results indicated that the noise levels measured in the trucks during the onroad tests were well below the Occupational Safety and Health Administration (OSHA) permissible exposure level (PEL) — 90 decibels (dBA) —and/or the National Institute for Occupational Safety and Health (NIOSH) recommended value-85 dBA for an 8-hour (h) work day. ${ }^{*}$ The noise levels in the test trucks also did not exceed the Action Level (AL), which is 50 percent of the maximum PEL. When the current 11-h driving time limit is considered for the worst case truck, the estimated dose percent was still not exceeded for the AL. This study showed overall noise levels to be somewhat lower than those reported in the literature from other studies, which showed noise levels greater than the AL. Slightly higher noise levels were measured during interstate travel relative to State highway travel. It is believed that noise from

\footnotetext{
*According to Federal Motor Carrier Safety Regulations (49 CFR part 393.94) the interior sound level at the driver's seating position must not exceed $90 \mathrm{dBA}$, as measured when the truck is parked with all doors, windows, and vents closed; all power-operated accessories turned off; and, with the transmission in neutral, the engine is accelerated to-and stabilized at - either its maximum governed engine speed if it is equipped with an engine governor, or its maximum rated horsepower. The regulation does not specify a maximum time-weighted-average dBA level for an 8-h work day, which was the standard used in this study.
} 
tires, engine revolutions per minute (rpm), and wind impacting the cab at higher road speeds contributed to the elevated noise levels during interstate driving because higher road speeds are permitted on the interstate system. Slightly higher noise levels were also noticed while driving on steeper terrains relative to driving on flat terrain. Basically, the noise levels were similar across the truck manufacturers, although some slight differences were observed.

Whole-body Vibration: Evaluation for seat vibration utilized the International Organization for Standardization (ISO) guidelines. Analysis of WBV from the driver and passenger seats involved two instrument measurement systems and two assessment methodologies. Overall results in all cases indicated that vibration from the seats was generally below the European Union (EU) exposure action level (EAV) $-0.5 \mathrm{~m} / \mathrm{s}^{2}$ for the root-mean square (RMS) and $9.1 \mathrm{~m} / \mathrm{s}^{1.75}$ for the vibration dose value (VDV) methods for an 8-h day. Exposure limits were exceeded in a few trucks, but for the most part these were isolated and were probably due to the poor condition of the roadway pavement. Significant differences in WBV existed between truck manufacturers, and between interstate and State highway driving, with the higher WBV occurring on the rural highway. If the EAV is projected to the current 11-h limit just three or four vehicles came close or were actually over this limit but this occurred mostly in the y-axis, which is less serious than vibration in the z-axis because the z-axis is the linear direction of the spinal column for a seated person. The comfort index of the seats, in the majority of the trucks, fell within the "a little uncomfortable" region. This was one comfort indicator removed from the best possible rating, which is the "not uncomfortable" region. It should be noted that very few studies have been conducted in the United States on WBV from heavy-duty diesel truck seats.

Air Quality: For the parked engine-idling tests, overall $\mathrm{CO}, \mathrm{NO}_{\mathrm{X}}$ and $\mathrm{PM}_{2.5}$ concentrations were relatively low inside the cab when the truck engine and the HVAC system were in off modes. Highest $\mathrm{CO}$ and $\mathrm{NO}_{\mathrm{X}}$ concentrations occurred during engine-on and $\mathrm{HVAC}$ in recirculation modes; high $\mathrm{PM}_{2.5}$ concentrations occurred during engine-on and HVAC in fresh-air mode and during engine-on and fan-off modes. The results demonstrate that long-haul trucks have a tendency to self-pollute the cab during extended periods of parked-idling conditions. Selfpollution occurs when a percentage of the vehicle's own exhaust enters the cab. It is believed this problem and the close proximity of many trucks idling at the same time in the truck-stop rest areas create conditions for diesel exhaust to enter the cab via the HVAC system or naturally from air infiltration around window and door seals and other areas. These results were also in line with a similar study that measured in-cab concentrations during parked-engine idling conditions at another truck-stop rest area.

Nonetheless, the measured concentrations of CO for all engine/HVAC modes of operation were well below the OSHA 8-h time weighted average (TWA) - 50 parts per million (ppm) by volume and should not pose health problems for the drivers sleeping in the cab during rest periods. The $\mathrm{NO}_{\mathrm{X}}$ concentrations were also below occupational or industrial exposure limits. However during several parked-idling scenarios, the $\mathrm{PM}_{2.5}$ concentrations were around the limits set by the U.S. Environmental Protection Agency (EPA) through the National Ambient Air Quality Standards (NAAQS) for the 24-h and annual means. It should be noted that these EPA standards are ambient air monitoring standards and that were set to protect general public health, including the health of sensitive populations such as asthmatics, children, and the elderly. In this study they were used for comparison purposes because industrial or workplace $\mathrm{PM}_{2.5}$ limits have not been established by OSHA. Primary and secondary NAAQS exist for CO, lead, nitrogen dioxide 
$\left(\mathrm{NO}_{2}\right)$, particulate matter, ozone, and sulfur dioxide. The averaging times for the NAAQS are different from typical workplace averaging times. Areas not meeting these NAAQS are required to create an implementation plan to meet the standards within a certain time period. For $\mathrm{PM}_{2.5}$ the EPA regulatory language (40 CFR part 81) is expressed in terms of attainment levels establishing that the 3-year averages of a population-oriented monitor in the area must not exceed $35 \mu \mathrm{g} / \mathrm{m}^{3}$ and $15 \mu \mathrm{g} / \mathrm{m}^{3}$ for the 24-h and annual means, respectively.

For the on-road tests, the in-cab concentrations of the three air pollutants were much lower than were the concentrations measured during the parked-idling tests. However, while driving on the interstate, the inside concentrations were slightly higher relative to the concentrations measured while driving on the State highway. This condition is thought to be caused by the higher vehicle densities normally present on the interstate-a larger number of vehicles producing a greater quantity of pollutants that enter trucks through their HVAC systems. Average $\mathrm{CO}, \mathrm{NO}_{\mathrm{X}}$, and $\mathrm{PM}_{2.5}$ concentrations during parked-idling were approximately 1.5, 7.1, and 3.0 times greater, respectively, than the average on-road concentrations. These results suggest that less of a chance exists for the exhaust of the truck to self-pollute the cab while the truck is driven than while it is parked and idling, and that the highway environment, rather than the truck itself, is the primary cause of the truck driver's in-cab exposure to air pollutants.

\section{RECOMMENDATIONS}

Results of this study suggest that the two main areas of concern are the overall perceived riding comfort index of the seats and the elevated $\mathrm{PM}_{2.5}$ concentrations measured in the cabin during several of the parked, engines idling conditions at the truck-stop rest area. Although the noise levels inside the cab were reasonably low, this fact was most likely the result of sound attenuation from cabin wall padding, privacy curtains, and floor carpeting installed by the truck manufacturer. In the future, if manufacturers decide to reduce material costs in the construction of truck cabs, the noise levels could rise and possibly become cause for alarm.

Seating: The sample of test trucks was relatively small in this study. At least 90 percent of the seats were manufactured by a single company. Also the vehicles were lease or rental-trucks, so it was likely that the standard (not the optional) seats were installed in the trucks for reasons of cost. Since a wider range of seats was not adequately represented in this study, it is unknown if all seats perform identically in the ability to attenuate vibration exposures for the driver. Therefore, it is recommended that a broader range of trucks are tested in future studies which will include more models from several different seat manufacturers.

While the seats for these test trucks were adequate in reducing WBV, opportunity still exists for improvements to be made on the comfort index since the levels reported in this study were not the best rating possible. In support of this view, several questionnaire-type studies in the past have also indicated driver seating discomfort. The potential for spinal damage from seating vibration is not well understood and should be investigated. Two additional areas that could have an impact on seat vibration should also be examined: the location of the fifth-wheel and the use of single-wide tires. The fifth-wheel is the coupling device used on trucks or tractors to connect trailers. The location of the fifth-wheel is not fixed and can be adjusted to distribute trailer load over the drive axles, thus influencing truck ride quality. Single-wide tires are slightly wider than 
traditional dual tires and can replace the double tires on each end of a drive or trailer axle. By reducing rolling friction, single-wide tires are a fuel savings innovation.

Heavy-duty truck seats are basically air or pneumatically operated with multiple adjustments to control the cushion, lumbar (or back) support, isolator engagement, fore and aft adjustment, height adjustment, cushion angle, and armrest angle. For the most part, none of these features were controlled or standardized to any degree in this study. It is noteworthy that the same driver also drove all the test trucks, and he was very knowledgeable in the operation of the seats. Currently, human exposure guidelines do not reflect the relationships between poor posture and driving posture, various seat configurations (e.g., seat back/cushion reclining angle) and/or sitting postures (e.g., torso/knee angle) and possible adjustments of the seat relative to the steering wheel. Additional research is suggested to determine optimal active seat settings which can minimize WBV. Also, it may be necessary to develop an effective strategy to train drivers in the proper use of the seating adjustments, so that they use the seat controls to full effect.

Air Quality: Offering a recommendation in this area is somewhat complicated because the most straightforward solution for improving the air quality in the cabin during periods of parked idling would be simply to prohibit engine idling while a driver is resting in the sleeper berth. However, to do this would severely limit the driver's use of the vehicle's heat and air conditioning or comfort appliances such as microwave or television that depend on the idling engine to operate.

The idling engine self-pollutes the cab for the resting driver. Numerous trucks parked and idling together in close proximity at a truck-stop rest area also create the potential for air-quality problems in the cabs for the drivers, as well as for persons working at the truck-stop. Since a possible $\mathrm{PM}_{2.5}$ problem exists, it is also likely that other gaseous hydrocarbon emissions, such as 1-3 butadiene, formaldehyde, or acetaldehyde, may be present in the cab during extended periods of parked idling. A diesel particulate matter exposure limit has been established by the U.S. Mine Safety and Health Administration (MSHA) for personal working in underground mines. This PEL is based on the airborne concentration of total carbon (TC). However, it should also be pointed out that the MSHA standard, while applicable in the mining workplace environment, does not apply to drivers who are resting in a travel center, as this is not defined at this time as a workplace environment. Additional research is needed to better define and identify whether other diesel engine combustion hydrocarbons, including TC, are present above acceptable workplace exposure limits inside the cabin during periods of idling.

The in-cab air quality during periods of parked-engine idling at truck-stop rest areas continues to be an issue which warrants further study. Design and testing of cabin air-filtration/purification systems are several possible areas for research. However, these systems, with typical low air flow rates may prove to be inadequate in reducing concentrations within the cabin environment because of the high cabin air exchange rates which exist in current cabs between inside and outside air, as measured and described elsewhere in this report.

External HVAC systems have been reported to be successful in reducing in-cab pollutant concentrations. Such systems use a high air exchange rate, which provides a mechanism for external air filtration while the truck engine is off, thus substantially reducing in-cab concentrations. Other technologies also are aimed at idle reduction, such as auxiliary power units 
(APU). The APU provides an alternative to the truck's main engine when power is needed for electricity or heating and cooling the cab during rest periods. 
[This page intentionally left blank.] 


\section{INTRODUCTION}

The Federal Motor Carrier Safety Administration (FMCSA) promulgates Hours of Service (HOS) regulations limiting the total of daily and weekly hours during which long-haul truck drivers are permitted to operate their vehicles on the public roadways. ${ }^{1}$ A heavy-duty diesel vehicle (HDDV) used for long-distance freight hauling usually has a sleeper berth behind the driver seat so the driver can rest during these Federally mandated restorative rest periods. Driver safety and public motor safety are the primary concerns influencing HOS regulation.

Understanding the factors contributing to commercial vehicle operator health and performance is important in developing future regulations.

\section{$1.1 \quad$ NOISE LEVEL}

The vibratory disturbance of air pressure on the ear drum is perceived as sound. Undesirable sound is defined as noise. Sound pressure is measured on a logarithmic scale, called the decibel scale $(\mathrm{dB})$. Sound pressure level (SPL) or $\mathrm{L}_{\mathrm{p}}$ is defined by the equation shown in Figure 1, where $\mathrm{P}$ is the measured sound pressure level, and $\mathrm{P}_{\text {ref }}$ is a reference sound pressure level. For studies involving human subjects, $\mathrm{P}_{\text {ref }}$ equals $20 \mu \mathrm{Pa}$, which is normally considered to be the threshold of human hearing. ${ }^{2}$

$$
L_{\mathrm{P}}=10 \log _{10}\left(\frac{\mathrm{P}}{\mathrm{P}_{\text {ref }}}\right)^{2} \mathrm{~dB}
$$

Figure 1. Equation. Instantaneous sound pressure level equation

The human ear also does not sense sound pressure uniformly because the ear is not equally sensitive to all frequencies. Thus, different filters or weightings are used for measuring noise levels. The A-weighting filter emphasizes frequencies at which the human ear is most sensitive; in other words, the A-filter attenuates the very high and very low frequencies to which the ear is insensitive. The C-weighting filter is used for subjective measurements at very high or peak sound pressure levels. The A-weighted sound level measurements are typically used in regulations for the protection of workers against occupational noise-induced hearing loss (NIHL), as well as for the purpose of evaluating noise annoyances in the community.

Since noise fluctuates over time, average measurements are normally used to describe noise. Additionally, both noise amplitude and duration establish the energy in the exposure, so simple computational procedures or exchange rates are used to combine amplitude and time. A general form of the equation used to determine SPL, or $\mathrm{L}_{\mathrm{Avg}}$ for discrete sound measurements is shown in Figure 2, where $L_{i}$ is the $d B$ level in the measurement interval $i$; $Q$ is the exchange rate in $d B$, $\mathrm{N}$ is the number of intervals, $\mathrm{T}$ is the total measurement time period, and $\mathrm{t}_{\mathrm{i}}$ is the time period of interval $\mathrm{i}$. The variable $\mathrm{q}$, the specific or actual exchange rate, is defined by the relationship $\mathrm{q}=$ $\mathrm{Q} / \log _{10} 2$. The Occupational Safety and Health Administration (OSHA) currently uses a 5-dB exchange rate; the National Institute for Occupation Safety and Health (NIOSH) and most European countries use a 3-dB exchange rate. 


$$
\mathrm{L}_{\text {Avg }}(\mathrm{Q})=\mathrm{q} \log _{10}\left[\frac{1}{\mathrm{~T}} \sum_{\mathrm{i}=1}^{\mathrm{N}}\left(10^{\frac{\mathrm{L}_{\mathrm{i}}}{\mathrm{q}}}\right) \mathrm{t}_{\mathrm{i}}\right]
$$

Figure 2. Equation. Average sound level equation for discrete sound-level measurements

Most occupational noise regulations stipulate that personnel exposure may not exceed a maximum daily accumulation of noise energy, where the combination of duration of exposure and intensity of noise defines the total noise exposure. The OSHA permissible exposure limit (PEL) for noise is $90 \mathrm{dBA}$ time-weighted average (TWA) for an 8-h workday. ${ }^{3}$ and NIOSH recommends $85 \mathrm{dBA}$ for the 8 -h TWA. ${ }^{4}$ The PEL is also referred to as a 100 -percent noise exposure. The action level (AL) is computed to be 50-percent of the maximum PEL. The exchange rate refers to how the sound energy is averaged over time. A 5-dB exchange rate means that an increase (or decrease) in decibel exposure by $5 \mathrm{~dB}$ is equivalent to a doubling (or halving) of exposure time. For instance, if noise is at $95 \mathrm{dBA}$, the allowable exposure per workday is half of $8 \mathrm{~h}$, or $4 \mathrm{~h}$; correspondingly, if noise is at $85 \mathrm{dBA}$, the allowable exposure time is twice $8 \mathrm{~h}$, or $16 \mathrm{~h}$. At the present, noise levels in commercial motor vehicles are not governed by OSHA regulations or NIOSH guidelines. ${ }^{\dagger}$

Background: Robinson et al. ${ }^{5}$ measured the in-cab noise level for nine trucks under different highway speed conditions of actual driving and compared these noise measurements to previous historical values to determine whether truck-cab noise has increased or decreased with modelyear changes. All trucks in their study were conventional engine-ahead-of-cab design, as opposed to cab-over engine. Trucks had standard sleeper berths. Model years were between 1992 and 1997. The overall broadband SPL across the several different driving conditions for the nine trucks was $89.1 \mathrm{dBA}$, which is just below the OSHA PEL of $90 \mathrm{dBA}$ for an 8-h period. Average sleeper-berth SPL was $81.6 \mathrm{dBA}$, and during engine idling, the in-cab SPL level was $68.7 \mathrm{dBA}$.

Hessel et al. ${ }^{6}$ used a sound level meter to measure noise levels in eight truck-tractors that were pulling loaded 40-foot trailers under a standardized condition. This condition included cruisingneither accelerating nor decelerating - in the highest gear, on dry, level, concrete pavement, usually of the interstate system with the driver's window and wing window fully open, the passenger's wing window partially open, and the radio off. A noise dosimeter was also used and was in operation during the entire driving shift. The average reported noise level in the cabs from the sound level meter was $83.4 \mathrm{dBA}$. None of the tractors tested under the standardized conditions exceeded the OSHA standard of $90 \mathrm{dBA}$ for an 8-h exposure. However, the calculated $\mathrm{dBA}$ levels obtained from the dosimeter readings were significantly higher than the sound level meter readings. The researchers concluded that since the dosimeter was used throughout the driving shift, those readings probably represented the actual exposure of the drivers better than

\footnotetext{
${ }^{\dagger}$ According to Federal Motor Carrier Safety Regulations (49 CFR part 393.94) the interior sound level at the driver's seating position must not exceed $90 \mathrm{dBA}$, as measured when the truck is parked with all doors, windows, and vents closed; all power-operated accessories turned off; and, with the transmission in neutral, the engine is accelerated to - and stabilized at - either its maximum governed engine speed if it is equipped with an engine governor, or its maximum rated horsepower. The regulation does not specify a maximum time-weighted-average $\mathrm{dBA}$ level for an 8-h work day, which was the standard used in this study.
} 
the sound level meter reading taken under the standardized conditions. Sound level meters are more inclusive that dosimeters; they measure real-time sound and can have functions such as signal analysis, noise dose measurement, and the different time and frequency weightings. Noise dosimeters are used for specific measurement capability for defined industrial safety criteria. Usually a dosimeter is worn by the employee in order to determine the personal noise during the work shift or sampling period.

Van den Heever et al. ${ }^{7}$ compared noise levels in the cabs of two different makes of trucks in South Africa. Triplicate measurements were made daily on each truck, with a different driver for each truck during a full work shift of $8 \mathrm{~h}$ or more. A total of 16 tests were made. The A-weighed sound pressure level, maximum sound pressure level, percentage dose, and exposure time were measured. Noise assessments were computed on a $3 \mathrm{~dB}$ exchange rate using the safety standard that prescribes $85 \mathrm{dBA}$ for an 8-h work shift. The results of the arithmetic average showed the $\mathrm{L}_{\text {eq }}$ were $84.7 \mathrm{dBA}$ and $85.5 \mathrm{dBA}$, L $\mathrm{L}_{\mathrm{Max}}$ were $108.9 \mathrm{dBA}$ and $110.5 \mathrm{dBA}$, and dose percent were 8.29 and 109.2, respectively for the two trucks. It was concluded that the high sound pressure levels were caused, partly because of driving with the open windows and proposed that drivers of such trucks wear hearing protection devices while driving.

To evaluate the noise exposure of truck drivers under normal operating conditions, Seshagiri ${ }^{8}$ conducted tests under several scenarios of highway driving in Canada, including different terrains and conditions - windows open or closed, radio on or off. Eight trucking companies voluntarily took part in the study. Measurements were restricted to long-haul and pick-up-anddelivery types of operations. Most of the tractors were double-axle, and most of the tractortrailers were 18 wheelers. Virtually all had vertical exhaust, either single or twin, located behind the cab. Two sound level meters were used for most tests, one to measure the personal noise exposure of the driver, and the other as an area sample in the cab. In a few instances, a third meter was also used to measure the noise level in the sleeper compartment. The exposure of the driver was evaluated using both $3-\mathrm{dB}$ and $5-\mathrm{dB}$ exchange rates. The $\mathrm{L}_{\mathrm{eq}}$ ranged from 78 to 89 $\mathrm{dBA}$, with a mean of $82.7 \mathrm{dBA}$; operating the radio increased the mean by $2.8 \mathrm{~dB}$; driving with the driver's side window open increased the mean exposure by $1.3 \mathrm{~dB}$; and driving with the window open and operating the ratio resulted in an increase of $3.9 \mathrm{~dB}$. Trucks with the cab mounted over the engine appeared to be quieter than standard trucks by about $2.6 \mathrm{~dB}$. Operations on four-lane highways were $1.6 \mathrm{~dB}$ noisier than on two-lane highways; operations on hilly terrain appeared to be quieter than on flat terrain by about $2.2 \mathrm{~dB}$. The researcher concluded that the differences between noise levels between both the number of lanes and the terrain conditions were most likely caused by higher speeds. Previous studies, where the noise evaluations were higher, included only real driving time measurements, and for the most part did not contain any non-driving time in the dose calculations. However, studies of noise levels in truck cabs as reported over the past 25 years have dramatically shown an overall decrease in noise. ${ }^{5,9}$

\subsection{WHOLE-BODY VIBRATION}

Vibration is a mechanical movement that oscillates about a fixed point. By definition, this movement is not constant but alternates between being greater than and being less than some equilibrium position. Whole-body vibration (WBV) results when a person's whole body mass is subjected to the mechanical vibration-for example, from a supporting surface, such as the seat 
of a vehicle. Hand-arm vibration (HAV) is vibration in which the body parts - hand and armare subjected to the mechanical vibration. For example, in the operation of an electric drill, the hand is in direct contact with the vibrating medium and the bulk of the body rests on a stationary surface. This classification of vibration, however, does not necessarily imply that parts of the body other than those in direct contact with the vibrating surface are immune to the effects of the vibration. In any case, occupational vibration issues are of concern because of possible harm or injury to the lumbar region of the spine or of personal discomfort and annoyance. ${ }^{10}$

In the United States, occupational vibration is an emerging topic. Standards or guidelines currently in use are available from the International Organization for Standardization (ISO), the British Standards Institution, and the American National Standards Institute (ANSI). The oldest standard for WBV is the ISO-2631-1. ${ }^{11}$ Occupational vibration standards are voluntary guidelines in the U.S., since OSHA has not established WBV standards for industry. On the other hand, ISO guidelines will be followed in the present study because this standard appears to be the most commonly referenced for WBV, and most of the other standards are practically identical to ISO-2631-1. The narrative that follows below was taken almost exclusively from the ISO2631-1 standard.

The three-dimensional coordinate system for the human body in a seated position is shown in Figure 3. The direction of the $\mathrm{x}$-axis is the orientation of back-to-front; rotation about the $\mathrm{x}$-axis is called roll. The direction of the $y$-axis is the orientation of right-to-left side; rotation about the $\mathrm{y}$-axis is called pitch. The direction of the z-axis is the orientation of head-to-buttocks; rotation about the $\mathrm{z}$-axis is called yaw.

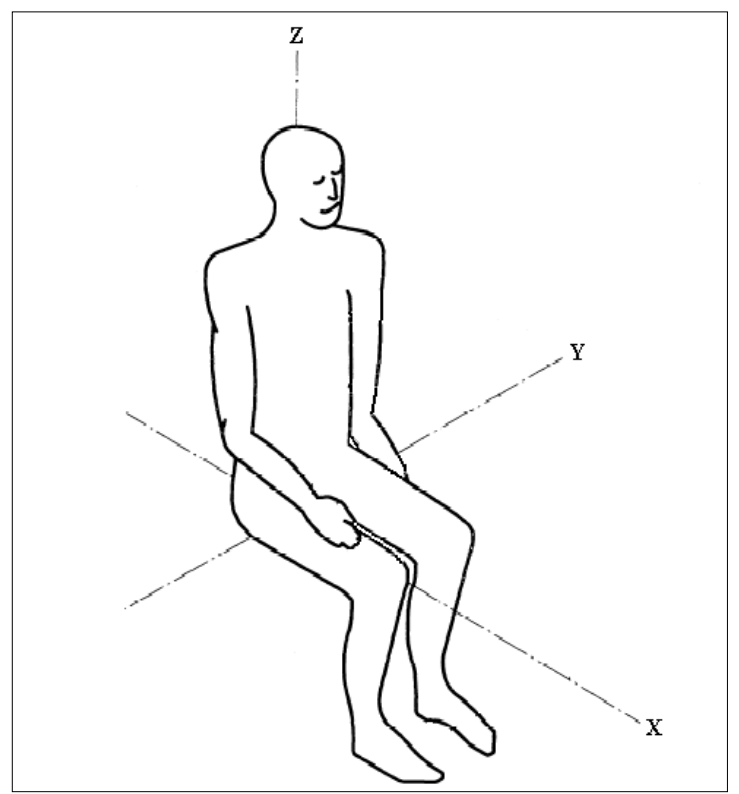

Figure 3. Diagram. Vibration measurement coordinate system for the seated person

According to ISO 2631-1, vibrations are determined using the frequency-weighted root mean square (RMS) acceleration for each axis of translational (or rotational) vibration on the surface which supports the person. The weighted RMS acceleration (awRMs) is calculated with the equation shown in Figure 4, where $\mathrm{a}_{\mathrm{w}}(\mathrm{t})$ is the weighted acceleration as a function of time, and $\mathrm{T}$ 
is the time duration of the measurement. Translational acceleration is expressed in units of meter per second squared $\left(\mathrm{m} / \mathrm{s}^{2}\right)$ and assessments are made independently along each axis with respect to the highest frequency-weighted RMS acceleration determined in any axis. Vibrations in the horizontal plane are also scaled by a correction factor $(\mathrm{k})$ for the seated persons $(\mathrm{k}=1.4)$, as the critical frequencies with respect to the possible harmful effects on the human body are different for the vertical ( $\mathrm{z}$ ) axis and the two horizontal ( $\mathrm{x}$ and $\mathrm{y}$ ) axes.

$$
\mathrm{a}_{\text {WRMS }}=\sqrt{\frac{1}{\mathrm{~T}} \int_{0}^{\mathrm{T}} \mathrm{a}_{\mathrm{w}}{ }^{2}(\mathrm{t}) \mathrm{dt}}
$$

Figure 4. Equation. Weighted root mean square acceleration equation

The three translational axes of acceleration, ( $\mathrm{x}, \mathrm{y}$ and $\mathrm{z}$ ) can also be combined into a single value, which will be called sigma $(\Sigma)$ for brevity, where $\Sigma=\mathrm{a}_{\mathrm{v}}=\left(\mathrm{k}_{\mathrm{x}}{ }^{2} \mathrm{a}_{\mathrm{wx}}{ }^{2}+\mathrm{k}_{\mathrm{y}}{ }^{2} \mathrm{a}_{\mathrm{wy}}{ }^{2}+\mathrm{k}_{\mathrm{z}}{ }^{2} \mathrm{a}_{\mathrm{wz}}{ }^{2}\right)^{0.5}$. On its own, $\Sigma$ is used as relative value for the perception of comfort. In ISO 2631-1, the recommended correction factors for a seated person are $\mathrm{k}_{\mathrm{x}}=\mathrm{k}_{\mathrm{y}}=\mathrm{k}_{\mathrm{y}}=1$. Since acceptable values for comfort depend on many factors, which can vary with each application, overall limits are not absolutely defined. However, the following ranges of values, listed in table 1, are recommended in ISO 2631-1 to illustrate the likely reactions. It should be noted that this quantitative evaluation of the "degree of comfort" is a subjective scaling to various degrees of WBV experienced in transportation vehicles. The presence of areas of overlap between the reaction groups by the range of scales is also problematic in determining the appropriate presumed reaction concerning the degree of comfort based on the physically recorded vibration level. This problem makes the evaluation of the nature of the establishment of a target characteristic value of design more difficult.

Table 1. Comfort Reactions to a Vibration Environment (Seating Position)

\begin{tabular}{|l|l|}
\hline \multicolumn{1}{|c|}{ Vibration Magnitude $(\boldsymbol{\Sigma})$} & \multicolumn{1}{c|}{ Likely Reaction } \\
\hline Less than $0.315 \mathrm{~m} / \mathrm{s}^{2}$ & Not uncomfortable \\
\hline $0.315 \mathrm{~m} / \mathrm{s}^{2}$ to $0.63 \mathrm{~m} / \mathrm{s}^{2}$ & A little uncomfortable \\
\hline $0.5 \mathrm{~m} / \mathrm{s}^{2}$ to $1 \mathrm{~m} / \mathrm{s}^{2}$ & Fairly uncomfortable \\
\hline $0.8 \mathrm{~m} / \mathrm{s}^{2}$ to $1.6 \mathrm{~m} / \mathrm{s}^{2}$ & Uncomfortable \\
\hline $1.25 \mathrm{~m} / \mathrm{s}^{2}$ to $2.5 \mathrm{~m} / \mathrm{s}^{2}$ & Very uncomfortable \\
\hline Greater than $2 \mathrm{~m} / \mathrm{s}^{2}$ & Extremely uncomfortable \\
\hline
\end{tabular}

In the areas of occupational health and safety, standards are always evolving. As with most regulations, the emphasis is on minimizing worker exposure levels, so that a predetermined daily accumulation level will not be exceeded during the work period. Debates continue over the appropriate minimum level of exposure to use as a standard. The over-exposure levels that cause fatigue, decrease in proficiency, reduced comfort, or actual damage to muscles, organs, and nervous system are not currently known with certainty. It is not the purpose of this study to enter into this discussion; nonetheless, a growing body of research is showing some health and safety consequences from occupational vibration exposures. ${ }^{2,10,12}$ 
For comparison purposes, the European Parliament Directive for Vibration ${ }^{13}$ will be used for health guidance; the European Union (EU) recommends $0.5 \mathrm{~m} / \mathrm{s}^{2}$ as the exposure action value (EAV) for an 8-h day and $1.15 \mathrm{~m} / \mathrm{s}^{2}$ as the exposure limit value (ELV). The EAV is that level of daily exposure at which, or beyond which, specific action must be taken to reduce the risk. The ELV is the level of a daily exposure that must not be exceeded. It is possible to project the daily exposure of a person to vibration from an 8-h level to $11 \mathrm{~h}$ by multiplying the health guidance recommendations above by the correction factor (8/11). ${ }^{1 / 2}$ Thus, the EAV and ELV for an 11-h work day are $0.43 \mathrm{~m} / \mathrm{s}^{2}$ and $0.98 \mathrm{~m} / \mathrm{s}^{2}$, respectively. ${ }^{14}$

For certain types of vibration, especially those involving occasional shocks or transient vibration (i.e., impulsive vibrations which have short-duration high peaks), the basic evaluation method (i.e., the frequency-weighted RMS method) may underestimate the severity with respect to human discomfort. Therefore, a dimensionless quantity called the crest factor (CF) is used to determine the suitability of the RMS method for describing the severity of the vibration. ${ }^{11}$ The CF is defined as the ratio of the peak acceleration to the RMS acceleration; as shown in Figure 5, where the peak acceleration is the maximum (max) instantaneous acceleration at any time during the measurement period, and the RMS acceleration is the weighted acceleration mentioned in the above paragraphs.

$$
\mathrm{CF}=\frac{\max \left(\mathrm{a}_{\mathrm{w}}(\mathrm{t})\right)}{\operatorname{RMS}\left(\mathrm{a}_{\mathrm{w}}(\mathrm{t})\right)}
$$

Figure 5. Equation. Crest factor equation

Normally, the basic evaluation method is sufficient for evaluating vibration with CF below or equal to nine. However, in cases where the CF is greater than nine, two alternative measures are recommended in ISO-2631-1:

- The running RMS method.

- The fourth-power vibration dose method.

The former method takes into account occasional shocks and transient vibration by use of a short integration time constant. Since this method is used infrequently, it will not be discussed further in this study. The latter method is more sensitive to peaks than the basic evaluation method because it uses the fourth power instead of the second power of the acceleration time history as the basis for averaging. The fourth-power vibration dose value (VDV) is defined in Figure 6, where $\mathrm{a}_{\mathrm{w}}$ is the instantaneous frequency weighted acceleration and $\mathrm{T}$ is the duration of measurement. The units for VDV are meters per second raised to the 1.75 power $\left(\mathrm{m} / \mathrm{s}^{1.75}\right)$. As an alternative measure of WBV, the EU-recommended VDVs are $9.1 \mathrm{~m} / \mathrm{s}^{1.75}$ for the EAV and 21 $\mathrm{m} / \mathrm{s}^{1.75}$ for the ELV. Finally, it is useful to mention that one additional human response indicator, called motion jerk, is sometimes used to characterize vibration. At low frequencies, motion jerk is related to riding comfort and can be important for determining load tie-down in freight hauling. Jerk is defined as the change of acceleration over time. The units for motion jerk are meters per second raised to the cubed power $\left(\mathrm{m} / \mathrm{s}^{3}\right)$. No standards exist at present for limiting human exposure to motion jerk. 


$$
\operatorname{VDV}=\sqrt[4]{\int_{0}^{\mathrm{T}} \mathrm{a}_{\mathrm{w}}{ }^{4}(\mathrm{t}) \mathrm{dt}}
$$

Figure 6. Equation. Fourth-power vibration dose method equation

Background: Exposure to WBV in heavy equipment operators and commercial vehicle drivers has been associated with an excess risk of back symptoms and disorders of the lumbar region of the spine. ${ }^{15-17}$ Miyamoto et al. ${ }^{18}$ investigated lower-back pain (LBP) in professional truck drivers indirectly, using the self-reporting method. The survey found that 52.9 percent of the drivers participating in the questionnaire reported that LBP was related to work. Additionally, most of these drivers claimed that vibration and road shock accounted for their LBP.

Bovenzi et al. ${ }^{19}$ investigated LBP in Italian drivers exposed to WBV. The sample of professional drivers included drivers of earth-moving machines, forklifts, commercial trucks, and buses. Questionnaires also were employed. However, more important, vibration measurements were made at the driver-seat interface under actual operating conditions on a representative sample of the industrial machines and vehicles used by the drivers. The z-axis (vertical) weighted acceleration was the dominant directional component of vibration measured in most of the machines and vehicles, and the horizontal vibrations were scaled by the correction factor for seated persons (i.e., $\mathrm{k}=1.4$ ). In earth-moving machines the total weighted RMS accelerations averaged $0.57-0.69 \mathrm{~m} / \mathrm{s}^{2}$; in transport vehicles, it was $0.5-1.1 \mathrm{~m} / \mathrm{s}^{2}$. The lowest values were measured on garbage trucks $\left(0.29-0.31 \mathrm{~m} / \mathrm{s}^{2}\right)$. Vibrations on buses varied from $0.51 \mathrm{~m} / \mathrm{s}^{2}$ (minibus) to $0.61 \mathrm{~m} / \mathrm{s}^{2}$ (city bus).

Cann et al. ${ }^{20}$ investigated the predictors of WBV on four truck manufacturers and compared the levels of WBV to the standards in ISO 2631. Each truck was tested using 5-min random samples at speeds greater than $80 \mathrm{~km} / \mathrm{h}$ on four separate highways whose surfaces ranged from smooth and resurfaced to rough and potholed. Truck type, seat type, road condition, driver experience, and truck mileage were the areas of interest used to predict WBV. The trucks used in the research study were cab-over trucks, designed with a freight container attached directly to tractor, and cab-behind trucks, day cabs, or sleeper trucks. The research discovered that the test trucks did not exceed the ISO 8-h driving day standard on average, but the standard was exceeded in certain instances while the trucks were driven on rough or potholed highways. The study also demonstrated that road condition and truck type showed a statistically significant relationship with the frequency-weighted RMS acceleration in regression analysis. Road condition showed a significant relationship for the three translational axes of direction, while truck type showed a significant relationship with the vertical axis.

\subsection{AIR QUALITY}

Long-haul truck drivers may be exposed to air pollutants within the cab and sleeper berth during conditions of driving and while the vehicle is parked with the engine idling at truck-travel/rest centers. Relationships between diesel vehicle emissions and detrimental human health effects have been demonstrated in numerous studies. ${ }^{21}$ The U.S. Environmental Protection Agency (EPA) has also concluded that diesel exhaust causes acute and chronic health effects. ${ }^{22}$ 
Background: Doraiswamy et al. ${ }^{23}$ measured air-pollutant concentrations of carbon monoxide (CO), oxides of nitrogen $\left(\mathrm{NO}_{\mathrm{X}}\right.$ ) and particulate matter less than $2.5-\mu \mathrm{m}$ in aerodynamic diameter $\left(\mathrm{PM}_{2.5}\right)$ inside and outside of six HDDVs, while the vehicles were idling at a commercial truckstop rest area. All trucks were conventional engine-ahead-of-cab design, all had standard sleeper berths; truck model years were between 1996 and 2003. The air samples were taken during several different modes of heating, ventilation, and air-conditioning (HVAC) settings and truck engine operating conditions. The study showed that average 1-h in-cab concentrations were: (1) $424 \mathrm{ppb}$ CO, $312 \mathrm{ppb} \mathrm{NO}_{\mathrm{X}}$, and $19 \mu \mathrm{g} / \mathrm{m}^{3} \mathrm{PM}_{2.5}$ for both engine and HVAC in off-mode; (2) 820 ppb CO, 1,013 ppb $\mathrm{NO}_{\mathrm{X}}$, and $71 \mu \mathrm{g} / \mathrm{m}^{3} \mathrm{PM}_{2.5}$ for both engine and HVAC in on-mode with air recirculation; (3) $493 \mathrm{ppb} \mathrm{CO}, 694 \mathrm{ppb} \mathrm{NO}_{\mathrm{X}}$, and $144 \mu \mathrm{g} / \mathrm{m}^{3} \mathrm{PM}_{2.5}$ for both engine and HVAC in on-mode with fresh air; and (4) $780 \mathrm{ppb} \mathrm{CO}, 531 \mathrm{ppb} \mathrm{NO}_{\mathrm{X}}$, and $209 \mu \mathrm{g} / \mathrm{m}^{3} \mathrm{PM}_{2.5}$ for engine in on-mode and HVAC in off-mode, where ppb is parts per billion by volume. This suggested that different modes of engine idling and HVAC operation influenced the in-cab air quality. For instance, emissions were lowest when both the truck engine and HVAC were off, and emissions were highest when both the truck engine and HVAC were on in the fresh-air mode.

Sabina et al. ${ }^{24}$ were concerned with health effects in children from diesel emissions in school buses. In-cab concentrations of soot or black carbon, particulate-bound polycyclic aromatic hydrocarbons (PB-PAH), and nitrogen dioxide $\left(\mathrm{NO}_{2}\right)$ were measured in school buses. The study found that for bus commutes with windows open, mean black carbon concentration inside the test buses were highest when the bus was following another diesel school bus. Also, the levels of black carbon and PB-PAH were 8 to 11 times higher when the test bus was following a dieselfueled bus rather than following a gasoline-fueled bus or no vehicle.

Diesel exhaust exposure was measured by Davis et al. ${ }^{25}$ at 36 trucking terminals across the United States. Both organic and elemental carbon (OC and EC, respectively) and $\mathrm{PM}_{2.5}$ were measured inside the cabs. (Analytical chemical methods are required to distinguish between OC and EC.) Diesel particulate matter is mostly unburned carbon. However, EC or soot is a selective marker of exposure in workplaces where diesel equipment is operated, so it is a good surrogate measure of exposure to this pollutant. OC includes hydrocarbons which can come from unburned fuel-but other sources of hydrocarbons exist besides gasoline and diesel fuel. Both short- and long-distance trips were observed, as well as information on the smoking status of the driver and characteristics of the truck. For the long-haul drivers, average EC, OC, and $\mathrm{PM}_{2.5}$ concentrations were 1.4, 21.6, and $52.6 \mu \mathrm{g} / \mathrm{m}^{3}$, respectively. These results also suggested that in-cab particle exposures were positively related to driver smoking, background or ambient particle concentrations, truck age and open windows. Laden et al. ${ }^{26}$ also provided insight into mortality patterns that were associated with job-specific exposures in the trucking industry. In this detailed assessment of specific job categories, an excess of mortality due to lung cancer and ischemic heart disease were noted particularly among commercial truck drivers.

The PEL established by OSHA for CO, average over an 8-h time period, is 50 parts per million by volume (ppm). ${ }^{27}$ The summation of nitrogen oxide (NO) and nitrogen dioxide $\left(\mathrm{NO}_{2}\right)$ is $\mathrm{NO}_{\mathrm{X}}$ concentration. By far, the most dominant nitrogen compound formed during combustion in spark or compression ignition engines is $\mathrm{NO}$ for gases burned at flame temperatures, and chemical equilibrium considerations indicate that $\mathrm{NO}_{2} / \mathrm{NO}$ ratios are negligible. While experimental data show this is true for spark-ignition engines, in diesel or compression-ignition engines, the $\mathrm{NO}_{2}$ concentration can be 10 to 30 percent of the total $\mathrm{NO}_{\mathrm{X}}$ exhaust emissions. ${ }^{28}$ Also in ambient air, 
$\mathrm{NO}$ can oxidize to $\mathrm{NO}_{2}$. Though no specific occupational standard exists for $\mathrm{NO}_{\mathrm{X}}$, OSHA has set the PEL for $\mathrm{NO}$ at $25 \mathrm{ppm}$ and has established a short term exposure limit (STEL) for $\mathrm{NO}_{2}$ at 1 ppm. For $\mathrm{PM}_{2.5}$, no enforceable workplace exposure limit has been established by OSHA, so in this case, the EPA National Ambient Air Quality Standards (NAAQS) for PM 2.5 will be used for comparison purposes. It should be noted here that the NAAQS are outside air monitoring, standards set to protect general public health, including the health of sensitive populations such as asthmatics, children, and the elderly. Also, averaging times for the NAAQS are usually different from typical occupation or workplace averaging times. The EPA has set NAAQS for $\mathrm{CO}$, lead, $\mathrm{NO}_{2}$, particulate matter, ozone, and sulfur dioxide. ${ }^{29}$ Areas not meeting any of the NAAQS are required by EPA to create a State Implementation Plan to meet the standards within a certain time period.

The NAAQS for $\mathrm{PM}_{2.5}$ are $35 \mu \mathrm{g} / \mathrm{m}^{3}$ (24-h average) and $15 \mu \mathrm{g} / \mathrm{m}^{3}$ (annual mean). In EPA parlance, for the former, the 3-year average of the 98th percentile of 24-h concentrations at each population-oriented monitor within an area must not exceed the standard, and for the latter, the 3-year average of the weighted annual mean concentrations from single or multiple communityoriented monitors must not exceed the standard. The NAAQS for $\mathrm{PM}_{10}$ is $150 \mu \mathrm{g} / \mathrm{m}^{3}$ (24-h average). Particulate matter less than $10 \mu \mathrm{m}$ in aerodynamic diameter is $\mathrm{PM}_{10}$, and the standard is not to be exceeded more than once per year on average over 3-years. For comparison purposes, the World Health Organization (WHO) ambient air quality guidelines for $\mathrm{PM}_{2.5}$ are $25 \mu \mathrm{g} / \mathrm{m}^{3}$ (24-h mean) and $10 \mu \mathrm{g} / \mathrm{m}^{3}$ (annual mean). For PM $\mathrm{PM}_{10}$, the WHO ambient air quality guidelines are $50 \mu \mathrm{g} / \mathrm{m}^{3}$ (24-h mean) and $20 \mu \mathrm{g} / \mathrm{m}^{3}$ (annual mean). ${ }^{30}$ In closure, the NAAQS for CO for a 1-h exposure is $35 \mathrm{ppm}$ and $9 \mathrm{ppm}$ for an 8-h exposure, both not to be exceeded more than once per year. The NAAQS for $\mathrm{NO}_{2}$ is 0.053 ppm (annual arithmetic mean). 
[This page intentionally left blank.] 


\section{OBJECTIVE}

The purpose of the present study was to measure several factors inside the cab of heavy-duty diesel vehicles that may affect the health and performance of drivers. The evaluated factors were the noise level, whole body vibration from driver and passenger seats, and the in-cab air quality. The concentrations of $\mathrm{CO}, \mathrm{NO}_{\mathrm{X}}$, and $\mathrm{PM}_{2.5}$ were measured inside the cab to determine the air quality. Vibration data from sensors located on the cab and truck body were also collected for computer modeling purposes; however, these results will not be discussed in this report. All measurements were conducted while the vehicles were parked with the engine idling at a truckstop rest area and/or during an actual on-road driving episode that included interstate and State highway driving over moderately steep and relatively flat terrains. A further aim of this study was to test the latest model year trucks available at the time and to have trucks represented from at least four different manufacturing companies since this data set will ultimately serve as baseline data for future studies. 
[This page intentionally left blank.] 


\section{EXPERIMENTAL METHOD}

The parked-idling and on-road tests for each truck were conducted over the course of a 2-day time period. On the first day of testing, the sampling equipment was installed; the truck was attached to a utility trailer, driven to a commercial travel center, and parked in the rest area reserved for extended or overnight truck parking. Each truck was tested at the same travel center, which was located approximately $8 \mathrm{~km}(5 \mathrm{mi})$ west of the city limits of Knoxville, TN and about $1.6 \mathrm{~km}(1 \mathrm{mi})$ north of Interstate 40 . Figure 7 is a photograph of a number of trucks parked at the travel center where the engine-idling testing occurred. The white truck located in the center of the photograph was one of the vehicles tested in this study.

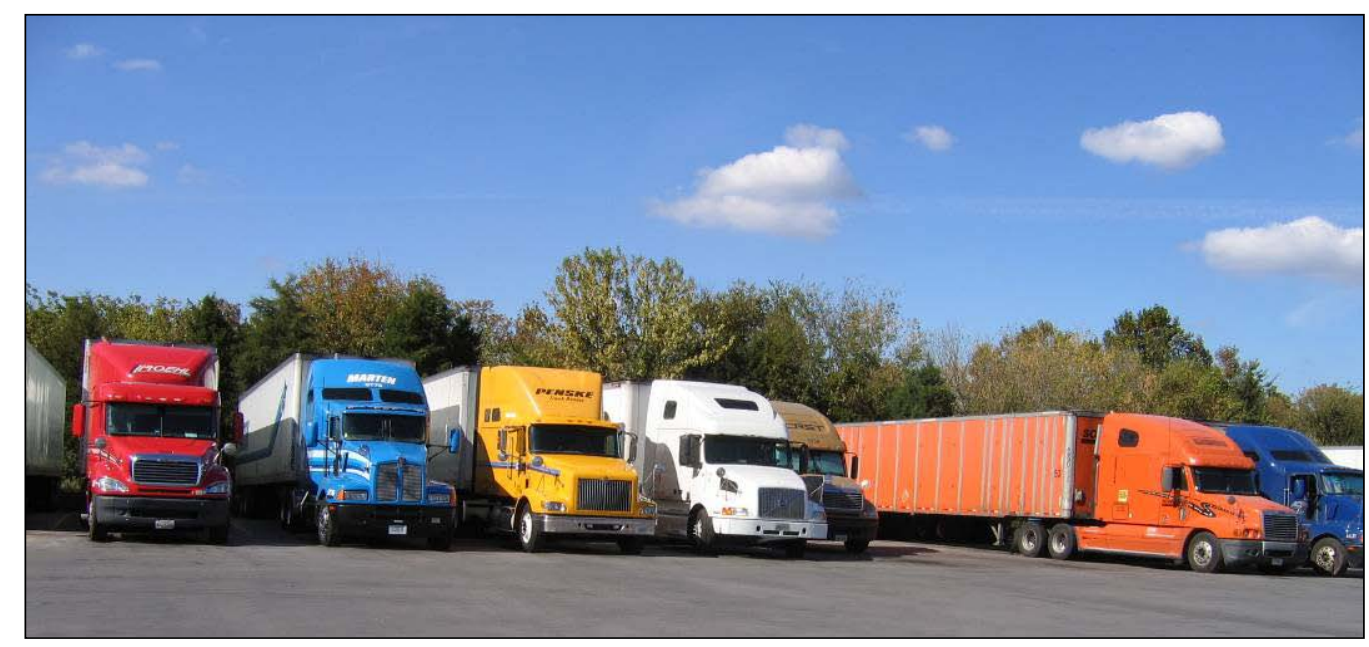

Figure 7. Photo. Trucks parked at a study-selected travel center rest area

On the second day of testing, the truck (with utility trailer) was driven over a prescribed route. The driving course included a mixture of interstate and rural highway travel. The round trip was approximately $260 \mathrm{~km}$ (160 mi), of which $120 \mathrm{~km}$ (75 mi) were interstate travel (I-40) over rolling hills and moderately steep terrain, $80 \mathrm{~km}$ (50 mi) were rural highway travel (US-27 and TN-68) over rolling hills, and $60 \mathrm{~km}$ (35 mi) were interstate travel (I-75) over relatively flat terrain. Figure 8 is a map showing the entire route from start to finish. Figure 9 is a map showing the variation in elevation of the hills and valleys along the route. For simplicity, the combination route US-27 and TN-68 will be identified as US-27 in this report. The average speed on the interstates was between 105 and $115 \mathrm{~km} / \mathrm{h}$ (65 and $70 \mathrm{mi} / \mathrm{h}$ ), and on the U.S. and State roads, it was $90 \mathrm{~km} / \mathrm{h}$ (55 mi/h). The US-27 highway went through two small (rural) towns where the speed dropped to $55 \mathrm{~km} / \mathrm{h}$ (35 mi/h). However, it took only about 5-min of driving time to pass through each town. For the most part, all measurements were conducted at the average speeds for the interstates and State highways.

The vehicles are classified by the EPA, as HDDV, Class (8b); they are truck and trailer configurations with a gross vehicle weight rating that is greater than $27,216 \mathrm{~kg}(60,000 \mathrm{lb}) .{ }^{31} \mathrm{On}$ occasion, the truck is called a tractor, and the tractor-trailer configuration is commonly referred to as an 18-wheeler. Each truck hauled a 16.2-m (53-ft) long, fully enclosed utility trailer that was pre-loaded with approximately 13,610 kg (30,000 lb) of palletized top-soil. The model year of the trailer was 2007 . Fewer than 12,875 road-kilometers (8,000 road-miles) had been logged 
on the trailer before it was rented, and the same trailer was used for all road testing. In total, 27 trucks were rented and tested: 2 trucks were from model year 2006, 22 trucks were from 2007, and 3 were from 2008. Vehicles from four truck manufacturing companies were represented in the study. All trucks were conventional engine-ahead-of-cab design and had in-cab sleeper berths, such as are used for long-haul highway driving.

Since the sample of test vehicles consisted of trucks from four separate manufacturers, it was appropriate-if differences became apparent between manufacturers after the test data were examined, that these differences would be reported. The purpose of this study however, was not to demonstrate that unwarranted differences exist between truck manufacturers, so in the interest of being impartial, the specific manufacturers will not be named directly for reporting purposes; instead, different truck manufacturers will be referred to as A, B, C, and D.

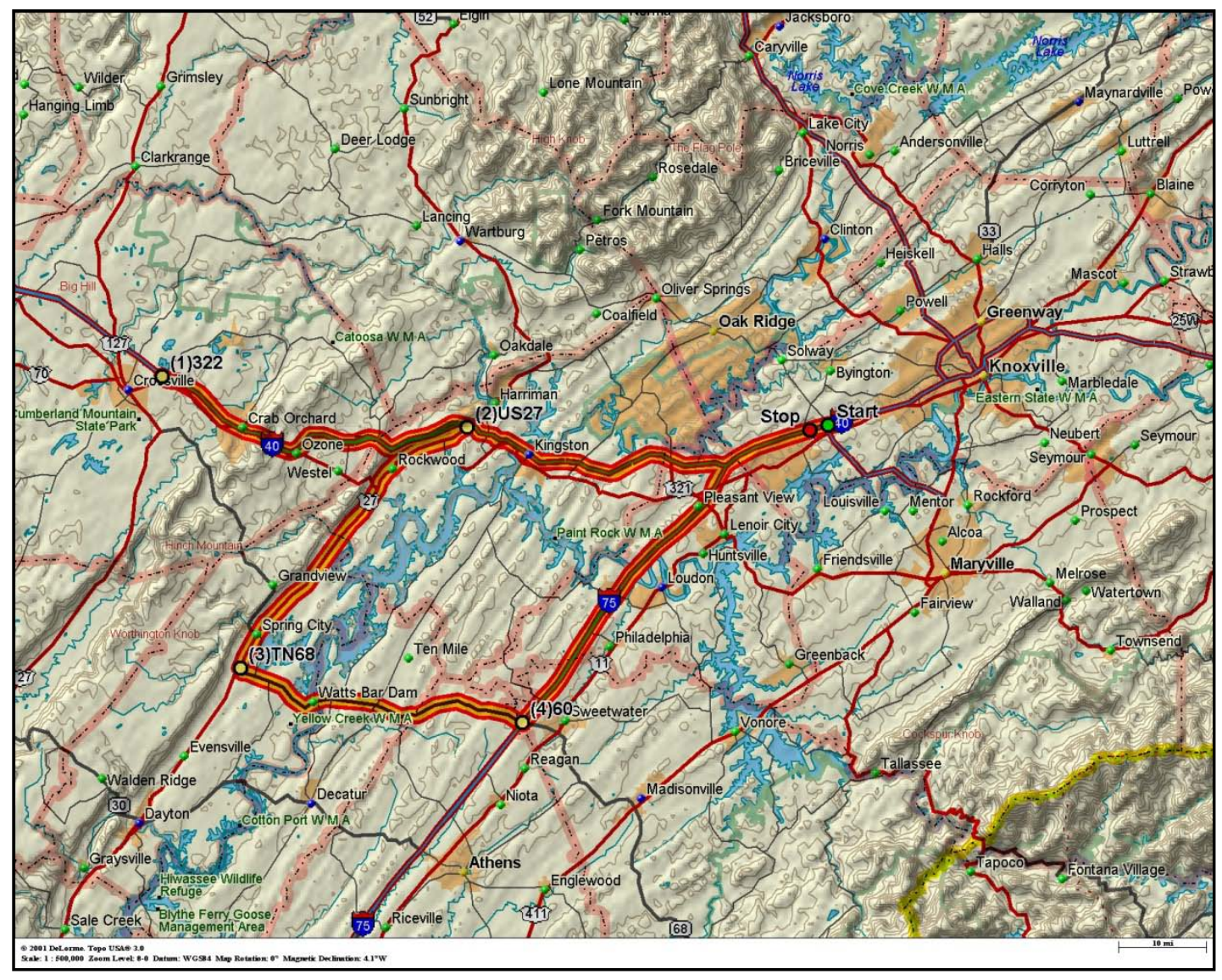

Figure 8. Map. Map showing the driving route along I-40, US-27 \& TN-68, and I-75 


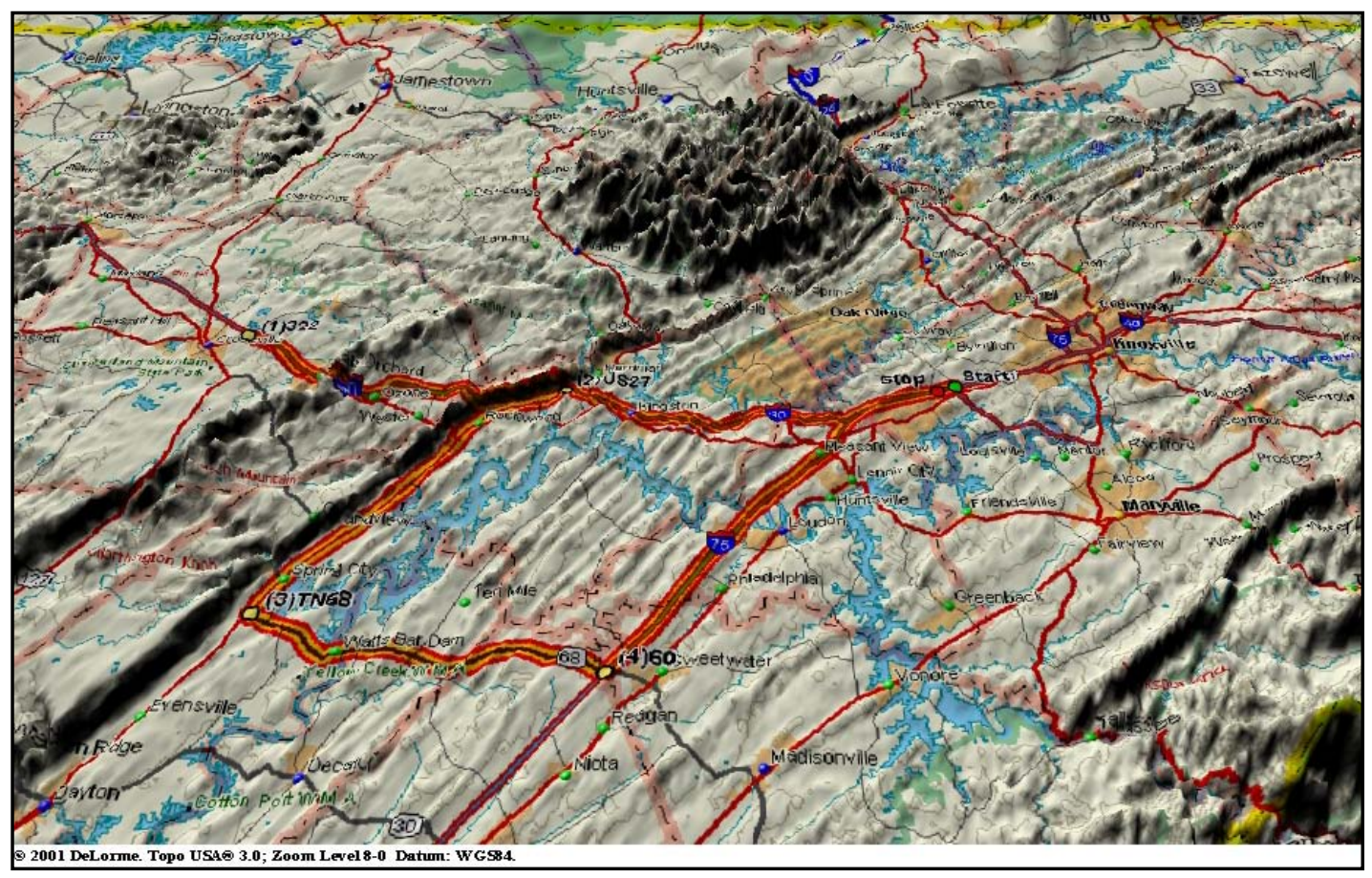

Figure 9. Map. Relief map showing terrain contrast along the driving route

No truck had a closed crankcase ventilation system-i.e., combustion gases that leak past the piston rings (blow-by) were vented to the atmosphere and were not routed back into the intake manifold of the engine, as is common for automobile gasoline-driven engines. Only one truck was equipped with a catalyzed regenerative particulate trap. All trucks were tested as received or as rented, and no trucks were subjected to any special maintenance procedures. All trucks used locally available standard diesel fuel.

Instantaneous or real-time measurements for noise, vibration, and $\mathrm{PM}_{2.5}$ concentrations were collected during the on-road test only. Measurements for $\mathrm{CO}$ and $\mathrm{NO}_{\mathrm{x}}$ concentrations were not collected instantaneously during the on-road test. Instead, air samples from inside the cab were collected and later analyzed for $\mathrm{CO}$ and NOx concentrations. This procedure was adopted because it was impossible to maintain the $\mathrm{CO}$ and $\mathrm{NO}_{\mathrm{X}}$ instruments on the DC-voltage battery system of the truck during the on-road test. However, during the parked-idling test, real-time measurements for all the parameters were collected-here, an external source of AC-voltage was available on-site that could be used simultaneously to power all analyzers and auxiliary equipment (e.g., data loggers, sampling pump, etc.).

During the parked-idling test, air sampling occurred according to several predetermined modes of truck engine and HVAC system operation:

- Engine Off/Inside - the truck engine was off, and all the windows were closed. This condition allowed for the determination of the in-cab air quality while the engine and HVAC system were both in off mode.

- Engine On/Recirculation - the truck engine was on with the idling speed adjusted via the cruise-control in the range of 900-1,000 revolutions per minute (rpm), and the windows 
were closed. The HVAC system was on recirculation mode. In some truck models, this would be the "Max A/C" setting. However, most new model vehicles have a recirculation button on the climate control panel that dedicates the HVAC system to recirculation of the inside air. The HVAC dash fan switch and the sleeper berth fan switch were both set at the medium speed.

- $\quad$ Engine On/Fresh Air - the truck engine was on and was set to idle between 900 and 1,000 rpm, and the windows were closed. The HVAC system was on. This setting typically allows the (fresh) outside air to be brought into the cab of the truck. The dash fan switch and the sleeper berth fan switch were both set at the medium speed.

- Engine On/Ventilation Off - the truck engine was on and set to idle at between 900 and 1,000 rpm, and the windows were closed. However, the HVAC system and both fans (dash and sleeper) were off. This condition allowed for the determination of the in-cab air quality while only the engine was idling.

- $\quad$ Engine Off/Outside - the truck engine was off, and the windows were open. This permitted outside air to enter the truck, and background ambient air concentrations could be established to determine whether a relationship existed between outside and inside air.

During the on-road test, the ventilation system was always in fresh-air mode, and both dash and sleeper berth fan switches were set to the medium speeds. Outside air was not sampled during the on-road test. The temperature or climate control setting during all HVAC system operations was adjusted by the occupant(s) at their discretion to maintain the cabin temperature in the comfort region, which was usually between 70 and 80 degrees F. In essence, the recirculation mode limits the amount of outside air entering the cab to decrease the time required to cool or heat the cab interior during extreme outside temperature conditions. It should be noted that depending on the truck HVAC configuration, the fresh air or recirculation mode might not be 100 percent outside air or 100 percent internal air recirculation, but may involve a mix of both to prevent the buildup of fumes or odors and to prevent in-cab oxygen depletion.

An attempt was also made to estimate the approximate cabin air exchange rate (AER) in several of the test trucks because this information would assist in characterizing the effects of the HVAC system and air leakage rates. The method was derived from the EPA Method IP- $4 \mathrm{~B}^{33}$ which is used to determine the AER between the outside and inside of buildings. Essentially, the procedure involves introducing a small amount of tracer gas into the cab with the windows closed, thoroughly mixing the air in the cab, and then measuring the rate of change or decay in the tracer gas concentration. The loss rate of a tracer gas concentration conforms to the exponential dilution law, which states that the dilution or loss rate of an escaping gas is proportional to its concentration. The AER is determined from the decay in tracer concentration, expressed mathematically by the equation shown in Figure 10:

$$
\mathrm{C}=\mathrm{C}_{0} \operatorname{Exp}^{-(\mathrm{AER}) \mathrm{t}}
$$

Figure 10. Equation. Exponential dilution law 
where $\mathrm{C}$ is the tracer gas concentration at time $\mathrm{t}$; $\mathrm{C}_{0}$ is the tracer concentration at time zero, AER is the air exchange rate. In this experiment, 99.9 percent pure carbon dioxide $\left(\mathrm{CO}_{2}\right)$ was used as the tracer gas, and several conditions of HVAC and fan settings were tested.

\subsection{SAMPLING EQUIPMENT}

\subsubsection{Noise Level}

Noise data were collected using an integrating, averaging sound-level meter. The instrument had been factory-calibrated at the beginning of this study. The sound meter was attached to the righthand arm-rest of the driver seat during noise-level measurements. Data were collected continuously for the duration of the on-road driving test. The sound meter takes three sets of measurements known as Integrators-1,-2, and -3. Integrator-1 provides measurements required by OSHA regulations. Integrator- 2 is configured for the OSHA hearing conservation program. Integrator-3 provides ISO $\mathrm{L}_{\mathrm{eq}}$ measurements. For the current project, only Integrator- 1 and Integrator-3 were selected. The criterion level (CL) is the normalized 8-h average weighted sound level that corresponds to the maximum permitted daily exposure. The CL for Integrator-1 and Integrator- 3 were $90 \mathrm{~dB}$ and $85 \mathrm{~dB}$, respectively. The criterion time for both integrators was $8 \mathrm{~h}$. A threshold value of $80 \mathrm{~dB}$ is used by Integrator-1, to calculate the average weighted sound level. This means that sound levels below the threshold are excluded from all averaging for Integrator-1. A threshold value is not used by Integrator-3. The exchange rates for Integrator-1 and Integrator- 3 are $5 \mathrm{~dB}$ and $3 \mathrm{~dB}$, respectively. The highest value reached by the sound pressure at any instant during a measurement period is called the peak value; it is used with the C-frequency weighting. The $\mathrm{LA}_{\mathrm{Min}}$ and $\mathrm{LA}_{\mathrm{Max}}$ are the minimum and maximum recorded sound levels, respectively; both use the A-frequency weighting. The TWA is the average of the measured $\mathrm{L}_{\text {Ave }}$ Over an 8-h period; TWA will be lower than the $\mathrm{L}_{\text {Ave }}$ when the measurement duration is less than $8 \mathrm{~h}$; TWA will be equal to the $\mathrm{L}_{\text {Ave }}$ for a measurement of $8 \mathrm{~h}$; TWA will be

higher than the $\mathrm{L}_{\text {Ave }}$ for measurements more than $8 \mathrm{~h}$. The sound meter logged or stored the data internally, and after the road test, all data were downloaded to a personal computer for later analysis.

\subsubsection{Whole-Body Vibration}

Several transducer accelerometer pads were used to measure WBV from the driver and passenger seats. On the driver seat, one pad each was installed on the back support (S1) and on the rump or cushion area (S2) of the seat. On the passenger seat, only a single pad was installed on the cushion area (S3) of the seat. Several accelerometers, also were used to measure vibration from the cab and truck body frame. Figure 11 is a top and side schematic of a truck showing the locations of all the vibration sensors. 


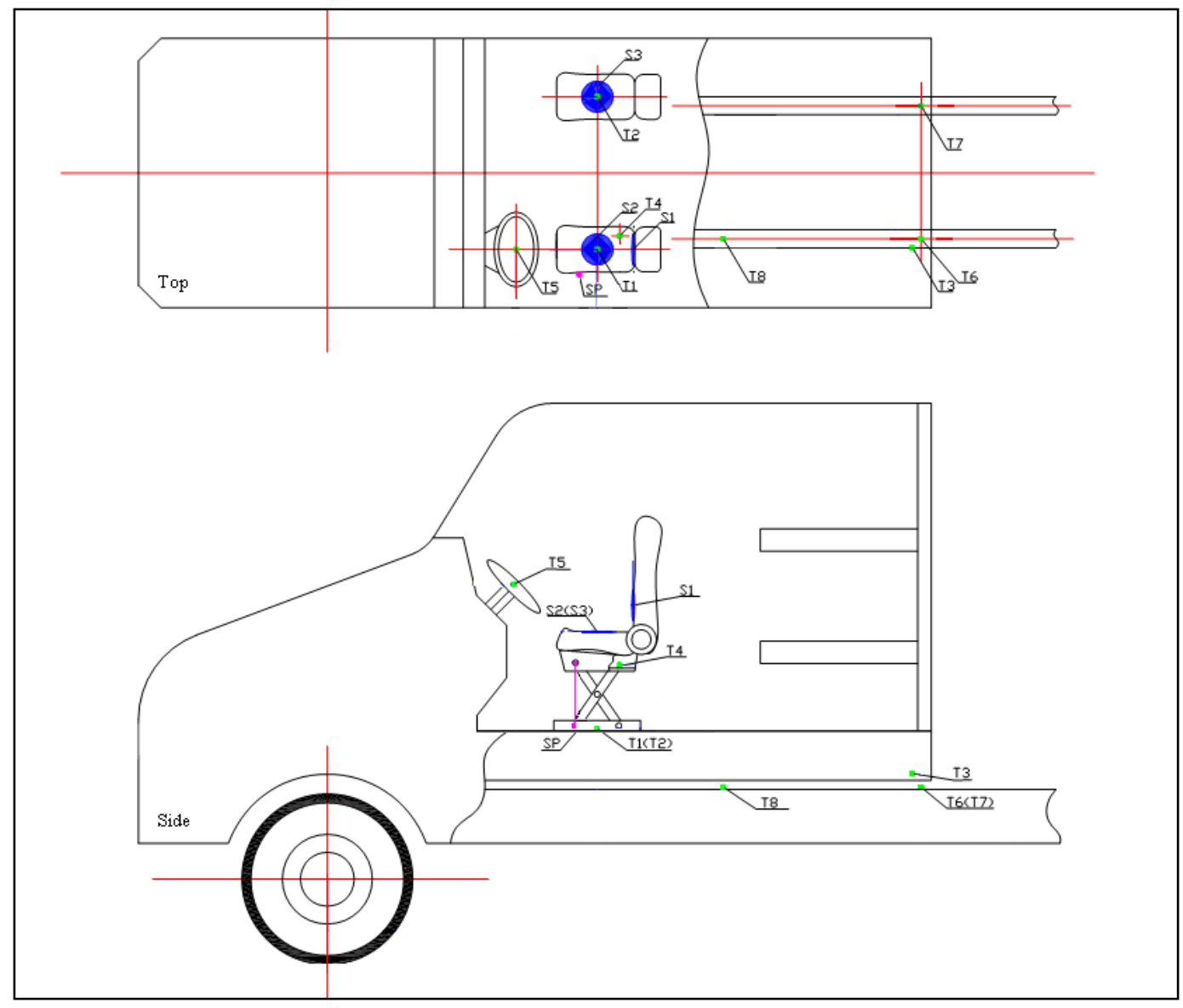

Figure 11. Diagram. Transducer placement for each HDDV

Three sensors were located inside the cab: one each on the floor beneath the driver (T1) and passenger seat (T2); one attached to the driver seat frame (T4); one attached to the center of the steering wheel (T5). Four sensors were located outside the cab: one was attached directly to the truck cab behind the driver seat (T3), and three sensors were attached to the structural frame of the truck directly beneath the cab (T6, T7, and T8). A linear position transducer also was used to measure the vertical displacement of the driver seat (SP). Vibration data (x-, y- and z-axes) collected from the seating pads were used for WBV analysis and data collected from other triaxial accelerometers were used for computer simulation experiments. Data from the driver seat pads (only) were collected using a human vibration meter. Vibration data from the driver and passenger seat pads and other transducers located throughout the truck cab and body were also collected with a data acquisition system (DAS).All data related to the measurement of vibration were then transferred to personal computers for storage and later analysis. As mentioned previously, the results from any data that were collected for computer modeling purposes will not be discussed in this report.

\subsubsection{Air Quality}

The in-cab air quality was determined by measuring mass concentrations of $\mathrm{CO}, \mathrm{NO}_{\mathrm{X}}$, and $\mathrm{PM}_{2.5}$. An analyzer which employs infrared adsorption as the detection principle was used to measure $\mathrm{CO}$ concentration. An analyzer, which employs chemiluminescence as the detection principle, was used to measure $\mathrm{NO}$ and $\mathrm{NO}_{2}$ concentrations. This instrument also reports $\mathrm{NO}_{\mathrm{X}}$ 
concentration, the summation of $\mathrm{NO}$ and $\mathrm{NO}_{2}$ concentrations. During the parked-idling test, these instruments were located in the bedding or trough area of the sleeper berth after the bottom mattress had been removed. Probes were connected to the input sampling port of the analyzers to bring continuous air into the analyzers during the parked-idling test. The sampling probes

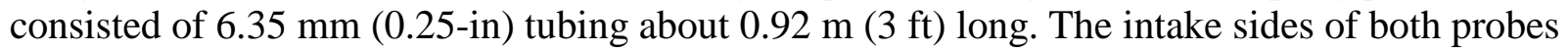
were mounted in the center area of the sleeper berth. During the on-road test, a low-flow portable personal sampling pump was used to collect and bag air samples. The flow rate for the sampling pump was $1.0 \mathrm{~L} / \mathrm{min}$. The bagged samples were subsequently analyzed in the laboratory for CO and $\mathrm{NO}_{\mathrm{X}}$ concentrations.

Two instruments were used for measuring $\mathrm{PM}_{2.5}$ concentrations. A Thermo Electron, DataRAM 4, Model DR-4000 (DRam) employs light-scattering as the detection principle, and the second, a Met One, Model EBam, employs beta-attenuation as the detection principle. Both units employed cyclonic type 2.5 - $\mu$ m cutoff separators. Flow-rates were $2 \mathrm{~L} / \mathrm{min}$ and $16.7 \mathrm{~L} / \mathrm{min}$, respectively. It should be noted that there was initial concern regarding the sampling of $\mathrm{PM}_{2.5}$ because unusually high PM concentrations were measured inside several trucks during several initial on-road tests. After further examination, it was found that the EBam monitor was not able to sample concentrations in the vibrating environment of the truck-apparently, the $\mathrm{PM}_{2.5}$ separator vibrates to such an extent that most of the particles passed through the separator, and thus the separator was unable to cut off sizes above $2.5 \mu \mathrm{m}$. This meant that it loaded all particles onto the filter, not just the $\mathrm{PM}_{2.5}$, and this resulted in an overestimation of the $\mathrm{PM}_{2.5}$. Consequently, the EBam was removed from the project, and none of its data will be reported.

This information about the problem associated with the monitor was provided in the report as a note of caution to other researchers when using cyclonic type cutoff separators to estimate $\mathrm{PM}_{2.5}$ concentration in vehicles that are driven over uneven road pavement conditions. For those uninitiated in cyclonic separation devices, fundamentally, a vortex of air containing particles is swirled down a conical tube. Larger or denser particles in the rotating air stream because of inertia cannot follow the tight curves of the air stream, strike the outside wall of the container, and fall to the bottom of the cone because of gravity and are not analyzed. The smaller particles remain in the air stream and eventually are directed to the analyzer. It is believed that vibration or shaking causes larger particles to re-enter the air stream and thus passed on to the analyzer.

As a follow-up, an optical particle counter (OPC) which is a more sophisticated instrument not requiring a $\mathrm{PM}_{2.5}$ separator, was substituted for the EBam. The detection principle for the OPC is also based on the principle of light-scattering from particles. The unit samples continuously in six channels ranging from $0.3 \mu \mathrm{m}$ up to $>10 \mu \mathrm{m}$. Size ranges were $0.3-0.5 \mu \mathrm{m}, 0.5-0.7 \mu \mathrm{m}, 0.7-$ $1.0 \mu \mathrm{m}, 1.0-5.0 \mu \mathrm{m}, 5.0-10.0 \mu \mathrm{m}$, and $>10 \mu \mathrm{m}$. The sampling flow rate for the OPC was 28.3 $\mathrm{L} / \mathrm{min}$. Using counts of the number of particles in each size range or channel from the OPC, the $\mathrm{PM}_{2.5}$ concentration was calculated using a numerical algorithm that converted particle size number to total mass and then to the fraction of the total mass concentration that was less than or equal to the 2.5- $\mu \mathrm{m}$ in aerodynamic diameter associated with the $\mathrm{PM}_{2.5}$. For simplicity, it was assumed that all particles were spherical in shape (where volume $=4 \pi \mathrm{r}^{3} / 3$ ) with a constant density of $2.5 \mathrm{~g} / \mathrm{cm}^{3}$. (Particulate mass is equal to volume multiplied by density.) A sampling probe that consisted of $6.35 \mathrm{~mm}(0.25$-in) tubing, about $0.31 \mathrm{~m}(1 \mathrm{ft})$ long, was used with the OPC. The inlet to the first monitor was provided by a (factory-supplied) nonflexible omnidirectional inlet device. Both analyzers were situated in the trough area of the sleeper berth 
during the entire parked-idling and/or the on-road tests. Also, to prevent the possible extraneous release of any particulate material into the cab environment from the sampling equipment located in the truck, high-efficiency particulate air (HEPA) filters were placed on the discharge side of all analyzers and/or sampling pumps. A photograph of several instruments situated in the sleeper berth area of a test truck is shown in Figure 12.

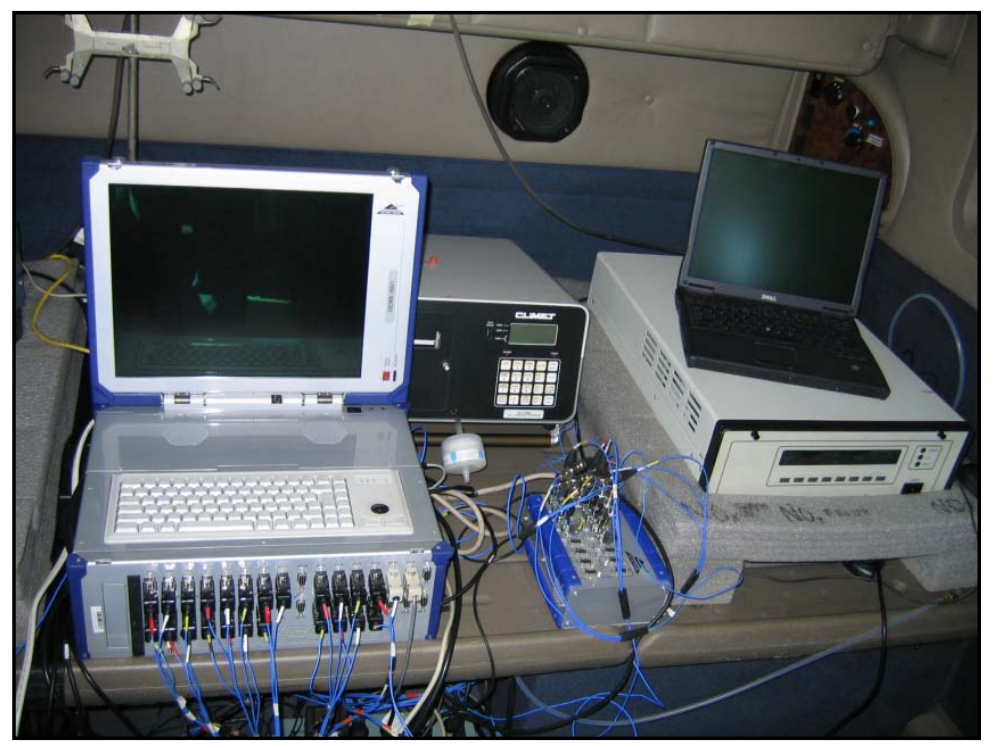

Figure 12. Photo. Assorted equipment located in sleeper berth area of truck

A mass flow calibrator was used with EPA protocol calibration gas to calibrate the $\mathrm{CO}$ and $\mathrm{NO}_{\mathrm{X}}$ analyzers. No certifiable standards exist to calibrate the PM instruments. However, vivificated calibration was performed on the analyzers as specified by manufacturer operating instructions. As an additional check to the accuracy of the analyzers, several collocation experiments were conducted using a tapered element oscillating microbalance (TEOM) particulate analyzer located at the Knox Air Pollution Board's ambient monitoring site in Knoxville, TN.

A portable gas analyzer was used to measure the decay rate of the $\mathrm{CO}_{2}$ that was released into the cab to determine the cabin AER. The gas analyzer is a single-beam spectrometer, scanning in the infrared spectral range. A portable GPS unit was also used to track the movement of trucks during the on-road test. This allowed verification between measured factors with spatial location along the route. It should be noted that most of the instruments used in air quality measurements also had internal data logging capability. However, to ensure data collection redundancy, an external unit also was used for data logging. All collected data were eventually saved to laptop and desktop personal computers.

\subsection{DATA ANALYSIS}

To analyze the data, a restricted (or residual) maximum likelihood (REML) method was selected to determine the significance or probability level of the condition or model effects. The REML method fits (or regresses) empirical data to a linear mixed factorial model using standard least squares algorithms. 
Mixed models contain both fixed and random effects. Fixed effects are factors chosen by the experimenter; for example, the truck manufacturer (TruckMfr), road types (Roadway), and engine/ventilation modes of operation (engine/HVAC) are fixed-effect factors. Random effect factors are beyond the control of the experimenter; for example, any truck (TruckId) that was selected for testing is a random effect factor because this truck was available at the leasing agency at the time it was rented for testing purposes, and information about a particular truck is relatively useless. Nonetheless, each particular truck adds variance when the data set is statistically analyzed. By using the REML method, any superfluous variance produced from a nuisance parameter or the random effects are ignored in determining the overall significance of any of the fixed effects. In general, REML is conservative in its restriction of nuisance parameters and can produce unbiased estimates of variance and covariance parameters. The objective is to construct the F-statistic (or F-test) and the associated DOF to obtain a $p$-value for the significance test. A probability level is simply a number that expresses the likelihood of the outcome of an event. Observed significant probabilities $(p)$ of 0.05 or less (meaning 95 out of $100)$ are often considered evidence that the model fits the data.

When a main effect from the REML method was found to be significant, pair-wise comparisons of the least-squares means differences between truck manufacturers and the various test conditions, such as roadway type or engine-idling/HVAC modes of operation, were achieved using the Tukey-HSD (honest significant difference) test. This test was selected because it is an excellent data-probing method when differences between pairs of means are the interest of focus and the sample sizes are unequal. Also the method minimizes the Type 1 error rate because when multiple comparisons are made the probability of making Type I error increases. (A Type 1 error is committed when the null hypothesis is rejected when in fact the null hypothesis is true.) Thus, when multiple comparisons are made, the Tukey-HSD test gives a more conservative estimation of pair-wise differences between conditions (i.e., means) than the standard $t$-test. ${ }^{34}$ 
[This page intentionally left blank.] 


\section{RESULTS AND DISCUSSION}

All regulatory standards or guidelines are summarized in appendix A for reference purposes.

\subsection{NOISE LEVEL}

In-cab noise-level data were collected and analyzed from only 22 trucks of the 27 trucks that were road-tested in this study. Seven trucks were from company A, four trucks were from company B, five trucks were from company $\mathrm{C}$, and six trucks were from company $\mathrm{D}$. As with the air-quality testing, in the interest of being impartial, the specific trucking companies will not be named. Data are missing from five trucks because of problems that were encountered with the sound level meter. A summary of the average noise-level data for each truck is given in appendix $\mathrm{B}$ for the peak value (C-filter), the minimum and maximum (A-filter) values, and the dose percent, estimated dose percent, $\mathrm{L}_{\mathrm{eq}}$ and TWA used with Integrators- 1 and -3 . The minimum and maximum values in the table are represented in bold blue and bold red, respectively or by asterisks. On average, the sampling rate was about 10 minutes in duration encompassing a total period of between 2.5 and $3 \mathrm{~h}$ per truck test. It should be noted that this sampling period was selected to coincide with the vibration sampling period in time duration because the file size of the vibration data was in the gigabyte range, and for convince, sound data were saved in $10 \mathrm{~min}$ intervals.

Since sound measurements were not collected over a full 8-h shift, the estimated dose percent and the $\mathrm{L}_{\mathrm{eq}}$ or $\mathrm{L}_{\mathrm{Avg}}$ are more suitable for comparison to the PEL values, than are dose percent and TWA because both of these parameters depended on an 8-h CL. Note also in appendix B that the dose, estimated dose, $\mathrm{L}_{\mathrm{eq}}$, and TWA values for Integrator- 1 are considerably lower than the corresponding values for Integrator-3. This is because the CL for Integrator-1 was higher than the CL for Integrator-3, Integrator-1 used a threshold value of $80 \mathrm{~dB}$ for calculating the average weighted sound level, which means that sound levels below this threshold were excluded from averaging for Integrator-1, and the exchange rate for ntegrator-3 is more stringent.

Dose is the total noise exposure expressed as a percentage of the PEL. It is the summation of the individual exposure times at the noise level divided by the reference duration time, which is based on the PEL and exchange rate. For example, the OSHA PEL for an 8-h daily noise exposure is $90 \mathrm{dBA}$. Thus, if the noise level were a constant $90 \mathrm{dBA}$ for $8 \mathrm{~h}$, this would generate a dose of 100 percent - that is, $(8 / 8) \times 100$. However, if during a total 8-h measurement, the noise was $90 \mathrm{dBA}$ for 4-h, $95 \mathrm{dBA}$ for 1.5-h, $75 \mathrm{dBA}$ for 1.5-h, and $85 \mathrm{dBA}$ for 1-h, then the dose percent would be approximately 93.8 percent-that is, $(4 / 8+1.5 / 4+1 / 16) \times 100$. Note that a threshold value of $80 \mathrm{dBA}$ is used when calculating the OSHA dose percent, so the $75 \mathrm{dBA}$ noise level is ignored. The estimated dose percent for an 8-h working day is $\{8 \times$ (dose percent $\div$ total time period) $\}$. To determine the estimated dose percent for an 11-h working day, the number 8 in the equation is replaced with an 11.

Overall, as shown in appendix B, truck A4 recorded the highest on-road in-cab noise levels, so it will be used in the following discussion. For Integrator- 1 the average dose was 3.8 percent, which means that the driver experienced about 4 percent of an 8-h noise dose of $90 \mathrm{dBA}$.

Average estimated dose is the percentage received by a person if the average level measured had 
existed for the period defined by the criterion time. This is a computation estimation of what the projected dose would have been for an actual 8-h work shift. For instance, if during a 4-h measurement the dose was 50 percent, then the estimated dose would be 100 percent for the 8-h time-that is, $(8 / 4) \times 50$ percent. Again referring to truck A4, for Integrator-1, the average estimated dose was 10.7 percent, which is much less than 100 percent, which implies that the 8-h TWA would not have been exceeded.

An estimated dose of 50 percent is usually referred to as the action level (AL). For the occupational exposure to noise according to OSHA, this means that within 6 months of an employee's first exposure at or above the AL, the employer must establish a valid baseline audiogram for the employee against which subsequent audiograms can be compared. In the previous example, the dose was 93.8 percent, thus the AL was exceeded, although the PEL was not exceeded. As shown in the appendix B, no average estimated dose from Integrator-1 or Integrator-3 exceeded the AL. When an 11-h shift is evaluated for truck A4 (the worst case), the estimated doses are 14.7 percent for Integrator- 1 and 40.5 percent for Integrator-3. So the AL still was not exceeded even when an 11-h shift was considered.

Graphs of the peak LS means for truck manufacturer, roadway, and the interaction effect of truck manufacturer and roadway are shown in the three figures below: REML statistical analysis showed that the truck-manufacturer effect (Figure 13) was not significant. REML analysis showed that the roadway effect (Figure 14$)$ was significant $(p=0.01)$. Accordingly, post-hoc Tukey's HSD tests showed that the I-40 condition had significantly higher peak values than the I-75 condition at the 0.05 level of significance; all other comparisons were not significant. REML analysis showed that the interaction effect between truck manufacturer and roadway (Figure 15) was not significant.

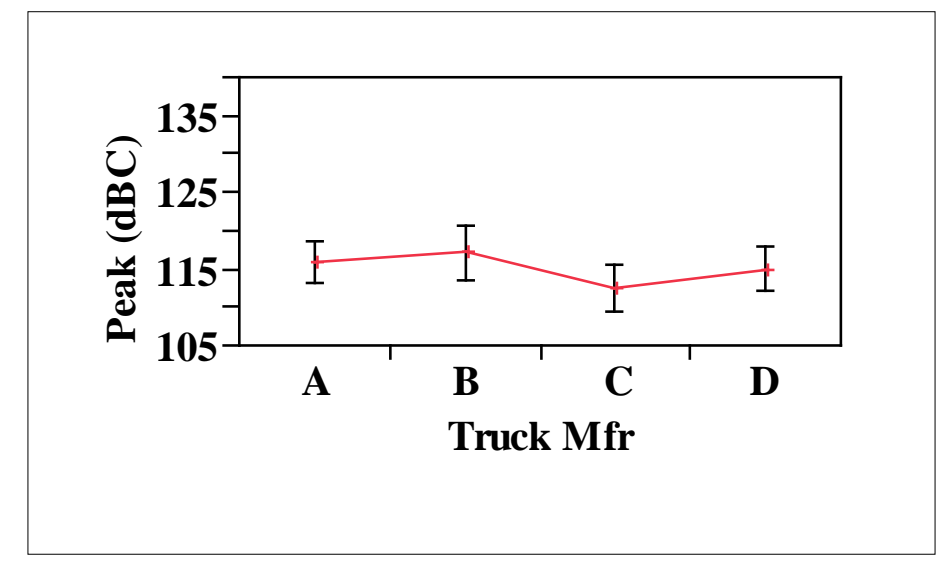

Figure 13. Graph. LS means peak noise level vs. truck manufacturer 


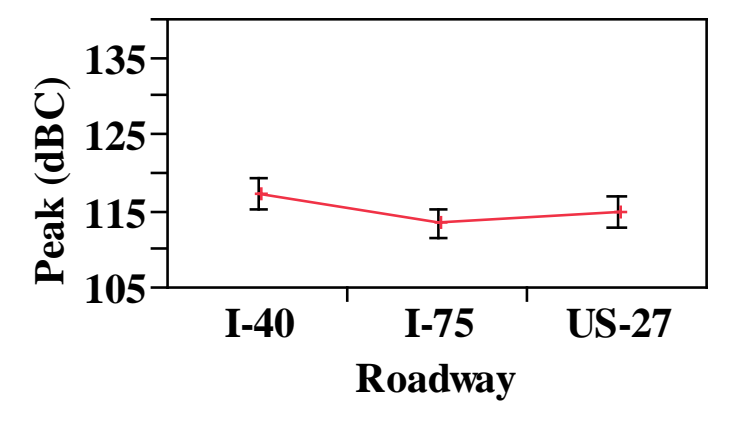

Figure 14. Graph. LS means peak noise level vs. roadway

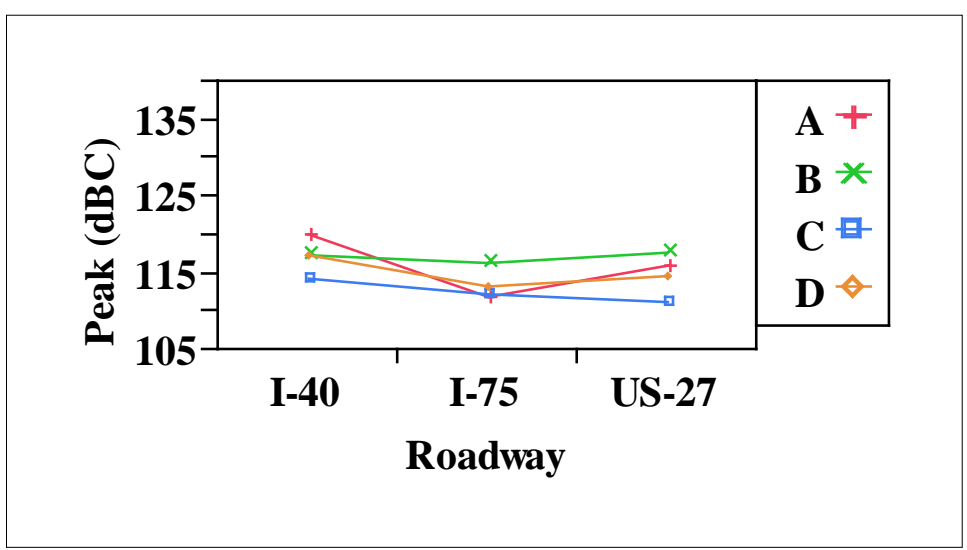

Figure 15. Graph. LS means peak noise level vs. roadway and manufacturer

Graphs of the $\mathrm{L}_{\mathrm{Max}}$ LS means for truck manufacturer, roadway, and the interaction effect of truck manufacturer and roadway are shown in the three figures below: REML analysis showed that the truck manufacturer effect (Figure 16) was not significant. REML analysis showed that the roadway effect (Figure 17) was significant $(p<0.0001)$. Accordingly, post-hoc Tukey's HSD tests showed that the I-40 condition had significantly higher $\mathrm{L}_{\mathrm{Max}}$ values than the I-75 and US-27 conditions at the 0.05 level of significance; all other comparisons were not significant. REML analysis showed that the interaction effect between manufacturer and roadway (Figure 18) was not significant. 


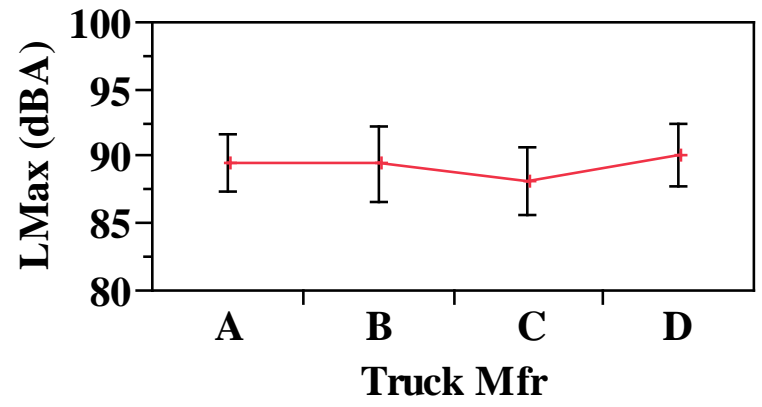

Figure 16. Graph. LS means maximum equivalent noise level vs. truck manufacturer

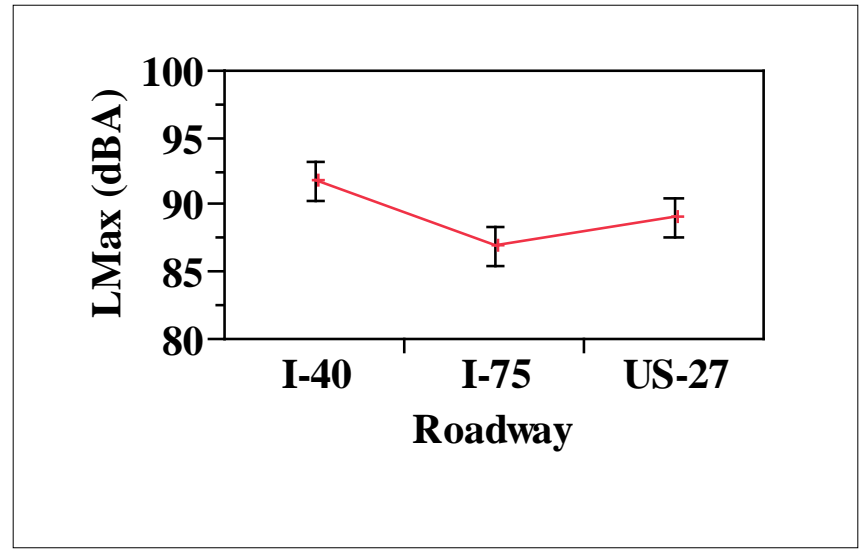

Figure 17. Graph. LS means maximum equivalent noise level vs. roadway

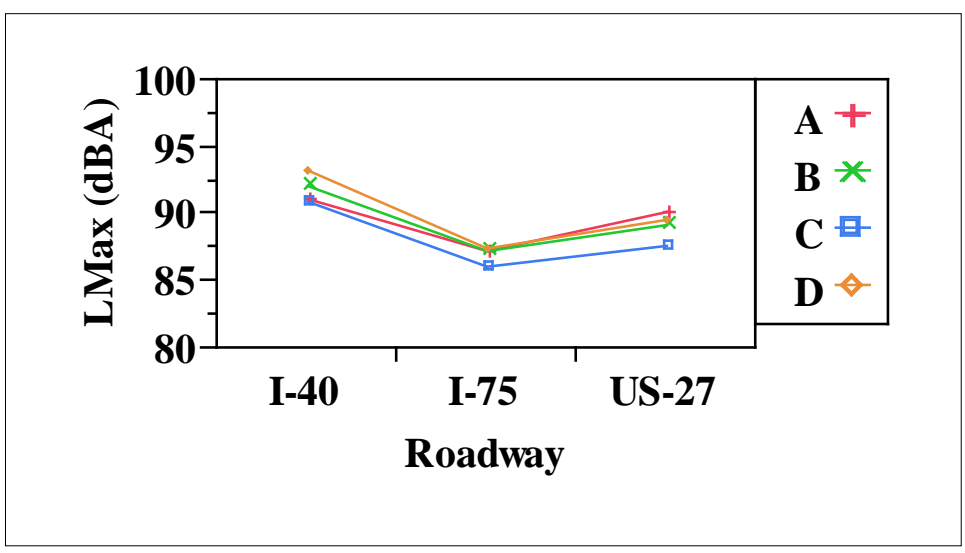

Figure 18. Graph. LS means max equivalent noise level vs. roadway and manufacturer

Graphs of the $\mathrm{L}_{\mathrm{eq}} \mathrm{LS}$ means for truck manufacturer, roadway, and the interaction effect of truck manufacturer and roadway from Integrator- 1 are shown in the three figures below: REML analysis showed that the truck manufacturer effect (Figure 19) was significant ( $p=0.003$ ). Accordingly, post-hoc Tukey's HSD tests showed that the trucks from manufacturer A had significantly higher $L_{e q}$ values than the trucks from manufacturers $B, C$ and $D$ at the 0.05 level of 
significance; all other comparisons were not significant. REML analysis showed that the roadway effect (Figure 20) was significant $(p=0.0002)$. Accordingly, post-hoc Tukey's HSD tests showed that the I-40 condition had significantly higher $\mathrm{L}_{\mathrm{eq}}$ values than the I-75 and US-27 conditions at the 0.05 level of significance; all other comparisons were not significant. REML analysis showed that the interaction effect between manufacturer and roadway (Figure 21) was not significant.

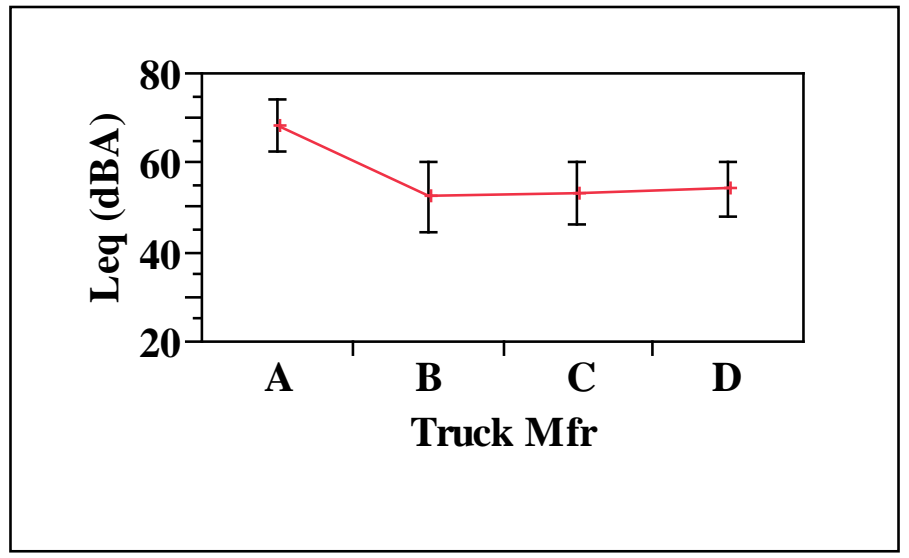

Figure 19. Graph. LS means $L_{\text {eq }}$ from Integrator-1 vs. truck manufacturer

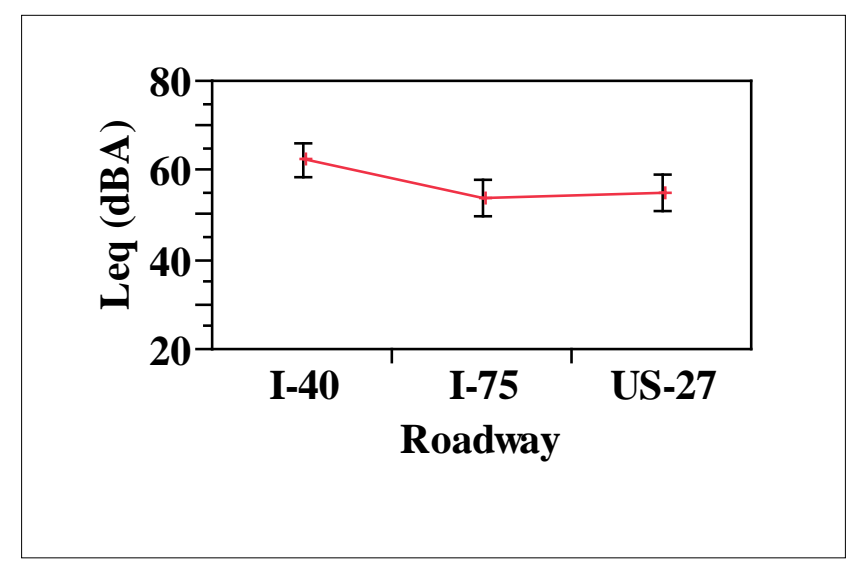

Figure 20. Graph. LS means $L_{\text {eq }}$ from Integrator-1 vs. roadway 


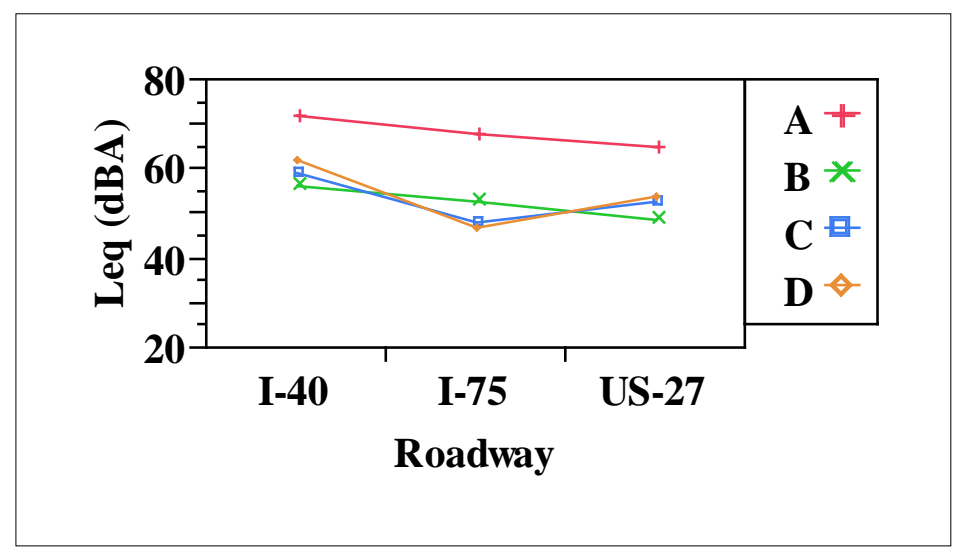

Figure 21. Graph. LS means $L_{e q}$ from Integrator-1 vs. roadway and manufacturer

Graphs of the $\mathrm{L}_{\mathrm{eq}} \mathrm{LS}$ means for truck manufacturer, roadway, and the interaction effect of truck manufacturer and roadway from Integrator-3 are shown in the three figures below: REML analysis showed that the truck manufacturer effect (Figure 22) was significant ( $p=0.01$ ). Accordingly, post-hoc Tukey's HSD tests showed that the trucks from manufacturer A had significantly higher $\mathrm{L}_{\mathrm{eq}}$ values than the trucks from manufacturers B, C and D at the 0.05 level of significance; all other comparisons were not significant. REML analysis showed that the roadway effect (Figure 23) was significant $(p<0.001)$. Accordingly, post-hoc Tukey's HSD tests showed that the I-40 and I-75 conditions had significantly higher $\mathrm{L}_{\mathrm{eq}}$ values than the US-27 condition and the I-40 condition had significantly higher Leq values than the I-75 condition both at the 0.05 level of significance; all other comparisons were not significant. REML analysis showed that the interaction effect between manufacturer and roadway (Figure 24) was not significant.

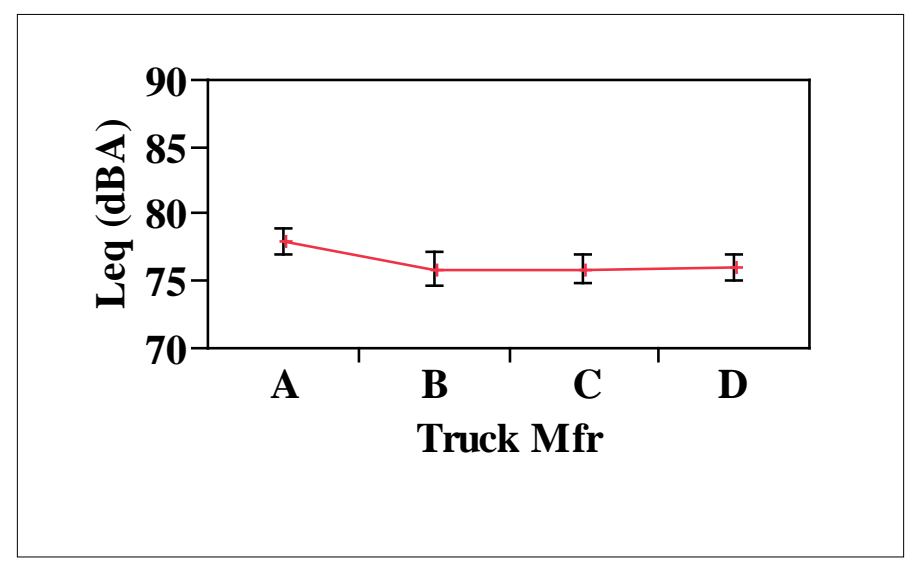

Figure 22. Graph. LS means Leq from Integrator-3 vs. truck manufacturer 


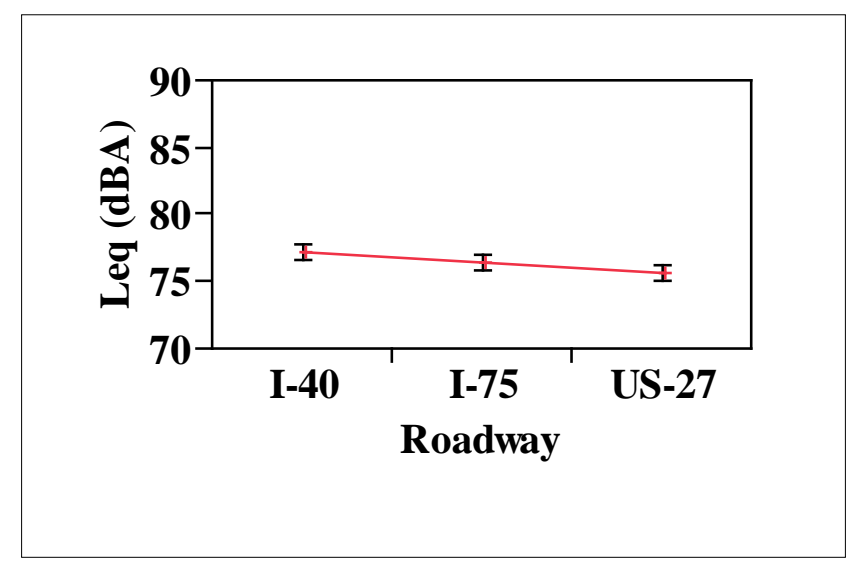

Figure 23. Graph. LS means Leq from Integrator-3 vs. roadway

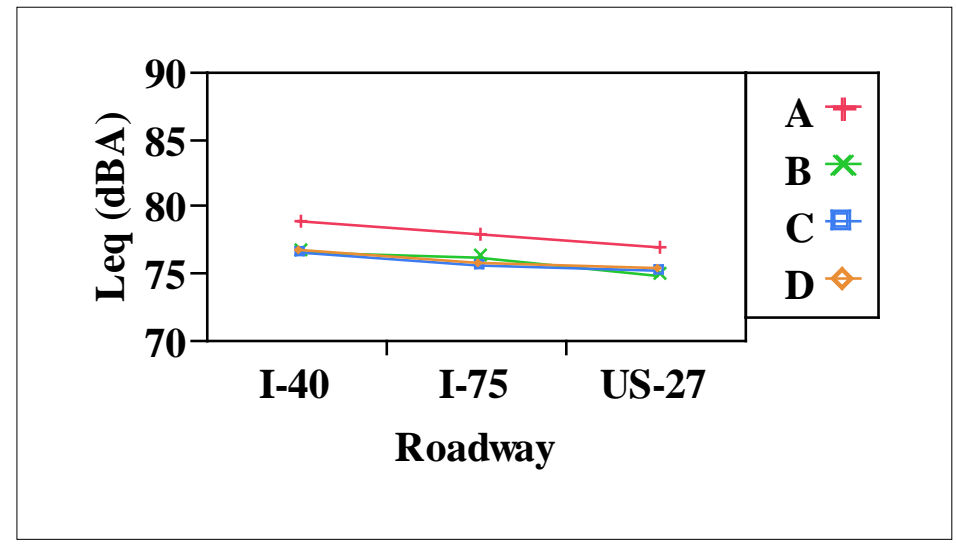

Figure 24. Graph. LS means Leq from Integrator-3 vs. roadway and manufacturer

In summary, slightly higher noise averages were observed from the trucks manufactured by company A, but for the most part, the noise conditions were quite similar for all the trucks. Higher noise averages were also generally observed while the trucks were driven on the interstate, as compared to the State highway. However, peak and maximum noise levels were generally higher on I-40 and US-27 and lower on I-75. The primary conclusions were (1) the $\mathrm{L}_{\mathrm{eq}}$ or $\mathrm{L}_{\mathrm{Ave}}$ values were well below the OSHA (90 dBA) standard and the NIOSH (85 dBA) recommended value and (2) the in-cab AL noise level, as measured by the estimated dose percent was not exceeded by any truck; even when an 11-h shift is considered for the worst case truck, the estimated dose for the AL was still not exceeded.

\subsection{WHOLE-BODY VIBRATION}

Two methods were used to acquire and analyze the vibration data. The first system collected data from the driver seat (cushion) only. The second system collected data from the driver seat (cushion) and the driver seat (back) rest and from the passenger seat (cushion). 


\subsection{DRIVER'S SEAT CUSHION MONITORING}

Data from the driver's seat cushion were collected and analyzed from 23 trucks of the 27 trucks that were road-tested in this study. Five trucks were from company A and six trucks each were from companies B, C, and D. Data are missing from four trucks because of problems that were encountered with the monitoring equipment. In general, the ranges of instantaneous frequencyweighted RMS accelerations measured in the three axes were between 0.1 and $0.6 \mathrm{~m} / \mathrm{s}^{2}$ in the $\mathrm{x}$ axis, 0.15 and $0.7 \mathrm{~m} / \mathrm{s}^{2}$ in the $y$-axis, and 0.15 and $0.8 \mathrm{~m} / \mathrm{s}^{2}$ in the $\mathrm{z}$-axis. Three events occurred in which the instantaneous acceleration exceeded $1 \mathrm{~m} / \mathrm{s}^{2}$ while driving over rough road conditions. The TWA equivalent RMS accelerations for the three translational axes for vibration and the $\Sigma$ (comfort) values from the driver seat cushion are listed in the table located in appendix $\mathrm{C}$ for each truck per type of roadway. Overall, driver seat cushion vibrations were highest from company B. However, as shown in the appendix, the EAV for a standard 8-h shift $\left(0.5 \mathrm{~m} / \mathrm{s}^{2}\right)$ was not exceeded by any of the trucks in the $\mathrm{x}-, \mathrm{y}-$, and $\mathrm{z}$-axes. If the EAV is projected to an 11 -h shift $\left(0.43 \mathrm{~m} / \mathrm{s}^{2}\right)$, two trucks from company $B$ and one truck from company $\mathrm{C}$ approached this limit in the y- and z-axes mainly while driving on I-75 and US-27. Finally, reviewing the indicator for comfort, it is shown that all sigma values for interstate and highway driving fell within the "little uncomfortable region" (i.e., between 0.315 and $0.63 \mathrm{~m} / \mathrm{s}^{2}$ ) for all trucks.

Graphs of the RMS vibration LS means for truck manufacturer, roadway, and the interaction effect of truck manufacturer and roadway for the $\mathrm{x}$-axis are shown in the three figures below: REML statistical analysis showed that the truck manufacturer effect (Figure 25) was not significant. REML analysis showed that the roadway effect (Figure 26) was significant ( $p<$ 0.001). Accordingly, post-hoc Tukey's HSD tests showed that the I-75 and US-27 conditions had significantly higher RMS vibration values in the $\mathrm{x}$-axis than the I-40 condition at the 0.05 level of significance; all other comparisons were not significant. REML analysis also showed a significant $(p=0.002)$ interaction effect between manufacturer and roadway (Figure 27) which suggests that the vibration effect of one parameter (e.g., roadway) depends on the effect from the other parameter (e.g., truck manufacturer).

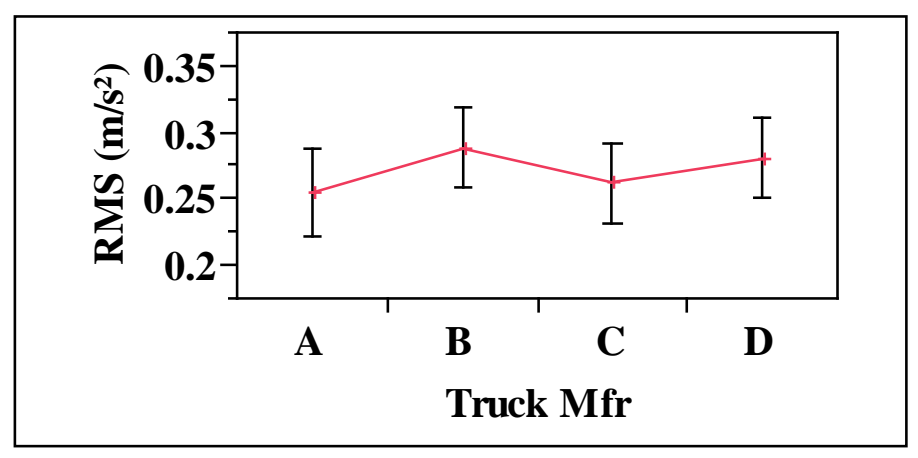

Figure 25. Graph. LS means x-axis vibration vs. truck manufacturer 


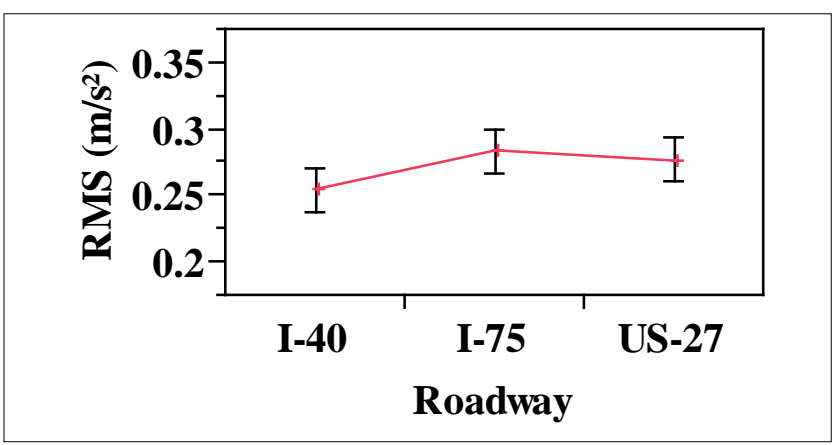

Figure 26. Graph. LS means x-axis vibration vs. roadway

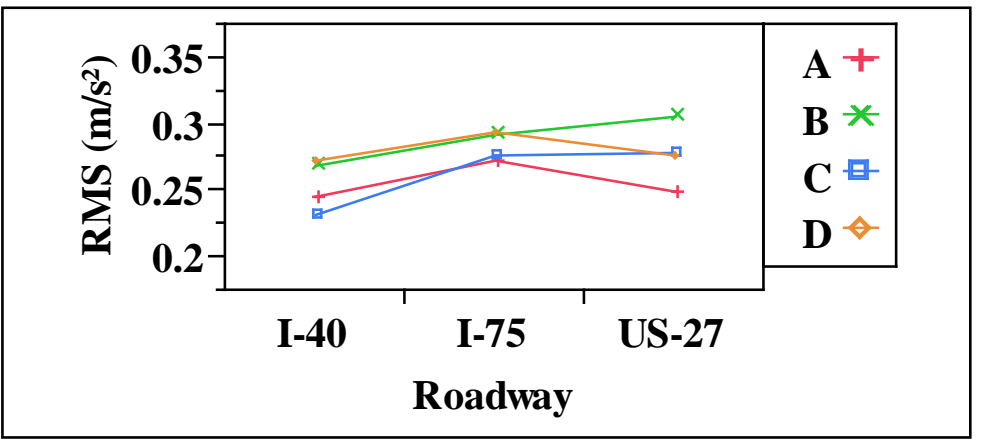

Figure 27. Graph. LS means x-axis vibration vs. roadway and manufacturer

Graphs of the RMS vibration LS means for truck manufacturer, roadway, and the interaction effect of truck manufacturer and roadway for the y-axis are shown in the three figures below: REML statistical analysis showed that the truck manufacturer effect (Figure 28) was significant $(p=0.02)$. Accordingly, post-hoc Tukey's HSD tests showed that the trucks from manufacturer $\mathrm{B}$ had significantly higher RMS vibration values in the $\mathrm{y}$-axis than the trucks from manufacturer A at the 0.05 level of significance; all other comparisons were not significant. REML statistical analysis showed that the roadway effect (Figure 29) and the roadway-manufacturer interaction effect (Figure 30) were both not significant.

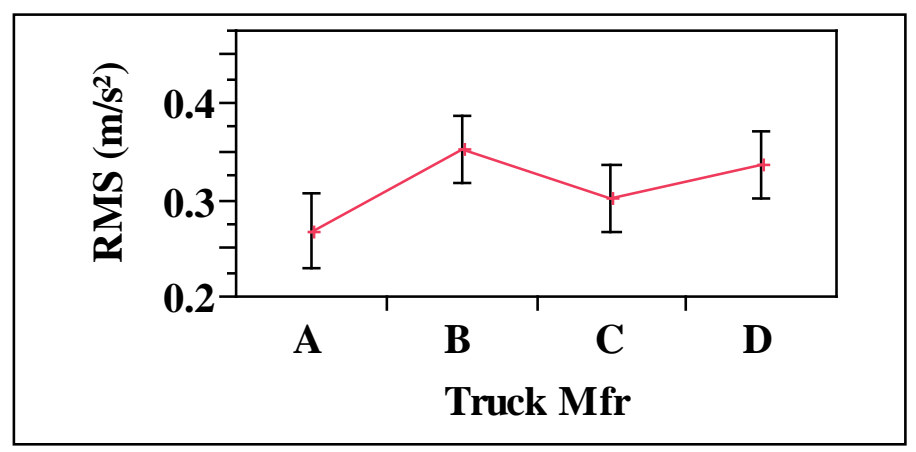

Figure 28. Graph. LS means y-axis vibration vs. truck manufacturer 


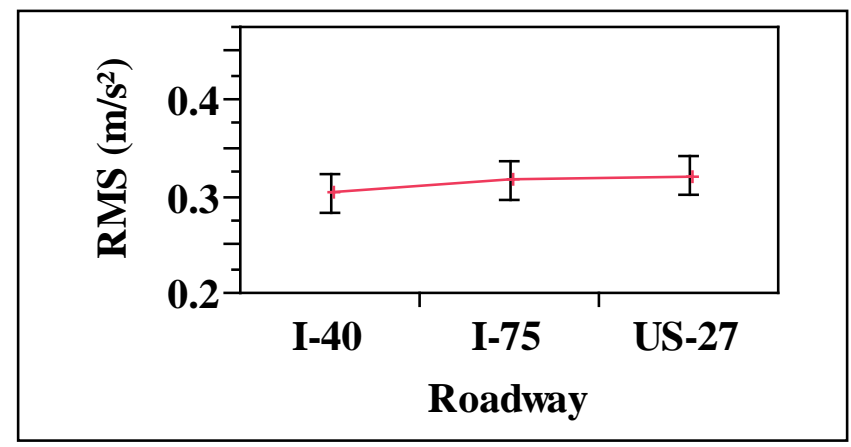

Figure 29. Graph. LS means y-axis vibration vs. roadway

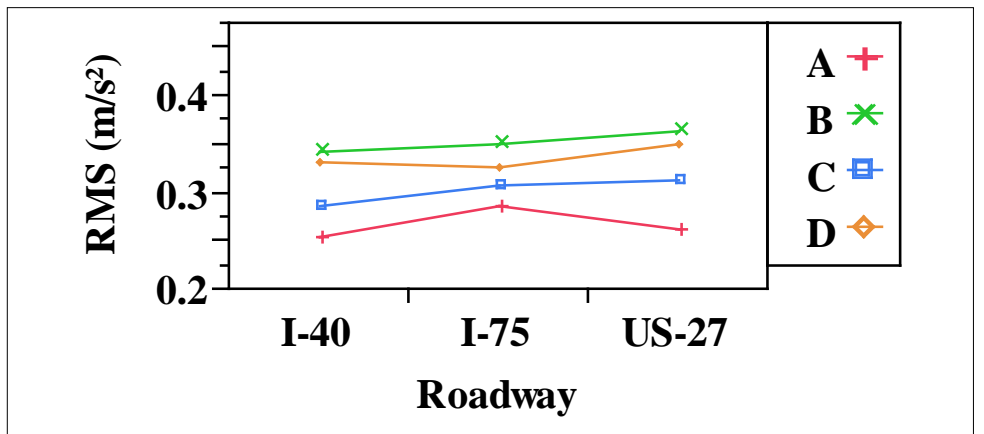

Figure 30. Graph. LS means y-axis vibration vs. roadway and manufacturer

Graphs of the RMS vibration LS means for truck manufacturer, roadway, and the interaction effect of truck manufacturer and roadway for the z-axis are shown in the three figures below: REML statistical analysis showed that the truck manufacturer effect (Figure 31) was significant $(p<0.0001)$. Accordingly, post-hoc Tukey's HSD tests showed that the trucks from manufacturer B had significantly higher RMS vibration values in the z-axis than the trucks from manufacturers A, C and D and trucks from manufacturers $C$ and D had significantly higher RMS vibration values than the trucks from manufacturer $A$, both at the 0.05 level of significance; all other comparisons were not significant. REML analysis showed that the roadway effect (Figure 32) was significant $(p<0.0001)$. Accordingly, post-hoc Tukey's HSD tests showed that the I-75 and US-27 conditions had significantly higher RMS vibration values in the z-axis than the I-40 condition at the 0.05 level of significance; all other comparisons were not significant. REML analysis also showed a significant $(p=0.005)$ interaction effect between roadway and manufacturer (Figure 33) which suggests that the vibration effect of one parameter (e.g., roadway) depends on the effect from the other parameter (e.g., truck manufacturer). 


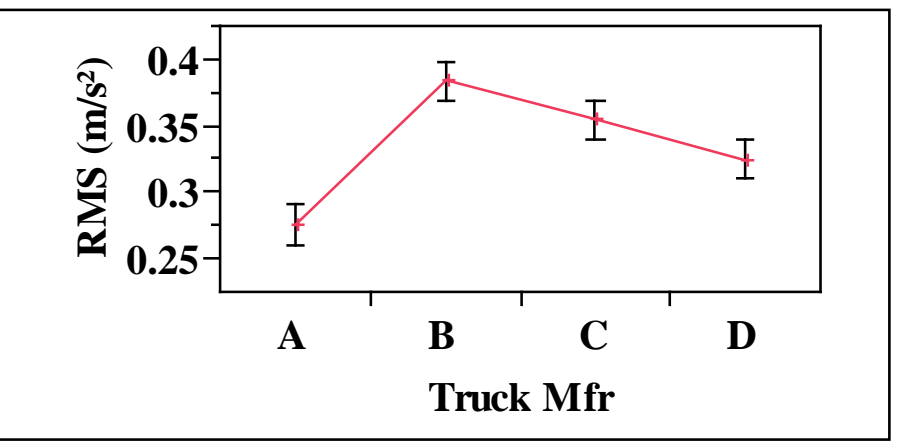

Figure 31. Graph. LS means z-axis vibration vs. truck manufacturer

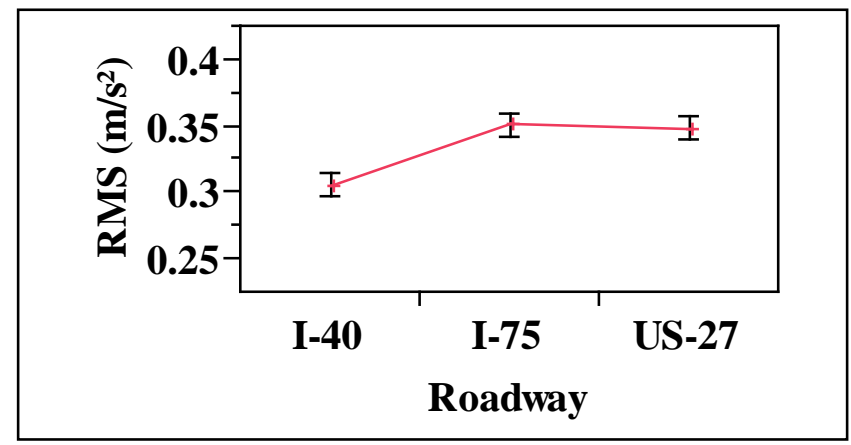

Figure 32. Graph. LS means z-axis vibration vs. roadway

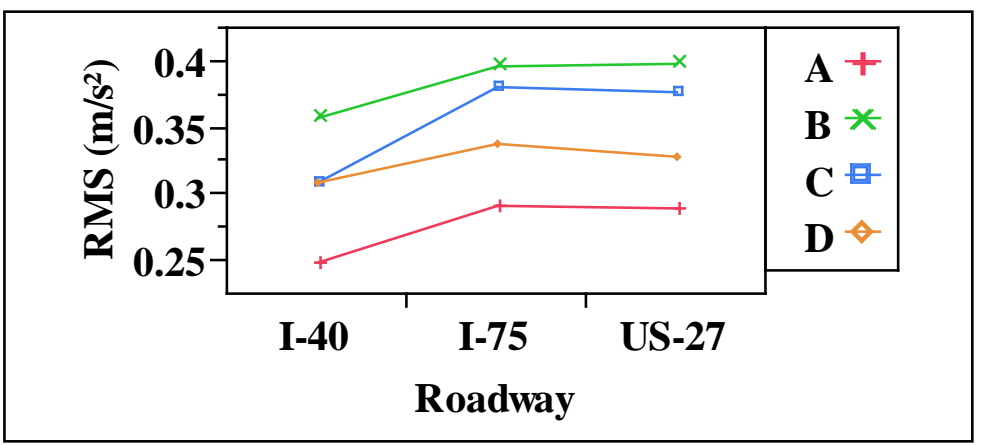

Figure 33. Graph. LS means z-axis vibration vs. roadway and manufacturer

Graphs of the RMS vibration LS means for truck manufacturer, roadway, and the interaction effect of truck manufacturer and roadway for comfort ( $\Sigma$ values) are shown in the three figures below: REML statistical analysis showed that the truck manufacturer effect (Figure 34) was significant ( $p=0.0001)$. Accordingly, post-hoc Tukey's HSD tests showed that the trucks from manufacturer B had significantly higher RMS vibration values for comfort than the trucks from manufacturers A, C and D and trucks from manufacturers C and D had significantly higher RMS vibration values than the trucks from manufacturer $\mathrm{A}$, both at the 0.05 level of significance; all other comparisons were not significant. REML analysis showed that the roadway effect (Figure 35) was significant $(p<0.0001)$. Accordingly, post-hoc Tukey's HSD tests showed that the I-75 and US-27 conditions had significantly higher RMS vibration values for comfort than the I-40 condition at the 0.05 level of significance; all other comparisons were not significant. REML analysis also showed a significant $(p=0.03)$ interaction effect between roadway and truck 
manufacturer (Figure 36) which suggests that the vibration effect of one parameter (e.g., roadway) depends on the effect from the other parameter (e.g., truck manufacturer).

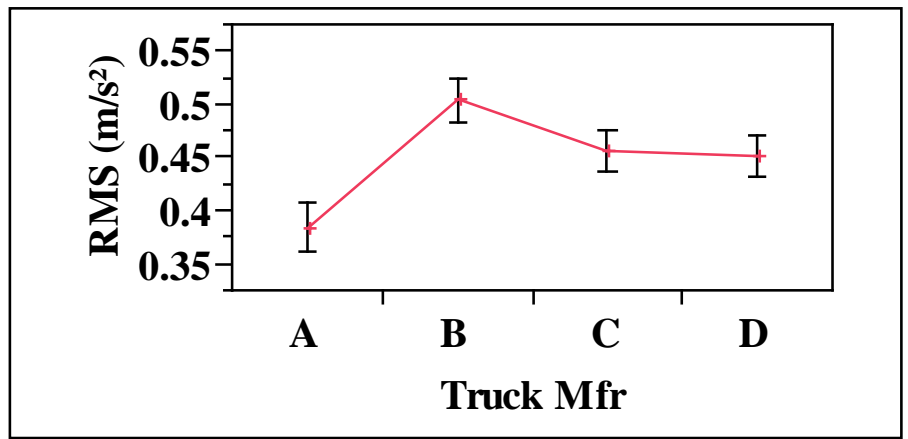

Figure 34. Graph. LS means $\Sigma$ (comfort) value vs. truck manufacturer

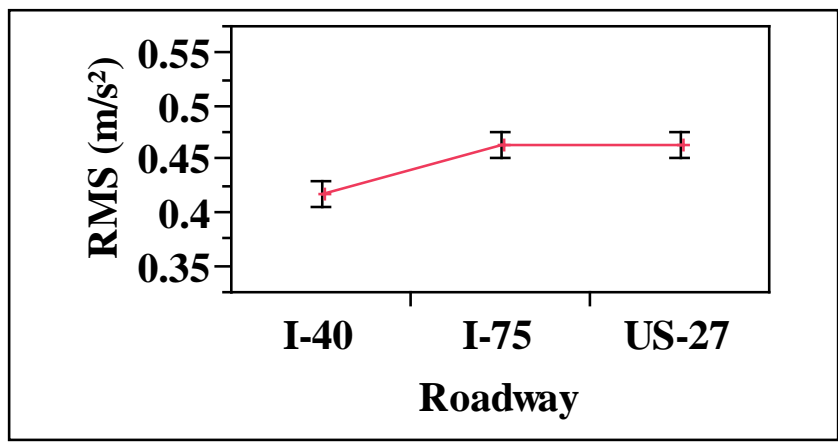

Figure 35. Graph. LS means $\Sigma$ (comfort) value vs. roadway

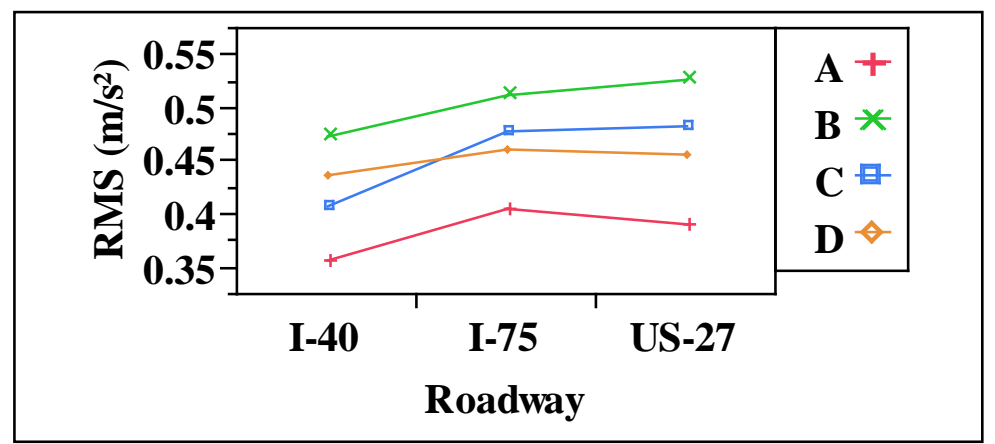

Figure 36. Graph. LS means $\Sigma$ (comfort) value vs. roadway and manufacturer

In summary, as is typical for most trucks, vibrations in the $\mathrm{x}$-axis and $\mathrm{y}$-axis were generally found to be well below the $\operatorname{EAV}\left(0.5 \mathrm{~m} / \mathrm{s}^{2}\right)$ for an 8-h driving day. In the z-axis, vibrations were also found to be below the EAV for an 8-h driving day. Trucks from company A had the lowest vibrations overall in the z-axis, relative to trucks from companies B, C, and D. Additionally, as seen from the comfort index, trucks from company A had the best comfort performance overall; trucks from companies $\mathrm{C}$ and D performed similarly in comfort, and trucks from company B fell well within the region of a little uncomfortable, which is the $\Sigma$ range 0.315 to $0.63 \mathrm{~m} / \mathrm{s}^{2}$. In almost all cases, vibrations from the driver seat cushion were lowest while driving on I-40, as compared to driving on I-75 or US-27. 


\subsection{DUAL-SEAT MONITORING}

Analysis of vibrations using accelerometers in both seats will proceed in several stages because of the vast amount of data collected and analyzed. The data sets that will be discussed are frequency-weighted RMS accelerations, crest factors (CFs), vibration dose values (VDVs), and jerk. Of the total of 27 trucks that were road-tested in the study, dual-seat data were collected and analyzed from only 24. Seven trucks were from company A, five trucks were from company B, and six trucks each were from companies $\mathrm{C}$ and $\mathrm{D}$. Missing data from three trucks were caused mainly by problems encountered with the instrumentation.

\subsubsection{Root Mean Square}

For reference purposes, the TWA equivalent RMS accelerations for the three translational axes for vibration and the $\Sigma$ (comfort) values from the driver seat cushion, the driver back rest, and the passenger seat cushion are shown in Appendices F, G, and H, respectively. As shown in these tables, vibrations in the $\mathrm{x}$-axis were relatively low across all truck manufacturers. For the driver seat cushion of vibration in the y-axis, four trucks exceeded the 8 -h EAV $\left(0.5 \mathrm{~m} / \mathrm{s}^{2}\right)$. The maximum level in the $y$-axis was $0.56 \mathrm{~m} / \mathrm{s}^{2}$. For the passenger seat cushion of vibration in the $\mathrm{y}$ axis, one truck exceeded the 8-h EAV. In almost every case, the highest vibrations occurred while the vehicles were driven on either I-75 or US-27. In the z-axis for the driver and passenger seat cushions, the vibrations were lowest for the A trucks and slightly higher for the $\mathrm{B}$, C, and D trucks. No trucks however, exceeded the 8-h EAV in the z-axis. If the EAV is projected to an 11h shift $\left(0.43 \mathrm{~m} / \mathrm{s}^{2}\right)$, seven trucks exceeded the 11 -h EAV. These were the same trucks that exceeded the 8-h value with the addition of three more vehicles for the driver seat cushion. Again these high EAVs were always in the y-axis. Finally, in reviewing the indicators for comfort, it is apparent that all sigma values for the driver seat cushion and back rest and the passenger seat cushion fell within the "little uncomfortable region“ (i.e., between 0.315 and 0.63 $\mathrm{m} / \mathrm{s}^{2}$ ) for interstate and highway driving in all trucks.

Graphs of the RMS vibration LS means from the driver seat cushion for truck manufacturer, roadway, and the interaction effect of truck manufacturer and roadway just for the comfort $(\Sigma)$ values are shown in the three figures below: REML statistical analysis showed that the truck manufacturer effect (Figure 37) was significant $(p<0.0001)$. Accordingly, post-hoc Tukey's HSD tests showed that the trucks from manufacturers B, C and D had significantly higher RMS vibration values for comfort than the trucks from manufacturer $A$ at the 0.05 level of significance; all other comparisons were not significant. REML analysis showed that the roadway effect (Figure 38) was significant $(p<0.0001)$. Accordingly, post-hoc Tukey's HSD tests showed that the I-75 and US-27 conditions had significantly higher RMS vibration values for comfort than the I-40 condition at the 0.05 level of significance; all other comparisons were not significant. REML analysis for the interaction effect between roadway and manufacturer was not significant (figure 39). 


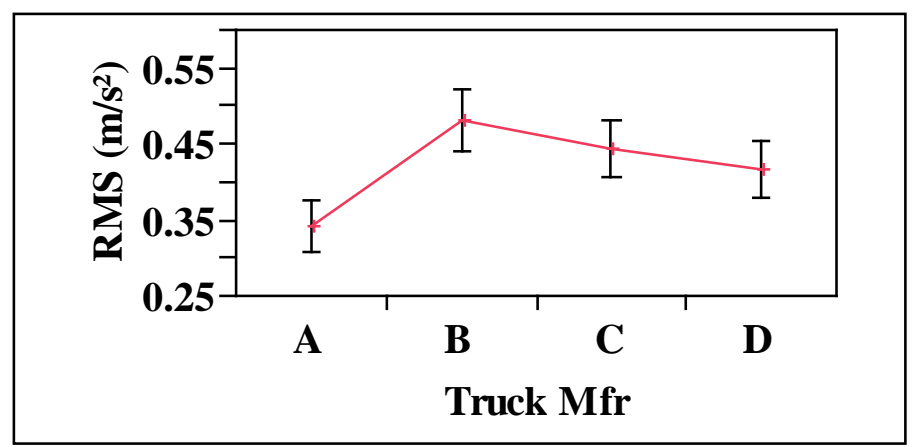

Figure 37. Graph. LS means comfort value (driver cushion) vs. truck manufacturer

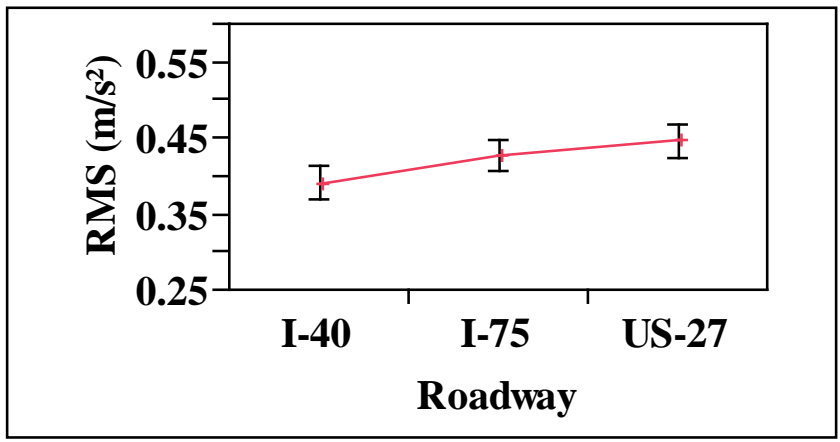

Figure 38. Graph. LS means comfort value (driver cushion) vs. roadway

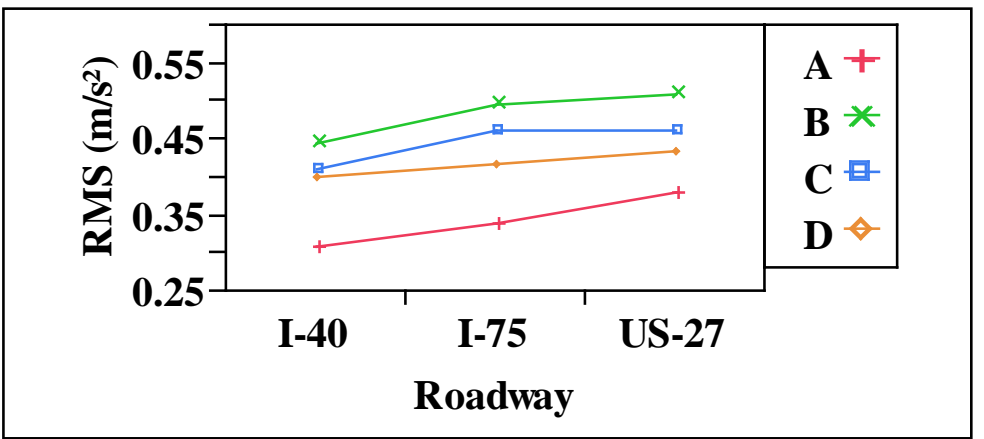

Figure 39. Graph. LS means comfort value (driver cushion) vs. roadway and manufacturer

Graphs of the RMS vibration (LS means) from the driver back pad for truck manufacturer, roadway, and the interaction effect of truck manufacturer and roadway just for the comfort $(\Sigma)$ values are shown in the three figures below: REML statistical analysis showed that the truck manufacturer effect (Figure 40) was significant ( $p=0.004)$. Accordingly, post-hoc Tukey's HSD tests showed that the trucks from manufacturers B and D had significantly higher RMS vibration values for comfort than the trucks from manufacturer A at the 0.05 level of significance; all other comparisons were not significant. REML analysis showed that the roadway effect (Figure 41) was significant $(p<0.0001)$. Accordingly, post-hoc Tukey's HSD tests showed that the I-75 and US-27 conditions had significantly higher RMS vibration values for comfort than the I-40 condition and the I-75 condition had significantly higher RMS vibration values than the US-27 condition, both at the 0.05 level of significance; all other comparisons were not significant. REML analysis for the interaction effect between roadway and manufacturer (Figure 42) was 
also significant $(p=0.006)$ which suggests that the vibration effect of one parameter (e.g., roadway) depends on the effect from the other parameter (e.g., truck manufacturer).

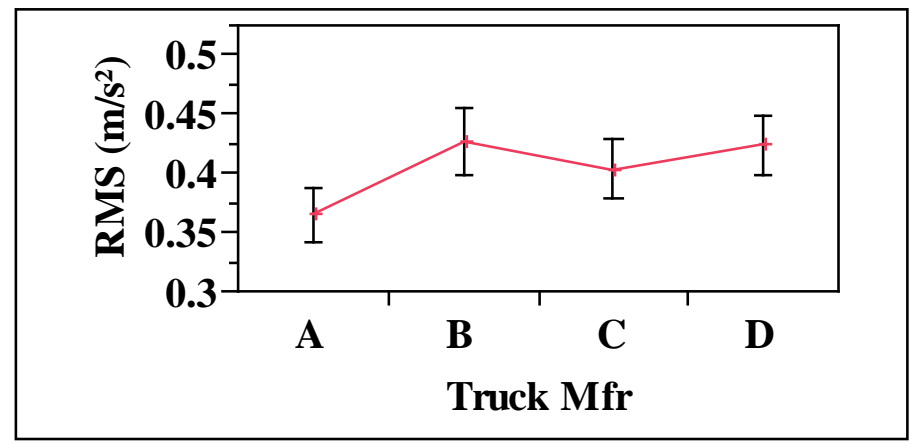

Figure 40. Graph. LS means comfort value (driver back) vs. truck manufacturer

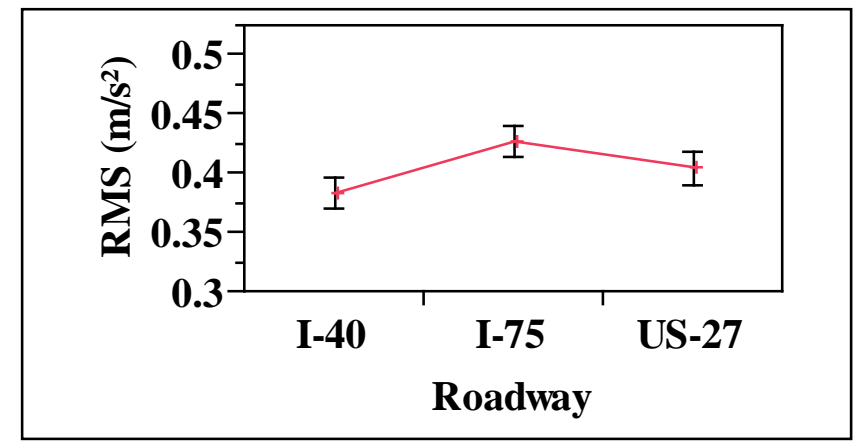

Figure 41. Graph. LS means comfort value (driver back) vs. roadway

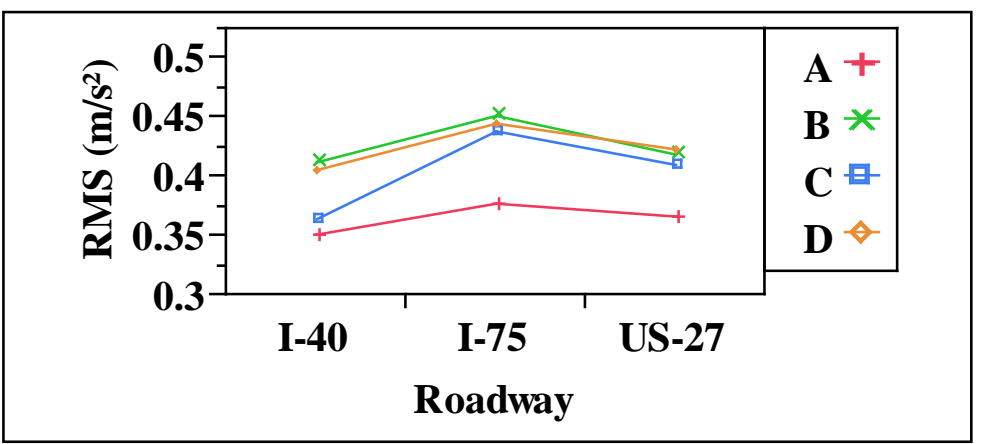

Figure 42. Graph. LS means comfort value (driver back) vs. roadway and manufacturer

Graphs of the RMS vibration (LS means) from the passenger seat cushion for truck manufacturer, roadway, and the interaction effect of truck manufacturer and roadway just for the comfort $(\Sigma)$ values are shown in the three figures below: REML statistical analysis showed that the truck manufacturer effect was significant $(p=0.009)$. Accordingly, post-hoc Tukey's HSD tests showed that the trucks from manufacturers B and C had significantly higher RMS vibration values for comfort than the trucks from manufacturer $A$ at the 0.05 level of significance; all other comparisons were not significant. REML analysis showed that the roadway effect was significant $(p<0.0001)$. Accordingly, post-hoc Tukey's HSD tests showed that the I-75 and US27 conditions had significantly higher RMS vibration values for comfort than the I-40 condition 
and the I-75 condition had significantly higher RMS vibration values than the US-27 condition, both at the 0.05 level of significance; all other comparisons were not significant. REML analysis for the interaction effect between roadway and manufacturer was also significant $(p=0.04)$ which suggests that the vibration effect of one parameter (e.g., roadway) depends on the effect from the other parameter (e.g., truck manufacturer).

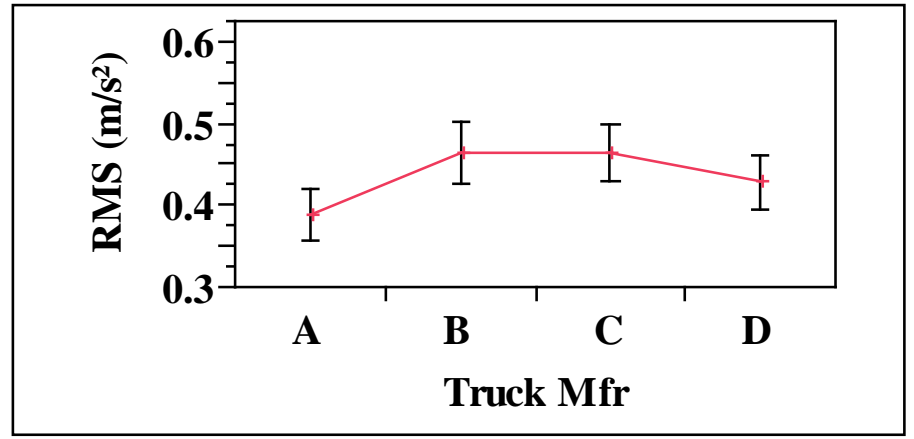

Figure 43. Graph. LS means comfort value (passenger cushion) vs. truck manufacturer

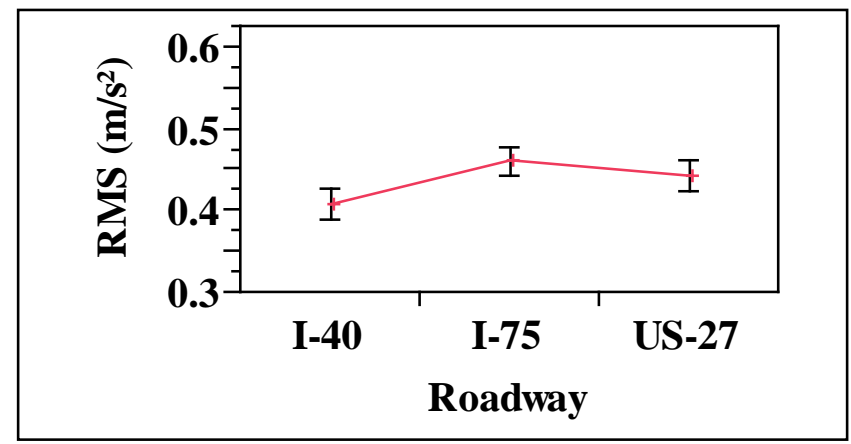

Figure 44. Graph. LS means comfort value (passenger cushion) vs. roadway

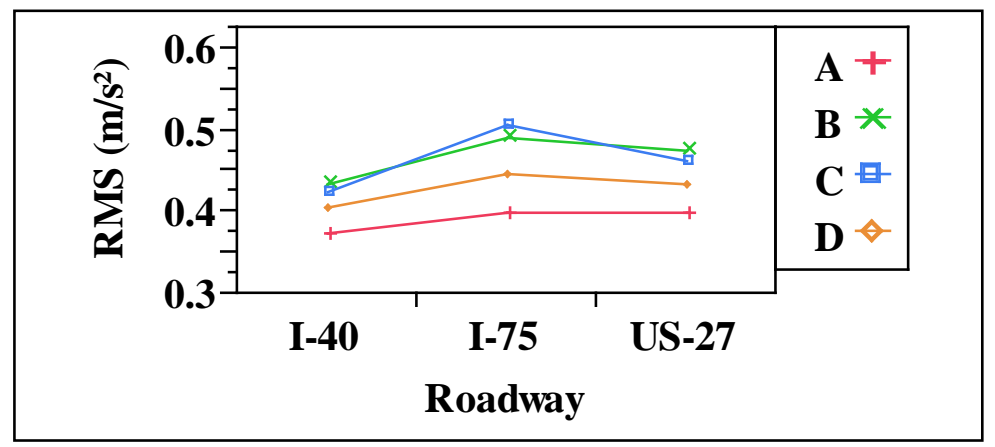

Figure 45. Graph. LS means comfort value (passenger cushion) vs. roadway and manufacturer

In summary, the RMS results from the dual-seat system were very similar to the results from the driver's seat cushion system. Vibrations in the $\mathrm{x}$ - and $\mathrm{z}$-axes were generally found to be well below the EAV. However, the EAV was exceeded in several trucks for the driver seat cushion in the y-axis. Trucks from company A had the lowest vibrations overall in the z-axis relative to trucks from companies $\mathrm{B}, \mathrm{C}$, and $\mathrm{D}$. Trucks from company A performed best in terms of the comfort index, and trucks from company B tended to perform more poorly on comfort. Again in 
almost all cases, the seat vibrations were lowest while driving on I-40 relative to driving on I-75 or US-27.

Pair-wise correlations between driver and passenger RMS accelerations for the different components or sections of the seats are shown in Table 2 for the three translational axes of vibration and the $\Sigma$ values. As shown in the table, the R-values or the correlation coefficients between the driver seat cushion and back rest and between the driver and passenger seat cushions showed that higher (positive) linear relationships existed for vibrations measured in the z-axis and for the comfort index for both sections of the seating comparisons relative to the correlations between the $\mathrm{x}$ - and y-axes. Moreover, all of the pair-wise correlations, except one in the y-axis between the driver cushion and back rest, were statistically significant at greater than the 0.05 probability level. However, these correlations indicated that there were some moderate differences in responses to vibration between the driver and passenger seats and between the cushion and back of the driver seat. It should be noted that the driver and passenger seats were predominantly identical in construction, except that more seating adjustment controls were usually available on the driver seat. In addition, the driver of the trucks was more knowledgeable in using the seating adjustments than the person who rode in the passenger seat.

Table 2. Multivariate Correlations between Driver and Passenger Seating

\begin{tabular}{|l|c|r|r|}
\hline \multicolumn{1}{|c|}{ Pair-wise Correlation } & Axis or Comfort & R-value & Probability \\
\hline Driver Cushion vs. Driver Back Pad & X & 0.42 & $0.0003^{\star}$ \\
\hline Driver Cushion vs. Driver Back Pad & Y & 0.29 & $0.0121^{\star}$ \\
\hline Driver Cushion vs. Driver Back Pad & Z & 0.74 & $<0.0001^{\star}$ \\
\hline Driver Cushion vs. Driver Back Pad & $\Sigma$ & 0.56 & $<0.0001^{\star}$ \\
\hline Driver Cushion vs. Passenger Cushion & X & 0.49 & $<0.0001^{\star}$ \\
\hline Driver Cushion vs. Passenger Cushion & Y & 0.13 & 0.2705 \\
\hline Driver Cushion vs. Passenger Cushion & $Z$ & 0.78 & $<0.0001^{\star}$ \\
\hline Driver Cushion vs. Passenger Cushion & $\Sigma$ & 0.70 & $<0.0001^{\star}$ \\
\hline
\end{tabular}

Note: Data for correlations were from the dual-seat system RMS acceleration values.

* Correlation statistic less than 0.05 probability.

\subsubsection{Crest Factor}

The ranges of CF values are shown in Table 3 for the three translational axes from the driver seat cushion, the driver back rest, and the passenger seat cushion. As previously mentioned, if the CF value is greater than 9.0, the basic evaluation method (i.e., the frequency weighted RMS method) may be insufficient for evaluating WBV. 
Table 3. Range of Values for Crest Factor from Driver and Passenger Seats

\begin{tabular}{|l|c|c|c|}
\hline \multicolumn{1}{|c|}{ Seat } & CF X-axis & CF Y-axis & CF Z-axis \\
\hline Driver Back & $8.8-12.5$ & $6.2-8.6$ & $8.2-12.0$ \\
\hline Driver Cushion & $8.4-19.7$ & $7.4-9.6$ & $7.9-11.1$ \\
\hline Passenger Cushion & $9.6-14.9$ & $6.7-13.1$ & $7.1-14.8$ \\
\hline
\end{tabular}

Table 4 lists the number of trucks in the study that had CF values over 9.0 during vibration testing. Inspection of the table shows that high CF values over 9.0 typically occurred in the $\mathrm{x}-$ and z-axes. According to ISO guidelines, where an additional method of evaluation is used, both the basic (RMS) and the (VDV) evaluation data should be reported, and this recommendation was followed in the present report.

Table 4. Total Number of Trucks with CF Values Greater than 9

\begin{tabular}{|l|c|c|c|}
\hline \multicolumn{1}{|c|}{ Seat } & CF X-axis & CF Y-axis & CF Z-axis \\
\hline Driver Back & 21 & 0 & 18 \\
\hline Driver Cushion & 23 & 6 & 11 \\
\hline Passenger Cushion & 24 & 1 & 20 \\
\hline
\end{tabular}




\subsubsection{Vibration Dose Values}

The VDVs for the three axes of translation from the driver seat cushion, the driver back rest, and the passenger seat cushion are shown in Appendices I, J, and K, respectively. As shown in these tables, the ELV of $21 \mathrm{~m} / \mathrm{s}^{1.75}$ was exceeded only once, by the driver seat cushion of truck A6 in the $\mathrm{x}$-axis while the truck was driven on US-27. The EAV of $9.1 \mathrm{~m} / \mathrm{s}^{1.75}$ was exceeded several times. In particular, the EAV was exceeded by the driver seat cushion of truck A6 in the y-axis while it was driven again on US-27 and of truck B2 in the x-axis while driving on I-75 and US27. For the driver back rest, the EAV was exceeded only once by the truck C4 in the z-axis while driving on I-75. For the passenger seat cushion, the EAV was exceeded again by truck B2, but this time in the z-axis while driving on I-75 and US-27 and by truck C4 in the z-axis while driving on I-75. In summary, the VDV results from the dual-seat system showed that overall the driver and passenger seats were fairly satisfactory in curtailing vibration. Once more, as demonstrated in the RMS method, the seat vibrations were lowest while the trucks were driven on I-40, as compared to driving on I-75 or US-27.

\subsubsection{Jerk}

The ranges of jerk values are shown for the three translational axes from the driver seat cushion, the driver back rest, and the passenger seat cushion in Table 5. From these comparisons of ranges, it is apparent that the driver and passenger seat cushions responded similarly to measurements of jerk, with the passenger seat cushion slightly higher overall in jerk values than the driver seat cushion. In addition, for the driver and passenger seat cushion, jerk values were higher in the $\mathrm{x}$ - and $\mathrm{y}$-axes than were the jerk values in the z-axis. This effect was reversed for the driver back rest, that is, the jerk values were higher in the z-axis for the driver back rest than in the $\mathrm{x}$ - and $\mathrm{y}$-axes. These results tend to indicate that the seat cushions and the back rest responded differently to conditions of jerk.

Table 5. Range of Values for Jerk from Driver and Passenger Seats

\begin{tabular}{|l|c|c|c|}
\hline \multicolumn{1}{|c|}{ Seat } & Jerk X-axis $\left(\mathrm{m} / \mathbf{s}^{\mathbf{3}}\right)$ & Jerk Y-axis $\left(\mathbf{m} / \mathbf{s}^{3}\right)$ & Jerk Z-axis $\left(\mathrm{m} / \mathbf{s}^{3}\right)$ \\
\hline Driver Back & $13-70$ & $22-121$ & $36-305$ \\
\hline Driver Cushion & $30-339$ & $20-231$ & $12-85$ \\
\hline Passenger Cushion & $60-463$ & $44-248$ & $25-98$ \\
\hline
\end{tabular}

\subsection{AIR QUALITY}

Air quality data were collected from 27 trucks. Nine trucks were from company A, and six trucks each were from companies B, C, and D. There were several instances in which data were not collected from an instrument during a particular truck test because of various sampling problems, but for the most part, data were collected from all trucks that were rented or leased in this study. 


\subsubsection{Calibration of Measured Concentrations}

\subsubsection{CO and $\mathrm{NO}_{X}$ Analyzers}

Calibration for the $\mathrm{CO}$ and $\mathrm{NO}_{\mathrm{X}}$ instruments was confirmed before each truck test, and both instruments were recalibrated as the need arose. Zero calibrations were achieved using ultra-pure zero air. The $\mathrm{CO}$ analyzer was calibrated using $1 \mathrm{ppm} \mathrm{CO}$. The $\mathrm{NO}_{\mathrm{X}}$ analyzer was calibrated using 2 ppm NO and was checked using 0.1 ppm NO $\mathrm{N}_{2}$. Spot checks using other concentration also were conducted using the dilution mass flow controller. During the early phase of the project neither instrument maintained the span calibration over time. These problems were remedied by replacing the infrared energy source and the correlation-chopper wheel on the CO instrument in-house and having the $\mathrm{NO}_{\mathrm{X}}$ instrument completely refurbished by the manufacturer. After the repairs the zero and span calibrations remained fairly consistent for both instruments during the latter stages of the project.

\subsubsection{PM Analyzers}

The $\mathrm{PM}_{2.5}$ instruments were collocated with a TEOM on 4 separate days, 2 days each for 5-h and 6-h time periods. Graphs of the 1-h average $\mathrm{PM}_{2.5}$ concentrations for the OPC and DRam versus the TEOM are shown in Figure 46 and Figure 47, respectively. The best-fit regression equations used to correct the actual DRam and OPC data also are shown in the graphs. A linear equation $\left(\mathrm{R}^{2} \sim 0.91\right)$ was the best-fit for the OPC and TEOM data. A two-level polynomial or quadratic equation $\left(\mathrm{R}^{2} \sim 0.94\right)$ was the best-fit equation for the DRam and TEOM data. The probability $(p)$ or significance levels associated with the analysis of variance or F-statistic for the two regression equations were both less than 0.0001. Significance levels for the parameter estimates were determined by Student $t$-tests. The parameter estimate probability levels for the linear correction equation were intercept (3.0), $p=0.004$ and slope (0.68), $p<0.0001$. For the polynomial equation the parameter estimate probability levels were intercept (5.7), $p=0.0019$, $\mathrm{x}$-coefficient $(-0.24), p=0.03$ and $x^{2}$ coefficient $(0.01), p<0.0001$. For the purpose of comparison, a plot of

the TEOM-corrected DRam and OPC data is shown in Figure 48. The $\mathrm{R}^{2}$ value $(\sim 0.86)$ for this comparison was reasonable $(p<0.0001)$ and the slope $(\sim 0.91)$ of the best-fit line for the corrected data was close to $1.0(p<0.0001)$. It should be noted that all $\mathrm{PM}_{2.5}$ data presented in this report were corrected to TEOM values unless otherwise specified, and concentrations are reported separately for DRam and OPC. 


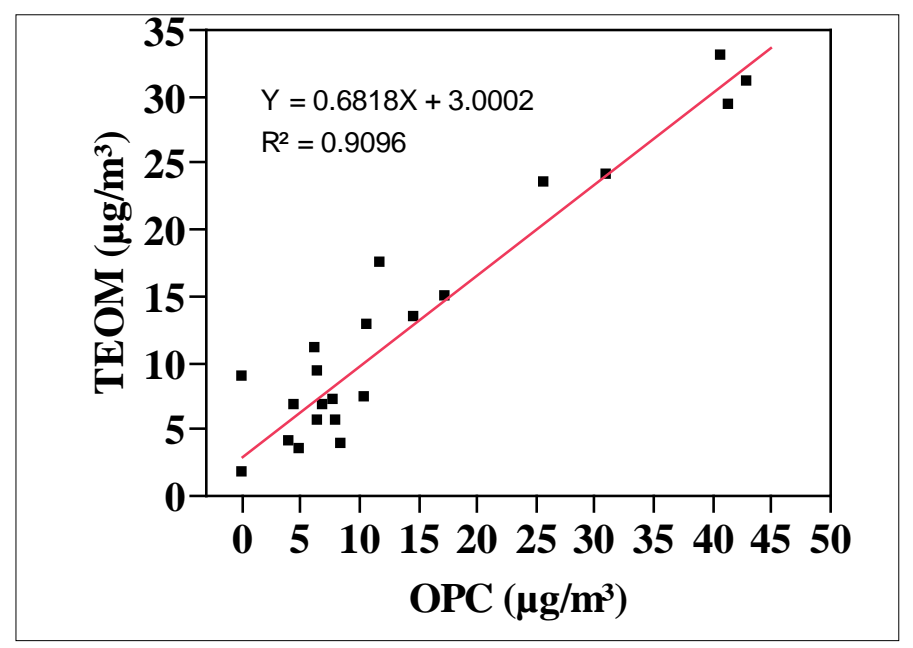

Figure 46. Graph. OPC to TEOM calibrations curve for $\mathrm{PM}_{2.5}$

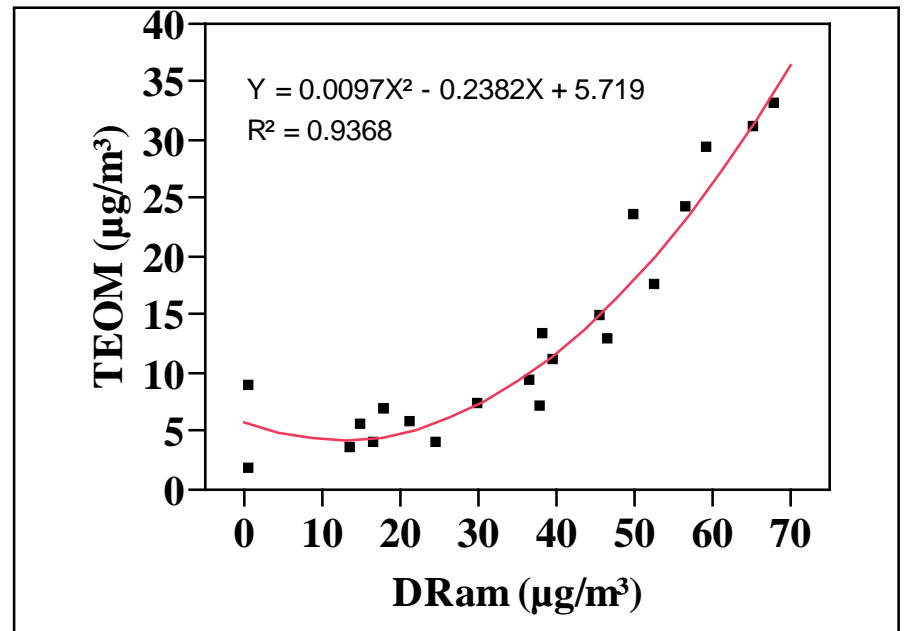

Figure 47. Graph. DRam to TEOM calibration curve for $\mathrm{PM}_{2.5}$

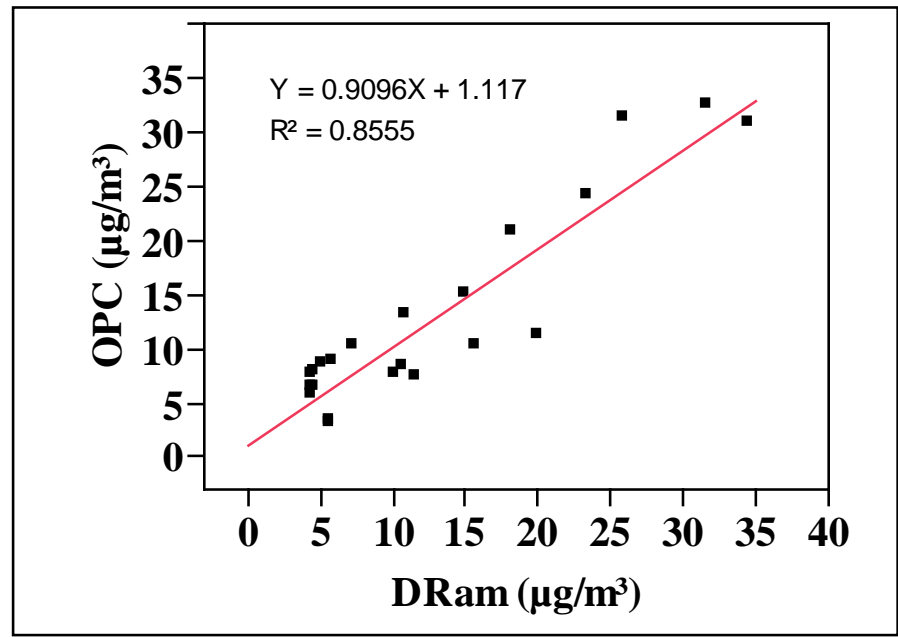

Figure 48. Graph. TEOM corrected DRam vs. OPC calibration data for $\mathrm{PM}_{2.5}$ 


\subsubsection{Truck Air Exchange Rates}

The air exchange rates were estimated by releasing the $\mathrm{CO}_{2}$ tracer gas into the cab and measuring the decay of the $\mathrm{CO}_{2}$ concentration over a period of time. The average results from this test are shown in Table 6 for several different truck engine/HVAC modes of operation and ventilation fan speeds. The exchange rate conveys the time in minutes for one cabin volume to replenish or exchange itself. The higher the exchange rate, the longer it takes to replenish the outside air in the cab. The standard deviation is the plus/minus value reported after the average values listed in Table 6. The highest or longest exchange rate occurred when the truck engine and the HVAC were both off, which was expected, since this is the extreme case for no mixing of inside and outside air. The most rapid exchange rate occurred during engine idling and HVAC on fresh-air mode, with dash and sleeper ventilation fans on four and two fan speeds, respectively.

Table 6. Air Exchange Rates for a Subset of Trucks

\begin{tabular}{|c|c|c|c|c|c|}
\hline $\begin{array}{c}\text { Truck } \\
\text { Count } \\
(\mathbf{n})\end{array}$ & $\begin{array}{c}\text { Engine } \\
\text { Mode }\end{array}$ & $\begin{array}{c}\text { HVAC } \\
\text { Mode }\end{array}$ & $\begin{array}{c}\text { Dash Fan } \\
\text { Speed } \\
\text { Mode }\end{array}$ & $\begin{array}{c}\text { Sleeper } \\
\text { Fan Speed } \\
\text { Mode }\end{array}$ & $\begin{array}{c}\text { Cabin Air Change Rate } \\
\text { (min/exchange) Average } \\
\pm \text { Standard Deviation }\end{array}$ \\
\hline 3 & Off & Off & 0 & 0 & $130 \pm 40$ \\
\hline 1 & On & Off & 0 & 0 & $76 \pm 0$ \\
\hline 2 & On & Recirculated Air & 4 & 0 & $45.9 \pm 16.1$ \\
\hline 9 & On & Recirculated Air & 4 & 2 & $44.1 \pm 47.1$ \\
\hline 3 & On & Fresh Air & 2 & 2 & $11.6 \pm 5.7$ \\
\hline 3 & On & Fresh Air & 4 & 0 & $5.3 \pm 1.8$ \\
\hline 9 & On & Fresh Air & 4 & 2 & $2.7 \pm 0.8$ \\
\hline
\end{tabular}

As previously mentioned, recirculation may not always be 100 percent recirculated air, to prevent the depletion of oxygen in the cab. In fact, the HVAC system from one of the truck manufacturers was designed to switch from full recirculation to partial recirculation mode after approximately $20 \mathrm{~min}$. This effect is demonstrated in Figure 49, which is a plot of the $\mathrm{CO}_{2}$ decay rate during engine idling while the HVAC was in recirculation air mode. Notice that between 1200 and 1400 seconds(s) on the graph, the slope of the decay curve changed shape. Slopes of the best-fit lines for each segment were 0.000387 exchange/s and 0.003582 exchange/s.

Converting seconds into minutes and inverting the values produce the air exchange rates, which are approximately $43 \mathrm{~min} /$ exchange and $4.7 \mathrm{~min} / \mathrm{exchange,} \mathrm{respectively,} \mathrm{for} \mathrm{the} \mathrm{earlier} \mathrm{and} \mathrm{later}$ time segments of the $\mathrm{CO}_{2}$ decay curve shown in the figure. Note again that these values are well within the range of the values shown in table 6 for the average recirculation and fresh air modes of operation for the trucks that were tested. 


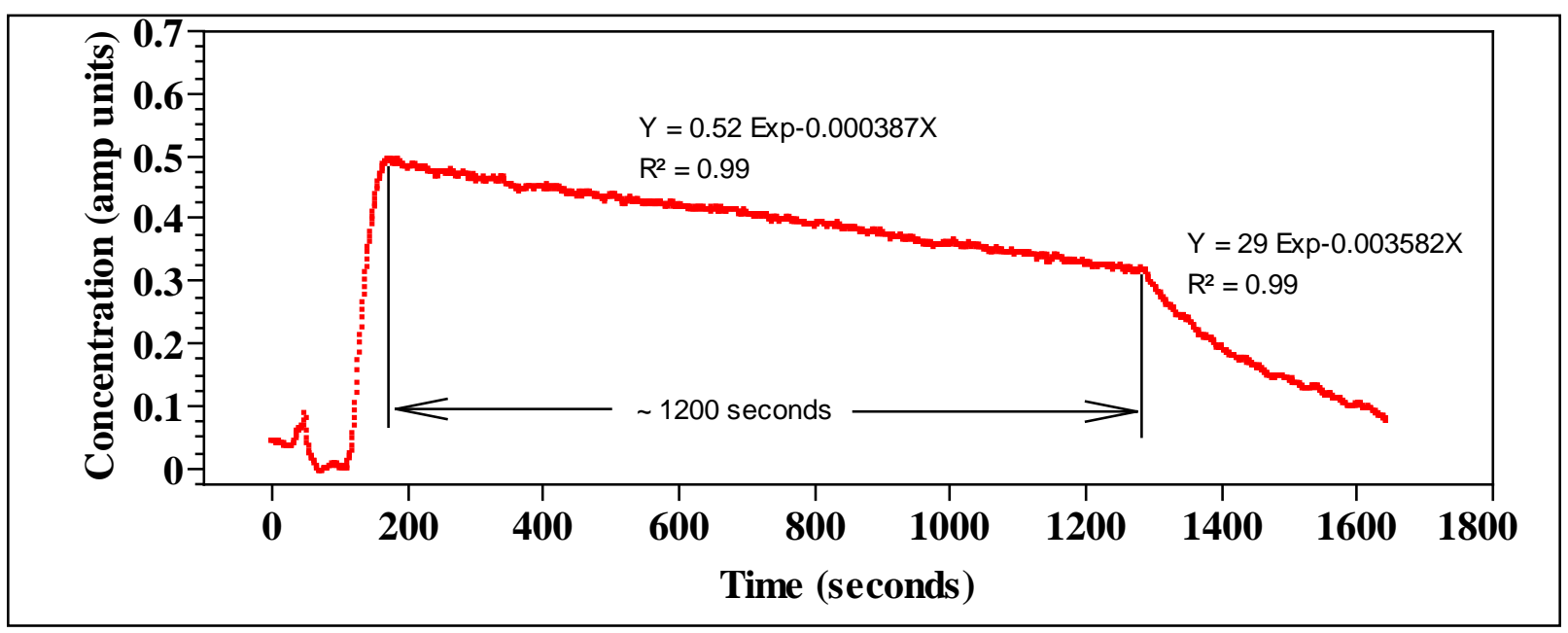

Figure 49. Graph. Decay curve for $\mathrm{CO}_{2}$ recirculaton air shifting to fresh-air mode

\subsubsection{Parked-Idling Test}

Average 1-h concentrations for $\mathrm{CO}, \mathrm{NO}_{\mathrm{X}}$, and $\mathrm{PM}_{2.5}$ and the ratio of $\mathrm{NO}$ to $\mathrm{NO}_{\mathrm{X}}$ are shown in table 7 for the five truck engine/HVAC modes of operation. Bar graphs of this data, excluding the $\mathrm{NO} / \mathrm{NO}_{\mathrm{X}}$ ratio, are also shown in Figure 50 and Figure 51. Cursory inspection of the overall average data suggests immediately that the different modes of truck engine and HVAC operation have a definite influence on the air quality inside the cab. Highest average $\mathrm{CO}$ and $\mathrm{NO}_{\mathrm{X}}$ concentrations occurred during engine on (or idling) and with the HVAC system in recirculation air mode; highest average $\mathrm{PM}_{2.5}$ concentrations occurred during engine on and with the HVAC system in fresh air mode. Concentrations of all pollutants were lowest when both the truck engine and HVAC were off. Even when the HVAC system was off and the truck engine was on, the in-cab concentrations were still generally higher than both the inside or outside background concentrations that were measured during the engine off conditions. The relative magnitudes of the $\mathrm{NO} / \mathrm{NO}_{\mathrm{X}}$ ratios for the engine/HVAC modes also demonstrated that when the truck engine was off, lower ratios were observed especially during the outside air sampling period.

Table 7. Overall Average 1-h Concentrations from Parked-Idling Test

\begin{tabular}{|c|c|c|c|c|c|c|c|}
\hline $\begin{array}{c}\text { Truck } \\
\text { Engine }\end{array}$ & $\begin{array}{l}\text { HVAC } \\
\text { System }\end{array}$ & $\begin{array}{l}\text { Sample } \\
\text { Location }\end{array}$ & $\begin{array}{c}\text { CO } \\
(p p b)\end{array}$ & $\mathrm{NO}_{x}(\mathrm{ppb})$ & NO/NO & $\begin{array}{c}\mathrm{PM}_{2.5} \text { DRam } \\
\left(\mu \mathrm{g} / \mathrm{m}^{3}\right)\end{array}$ & $\begin{array}{c}\mathrm{PM}_{2.5} \text { OPC } \\
\left(\mu \mathrm{g} / \mathrm{m}^{3}\right)\end{array}$ \\
\hline Off & Fan Off & In-cab & 396 & 120 & 0.73 & 7 & 14 \\
\hline Off & Fan Off & Outside & 295 & 119 & 0.61 & 13 & 27 \\
\hline On & Fan Off & In-cab & 508 & 624 & 0.85 & 19 & 48 \\
\hline On & Fresh Air & In-cab & 472 & 466 & 0.81 & 22 & 51 \\
\hline On & Recirculation & In-cab & 585 & 643 & 0.85 & 9 & 28 \\
\hline
\end{tabular}




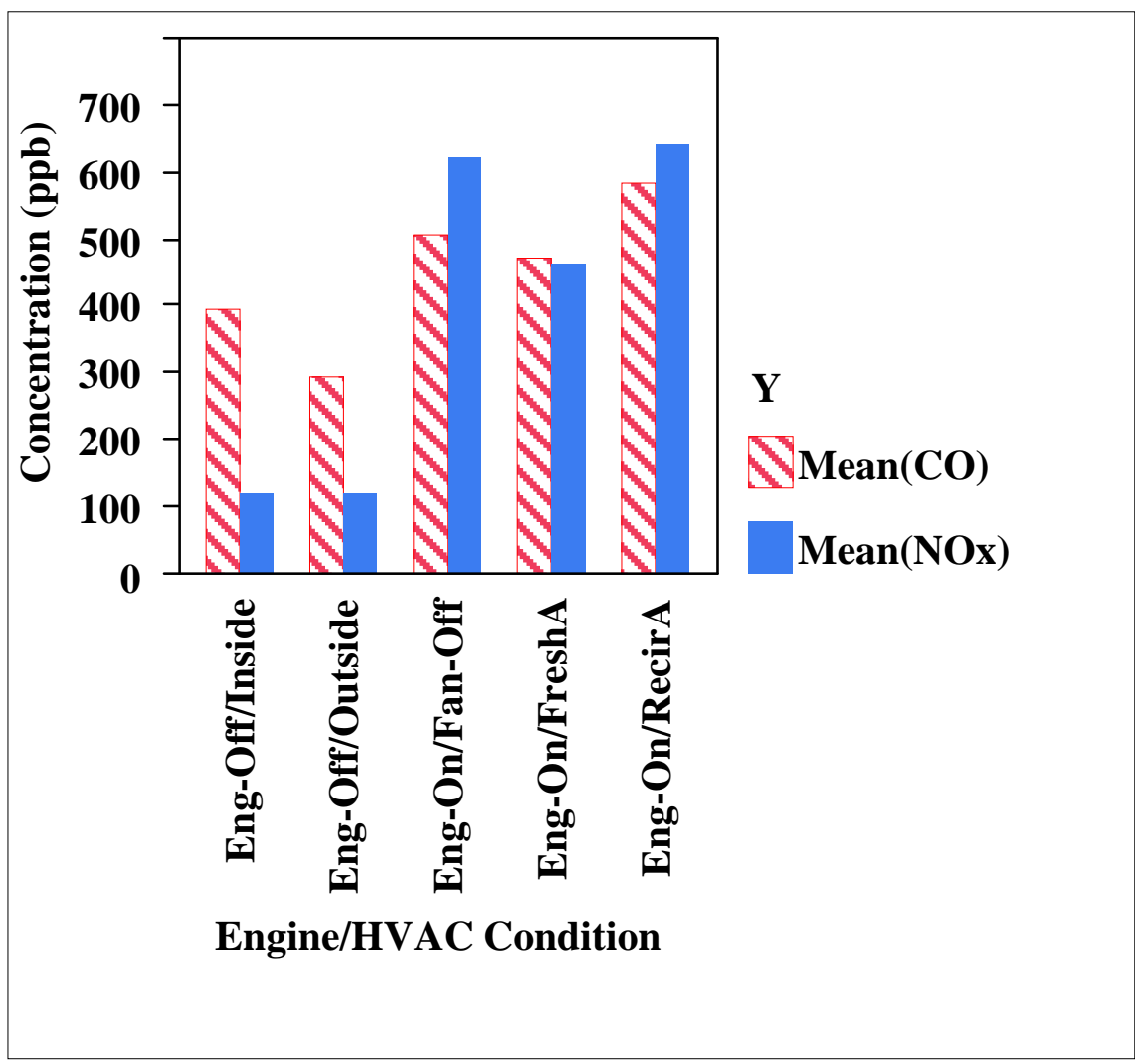

Figure 50. Graph. Overall average 1-h $\mathrm{CO}$ and $\mathrm{NO}_{x}$ concentrations from parked-idling test

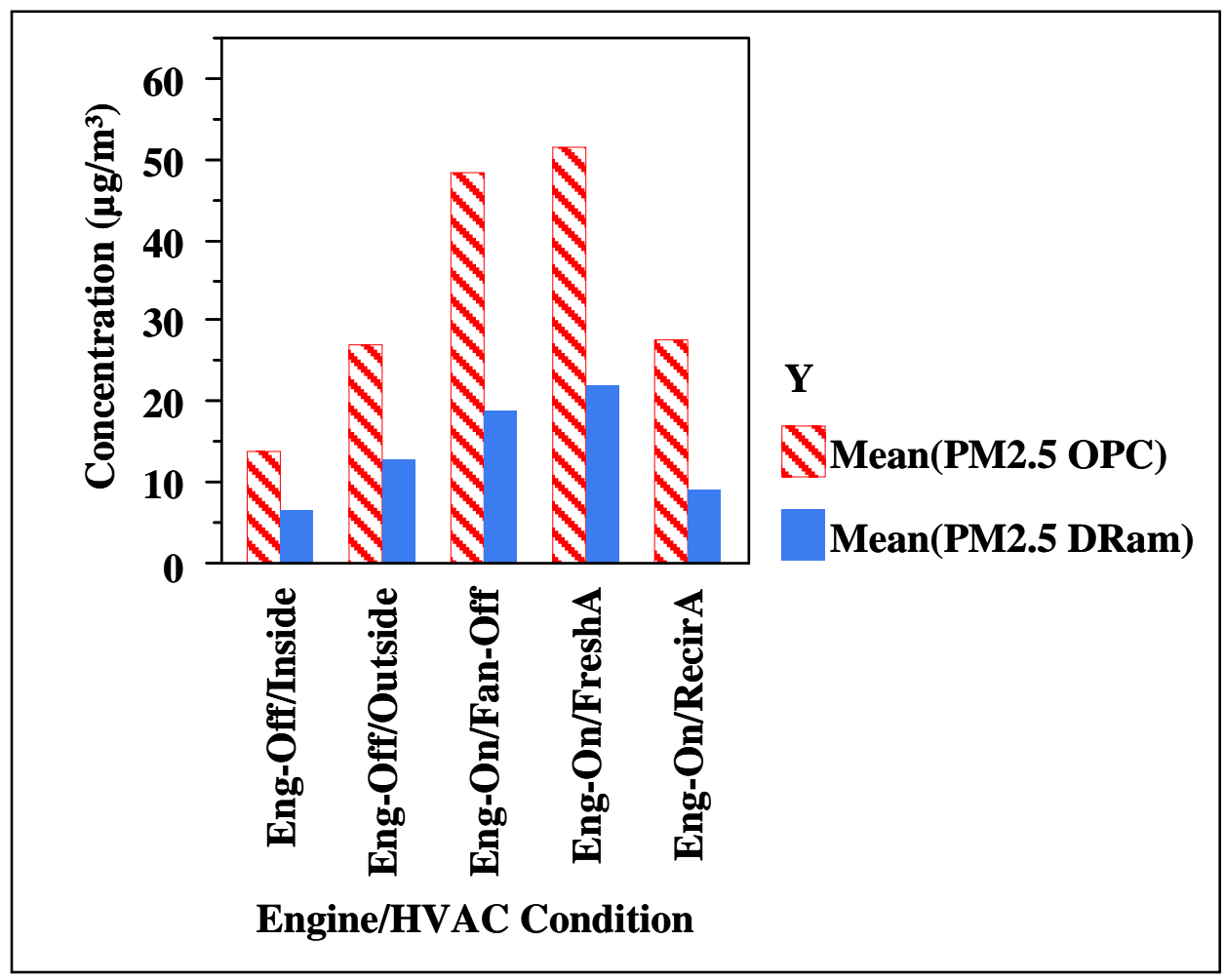

Figure 51. Graph. Overall average 1-h $\mathrm{PM}_{2.5}$ concentrations from parked-idling test 
Graphs of the CO concentration LS means for truck manufacturer, engine/HVAC condition, and the interaction effect of truck manufacturer and engine/HVAC condition are shown in the three figures below: REML statistical analysis showed that the truck manufacturer effect (Figure 52) was significant ( $p=0.01$ ). Accordingly, post-hoc Tukey's HSD tests showed that the trucks from manufacturer A had significantly higher $\mathrm{CO}$ concentrations than the trucks from manufacturers $\mathrm{B}$ and $\mathrm{C}$ at the 0.05 level of significance; all other comparisons were not significant. REML analysis showed that the engine/HVAC effect (Figure 53) was significant ( $p$ $=0.005)$. Accordingly, post-hoc Tukey's HSD tests showed that the Eng-On/Fan-Off and EngOn/Recirculation Air conditions had significantly higher CO concentrations than the EngOff/Outside condition at the 0.05 level of significance; all other comparisons were not significant. REML analysis for the interaction effect between truck manufacturer and engine/HVAC condition (Figure 54) was not significant.

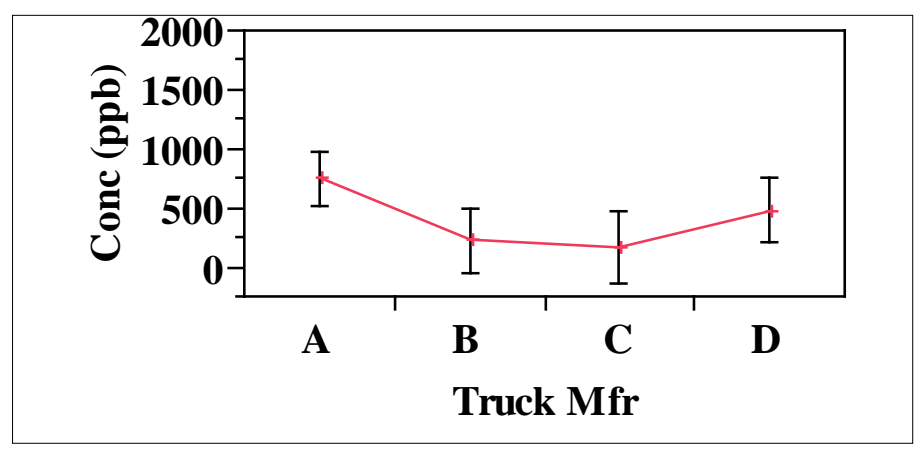

Figure 52. Graph. LS means CO concentration vs. truck manufacturer

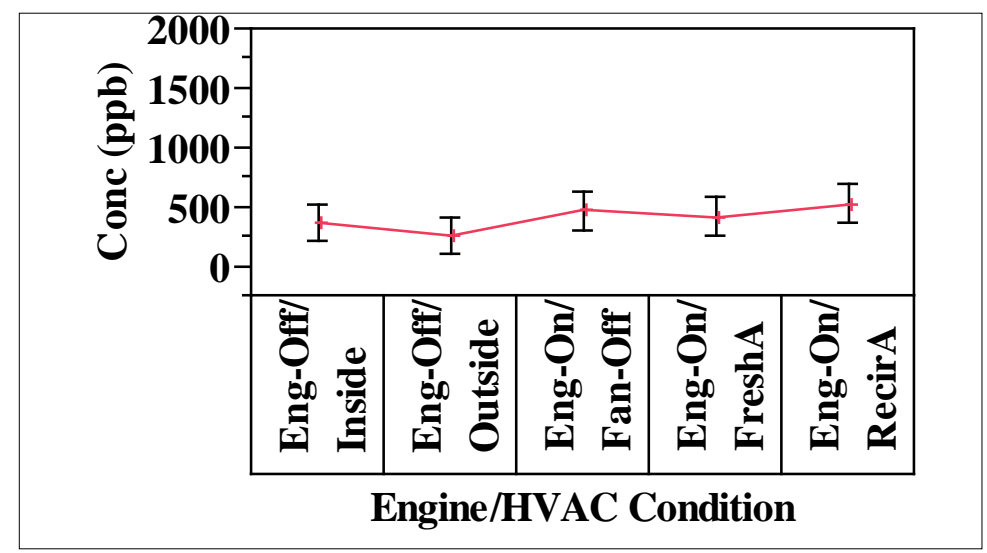

Figure 53. Graph. LS means CO concentration vs. engine/HVAC condition 


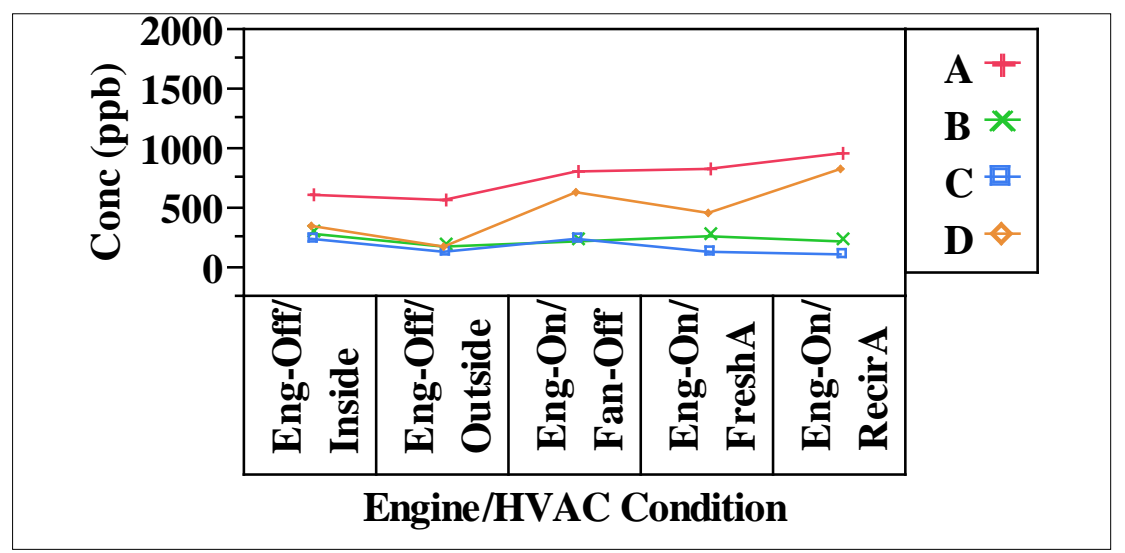

Figure 54. Graph. LS means CO concentration vs. engine/HVAC and manufacturer

Graphs of the $\mathrm{NO}_{\mathrm{X}}$ concentration LS means for truck manufacturer, engine/HVAC condition, and the interaction effect of truck manufacturer and engine/HVAC condition are shown in the three figures below: REML statistical analysis showed that the truck manufacturer effect (Figure 55) was not significant. REML analysis showed that the engine/HVAC effect (Figure 56) was significant $(p=0.003$ ). Accordingly, post-hoc Tukey's HSD tests showed that the Eng-On/FanOff and Eng-On/Recirculation Air conditions had significantly higher $\mathrm{NO}_{\mathrm{X}}$ concentrations than the Eng-Off/Inside and Eng-Off Outside conditions at the 0.05 level of significance; all other comparisons were not significant. REML analysis for the interaction effect between truck manufacturer and engine/HVAC condition (Figure 57) was not significant.

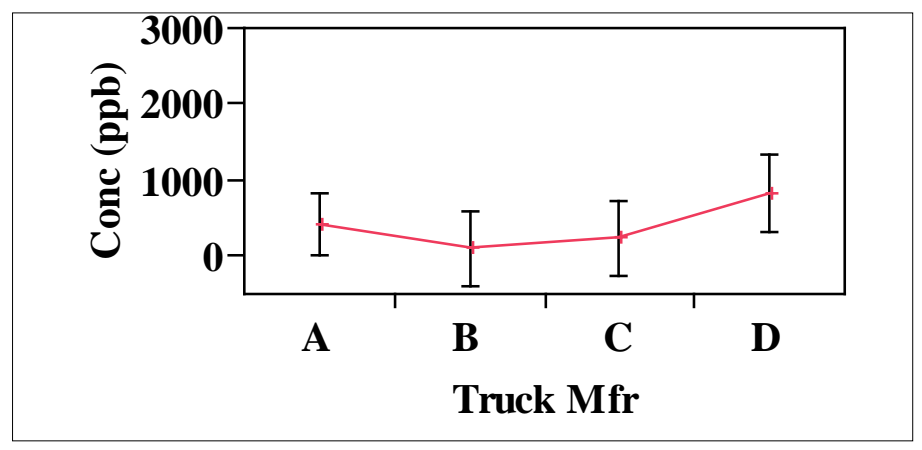

Figure 55. Graph. LS means NOX concentration vs. truck manufacturer 


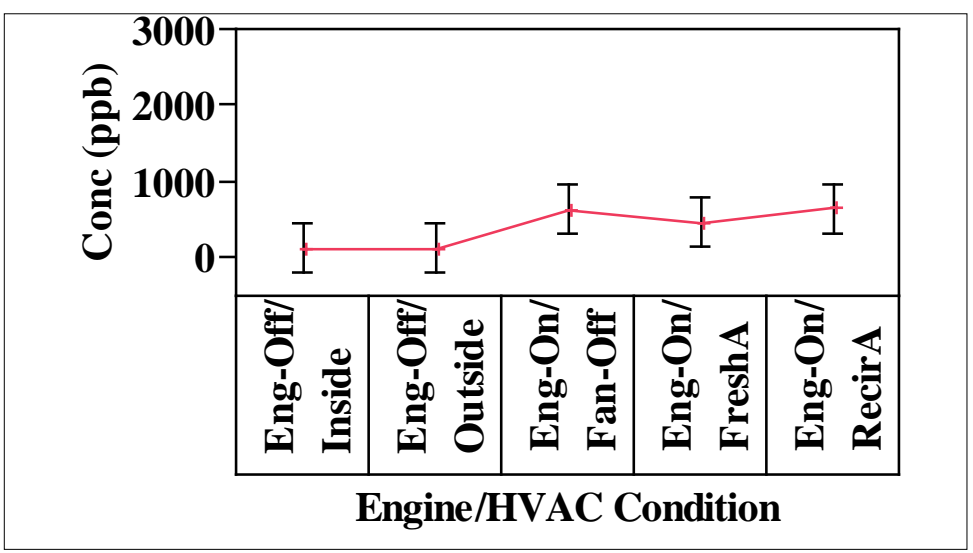

Figure 56. Graph. LS means $\mathrm{NO}_{x}$ concentration vs. engine/HVAC condition

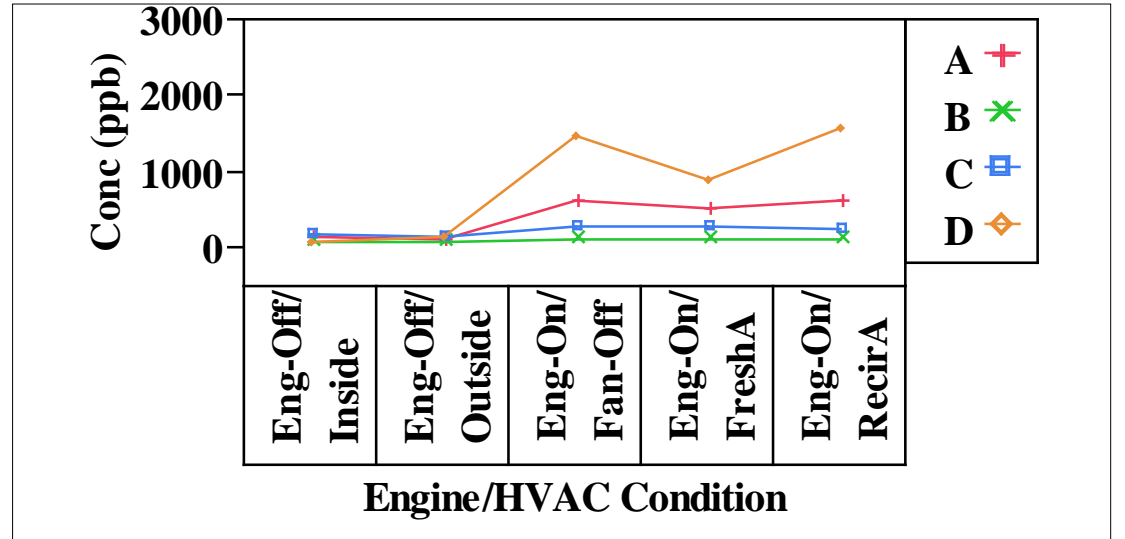

Figure 57. Graph. LS means NOX concentration vs. engine/HVAC and manufacturer

Graphs of the $\mathrm{PM}_{2.5}$ (OPC) concentration LS means for truck manufacturer, engine/HVAC condition, and the interaction effect of truck manufacturer and engine/HVAC condition are shown in the three figures below: REML statistical analysis showed that the truck manufacturer effect (Figure 58) was not significant. REML analysis showed that the engine/HVAC effect (Figure 59) was significant ( $p=0.0001)$. Accordingly, post-hoc Tukey's HSD tests showed that the Eng-On/Fan-Off and Eng-On/Fresh Air conditions had significantly higher $\mathrm{PM}_{2.5}$ (OPC) concentrations than the Eng-Off/Inside condition at the 0.05 level of significance; all other comparisons were not significant. REML analysis for the interaction effect between truck manufacturer and engine/HVAC condition (Figure 60) was statistically significant ( $p=0.05$ ) which suggests that the effect of one parameter (e.g., engine/HVAC) depends on the effect from the other parameter (e.g., truck manufacturer). 


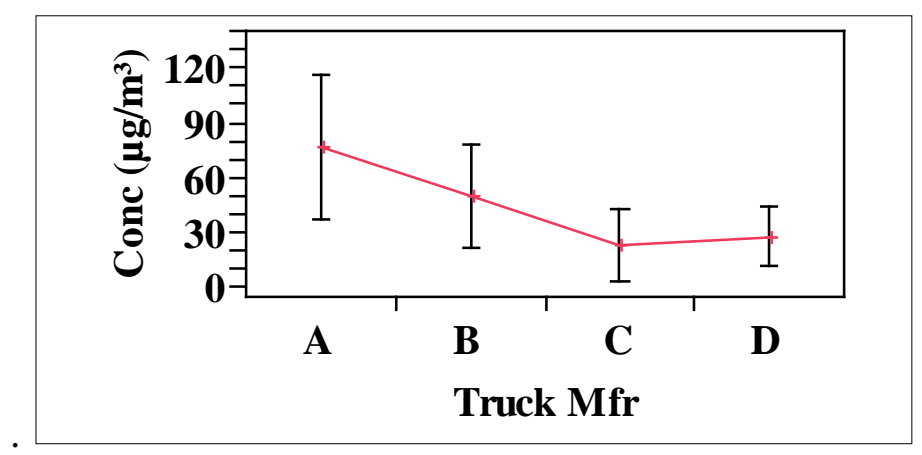

Figure 58. Graph. LS means PM2.5 (OPC) concentration vs. truck manufacturer

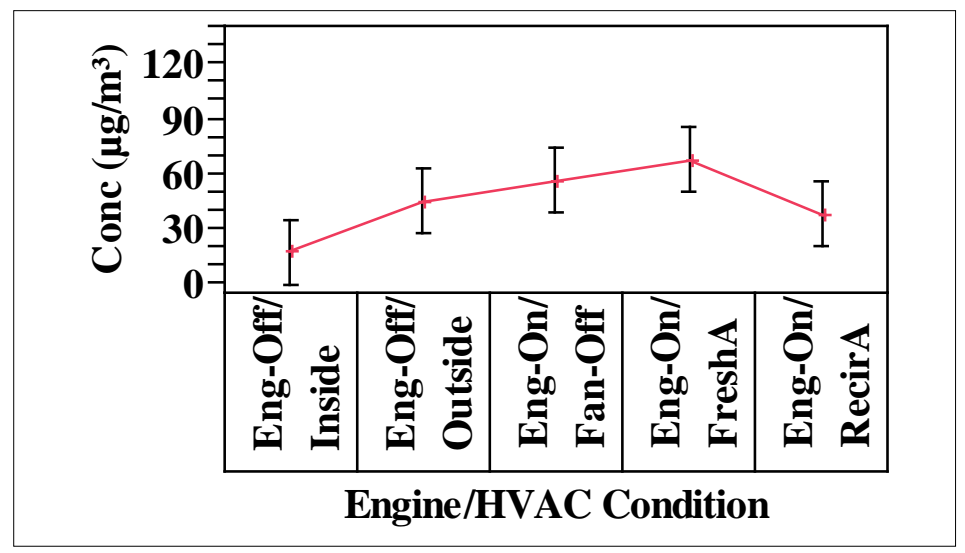

Figure 59. Graph. LS means $\mathrm{PM}_{2.5}$ (OPC) concentration vs. engine/HVAC condition

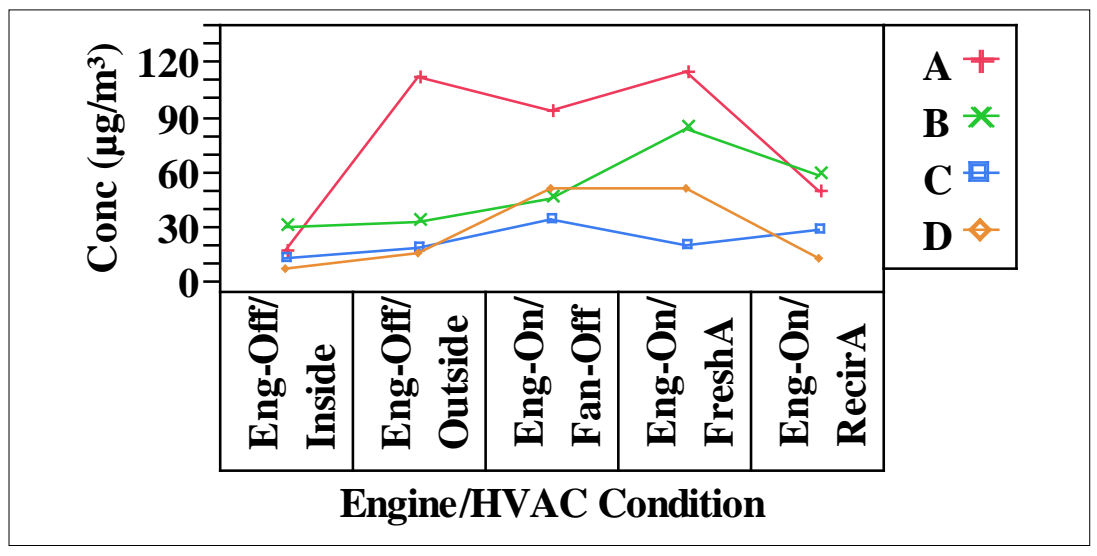

Figure 60. Graph. LS means PM2.5 (OPC) concentration vs. engine/HVAC and manufacturer

Graphs of the $\mathrm{PM}_{2.5}$ (DRam) concentration LS means for truck manufacturer, engine/HVAC condition, and the interaction effect of truck manufacturer and engine/HVAC condition are shown in the three figures below: REML statistical analysis showed that the truck manufacturer effect (Figure 61) was not significant. REML analysis showed that the engine/HVAC effect (Figure 62) was significant $(p=0.007)$. Accordingly, post-hoc Tukey's HSD tests showed that the Eng-On/Fresh Air condition had significantly higher $\mathrm{PM}_{2.5}$ (DRam) concentrations than the Eng-Off/Inside condition at the 0.05 level of significance; all other comparisons were not 
significant. REML analysis for the interaction effect between truck manufacturer and engine/HVAC condition (Figure 63) was not significant.

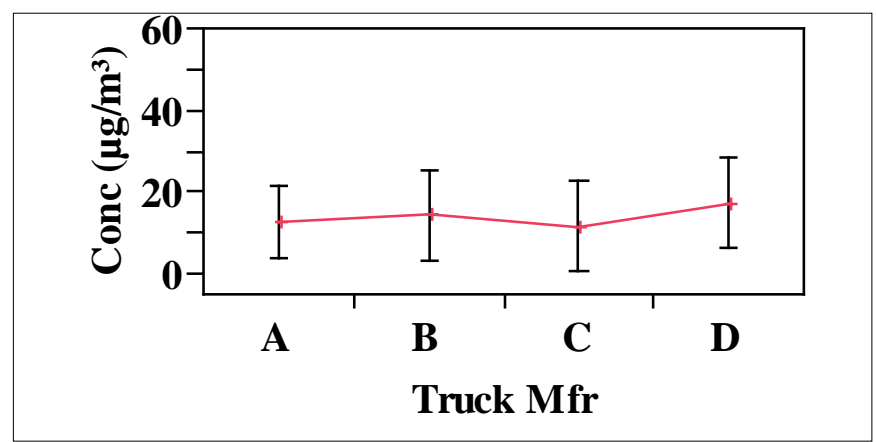

Figure 61. Graph. LS means PM2.5 (DRam) concentration vs. truck manufacturer

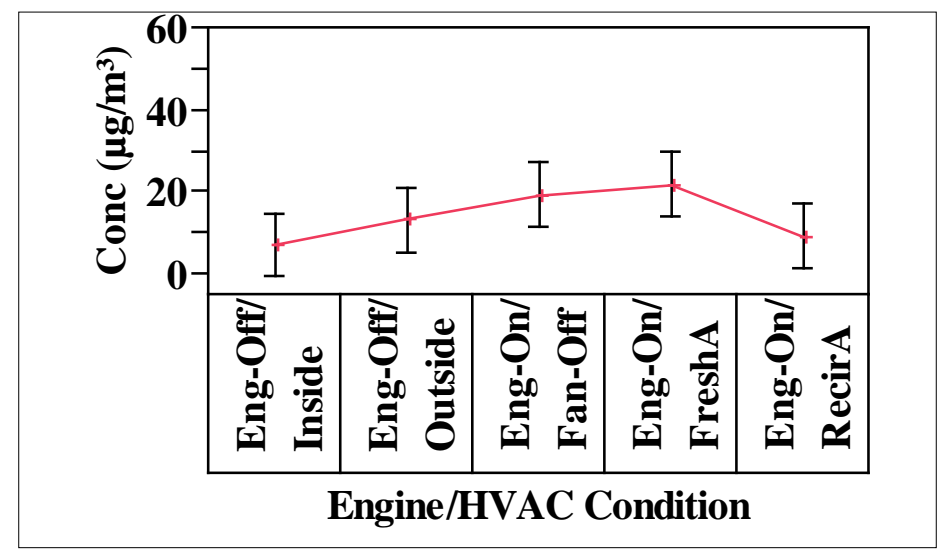

Figure 62. Graph. LS means $\mathrm{PM}_{2.5}$ (DRam) concentration vs. engine/HVAC condition

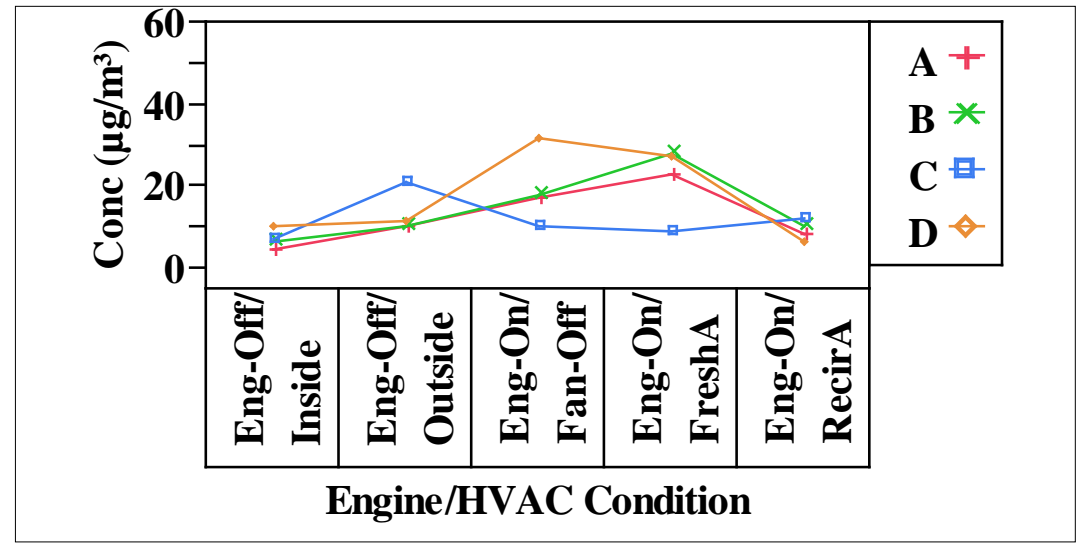

Figure 63. Graph. LS means PM2.5 (DRam) concentration vs. engine/HVAC and manufacturer

In summary, trucks manufactured by company A had slightly higher average $\mathrm{CO}$ concentration, however, no differences between truck manufacturers were observed for the $\mathrm{NO}_{\mathrm{X}}$ and $\mathrm{PM}_{2.5}$ concentrations. Overall, the average concentrations for all three pollutants were highest for the engine-on conditions, as compared to the engine-off conditions. Maximum average CO concentration was only approximately 3.5 ppm, and it occurred during Engine-On/Recirculation 
mode. Nonetheless, the CO concentrations were very low in comparison to the OSHA TWA (50 ppm). The maximum $\mathrm{NO}_{\mathrm{X}}$ concentration was approximately $7.3 \mathrm{ppm}$, and this condition also occurred during Engine-On/Recirculation. An OSHA TWA does not exist for $\mathrm{NO}_{\mathrm{X}}$. However, the TWA for $\mathrm{NO}$ is $25 \mathrm{ppm}$, and the ceiling for $\mathrm{NO}_{2}$ is $5 \mathrm{ppm}$. Usually between 70 and 80 percent of the $\mathrm{NO}_{\mathrm{X}}$ is $\mathrm{NO}$ concentration. Since the 90 percent quartile for $\mathrm{NO}_{\mathrm{X}}$ was about 0.8 ppm, it is unlikely that the $\mathrm{NO}$ or $\mathrm{NO}_{2}$ OSHA standards were exceeded during parked idling.

The $\mathrm{PM}_{2.5}$ concentrations measured by the OPC and the DRam were relatively high for most of the trucks tested, especially during the three engine-on conditions. Several instances occurred in which the $\mathrm{PM}_{2.5}$ concentrations were also high in the outside air. It must be noted that most of these high concentrations were in reference to the EPA NAAQS for the $24-\mathrm{h}\left(35 \mu \mathrm{g} / \mathrm{m}^{3}\right)$ and annual $(15 \mu \mathrm{g} / \mathrm{m} 3)$ averages. Again, the NAAQS were used for comparison purposes since a $\mathrm{PM}_{2.5}$ occupational standard does not exist. Overall, the $\mathrm{PM}_{2.5}$ concentrations as measured by the OCP were about 2.5 times larger than the $\mathrm{PM}_{2.5}$ values reported by the DRam for the same group of trucks. Approximately 70 percent of the trucks had concentrations around or higher than the NAAQS, with these higher concentrations occurring during the several engine-on conditions. The correlation coefficient or the R-value between the OPC and the DRam using the 1-h average $\mathrm{PM}_{2.5}$ data was approximately $0.81(p<0.0001)$ which indicates a fairly good agreement between the OPC and the DRam measurements.

\subsubsection{On-Road Test}

The average 15-min concentrations from the 27 trucks for $\mathrm{CO}, \mathrm{NO}_{\mathrm{X}}$, and $\mathrm{PM}_{2.5}$ and the ratio of $\mathrm{NO}$ to $\mathrm{NO}_{\mathrm{X}}$ are shown in Table 8 for the three roadways or routes driven during the on-road test. Bar graphs of this data, excluding the $\mathrm{NO} / \mathrm{NO}_{\mathrm{X}}$ results, are also shown in Figure 64 and Figure 65. Cursory inspection of the overall average data shows that the on-road in-cab concentrations were relatively low for all the measured pollutants. In particular for the gaseous pollutants, the in-cab concentrations were somewhat higher while driving on the interstates than while driving on the rural highway and the concentrations on I-40 were somewhat higher than concentrations measured on I-75. The overall average $\mathrm{CO}$ and $\mathrm{NO}_{\mathrm{X}}$ concentrations were around $350 \mathrm{ppb}$ and 80 $\mathrm{ppb}$, respectively. The ratios of $\mathrm{NO}$ to $\mathrm{NO}_{\mathrm{X}}$ were closer to what would normally be expected from background air than from $\mathrm{NO} / \mathrm{NO}_{\mathrm{X}}$ ratios, which also indicated that the vehicles were not self-polluting themselves while being driven on these roadways. Finally, the overall average $\mathrm{PM}_{2.5}$ concentrations were approximately 8 and $12 \mu \mathrm{g} / \mathrm{m}^{3}$, as measured by the OPC and DRam monitors, respectively.

Table 8. Overall Average 15-min Concentrations from On-Road Test

\begin{tabular}{|c|c|c|c|c|c|}
\hline Road Type & CO (ppb) & $\mathrm{NO}_{\mathrm{x}}(\mathrm{ppb})$ & NO/NO & $\begin{array}{c}\mathrm{PM}_{2.5} \text { OPC } \\
\left(\mu \mathrm{g} / \mathrm{m}^{3}\right)\end{array}$ & $\begin{array}{c}\mathrm{PM}_{2.5} \text { DRam } \\
\left(\mu \mathrm{g} / \mathrm{m}^{3}\right)\end{array}$ \\
\hline Interstate (I-40) & 414 & 109 & 0.74 & 9 & 12 \\
\hline Rural Highway (US-27) & 285 & 39 & 0.52 & 7 & 12 \\
\hline Interstate (I-75) & 362 & 96 & 0.65 & 7 & 13 \\
\hline
\end{tabular}




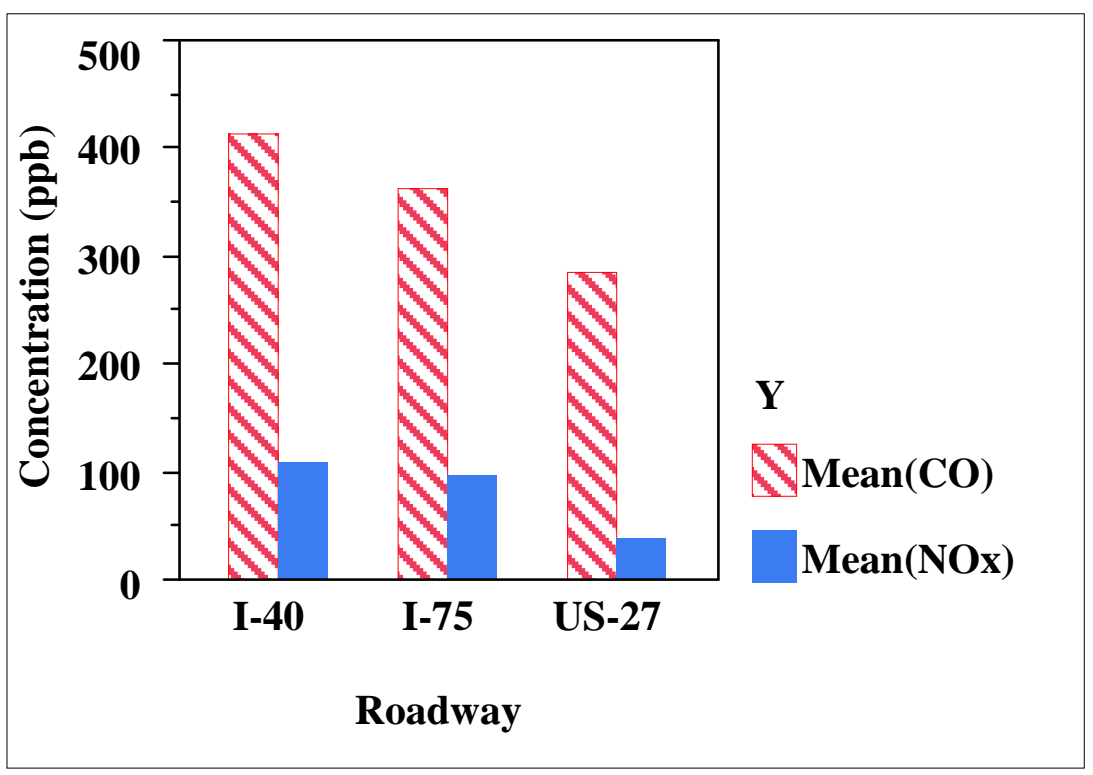

Figure 64. Graph. Overall average 15-min $\mathrm{CO}$ and $\mathrm{NO}_{x}$ concentrations from on-road test

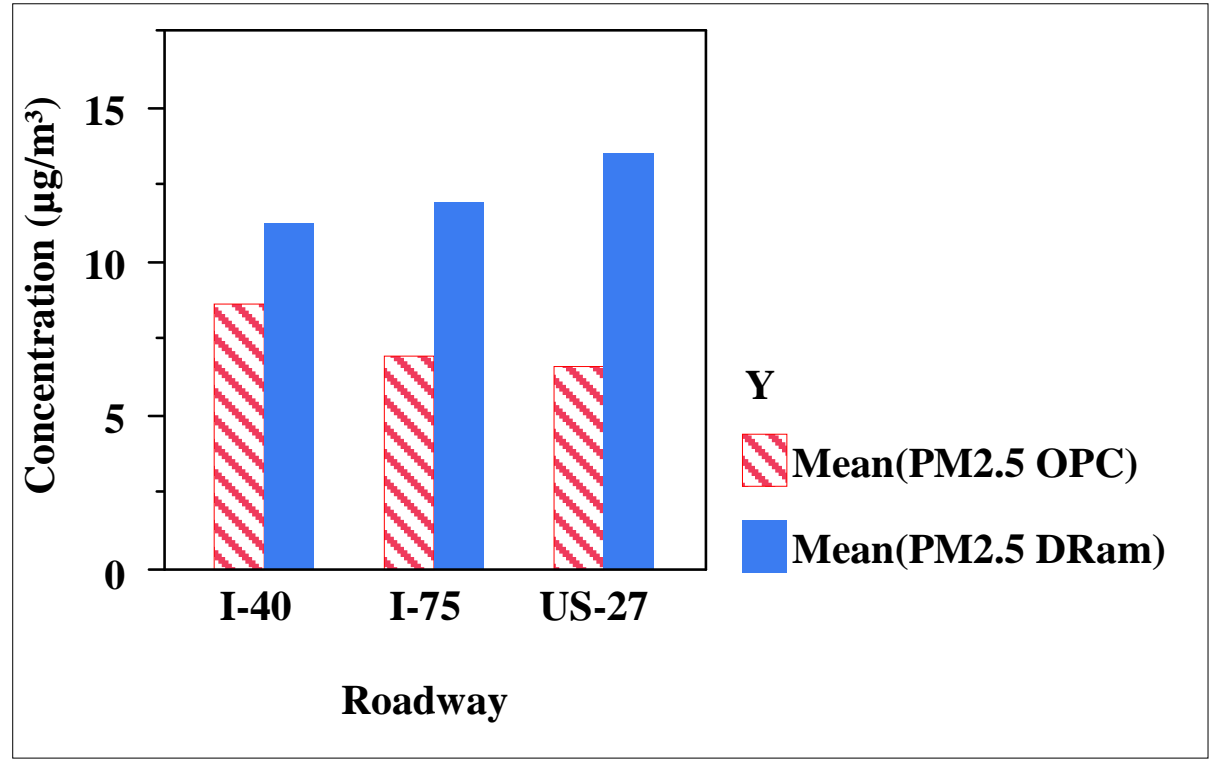

Figure 65. Graph. Overall average 15-min $\mathrm{PM}_{2.5}$ concentrations from on-road test

Graphs of the CO concentration (LS means) for truck manufacturer, roadway, and the interaction effect of truck manufacturer and roadway are shown in Figure 66, Figure 67, and Figure 68, respectively. REML statistical analysis showed that the truck manufacturer effect was significant ( $p=0.006)$. Tukey-HSD analysis of LS means differences showed that CO concentration for truck manufacturer A was significantly different $(p=0.05)$ from manufacturer $C$ when pair-wise comparisons were made among truck companies. REML analysis showed that the roadway effect was significant $(p<0.0001)$. Tukey-HSD analysis of LS means differences showed that CO concentrations for roadway I-40 and I-75 were significantly different ( $p=0.05)$ when pair-wise comparisons were made with US-27. REML analysis for the interaction effect between truck manufacturer and roadway were not significant. 


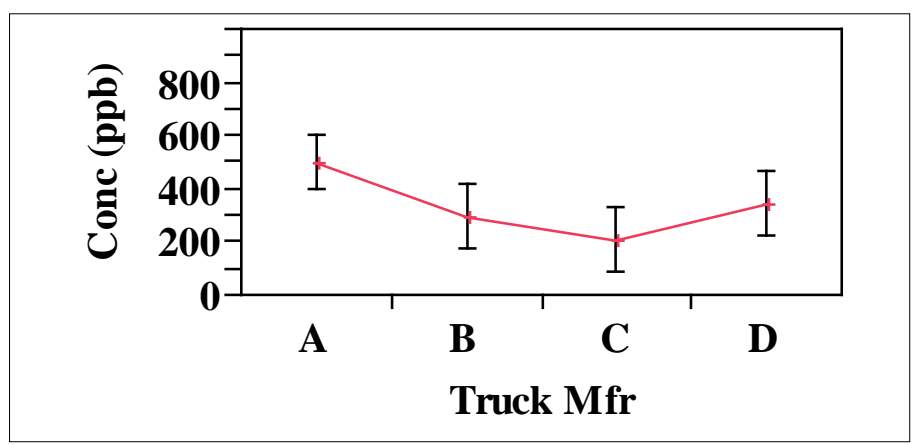

Figure 66. Graph. LS means CO concentration vs. truck manufacturer

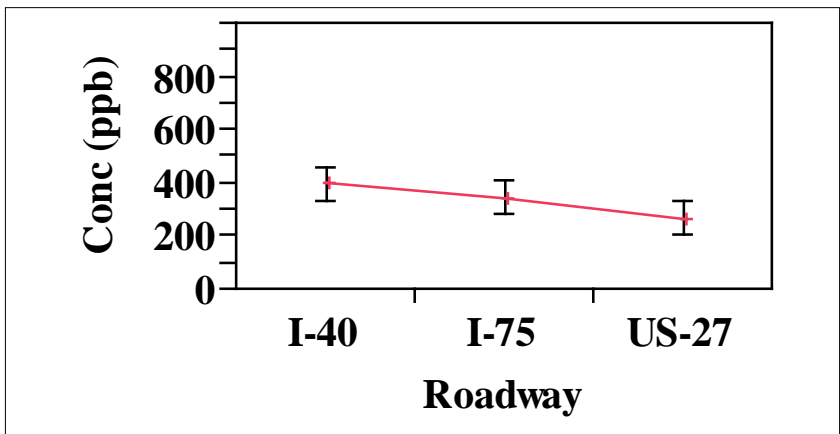

Figure 67. Graph. LS means CO concentration vs. roadway

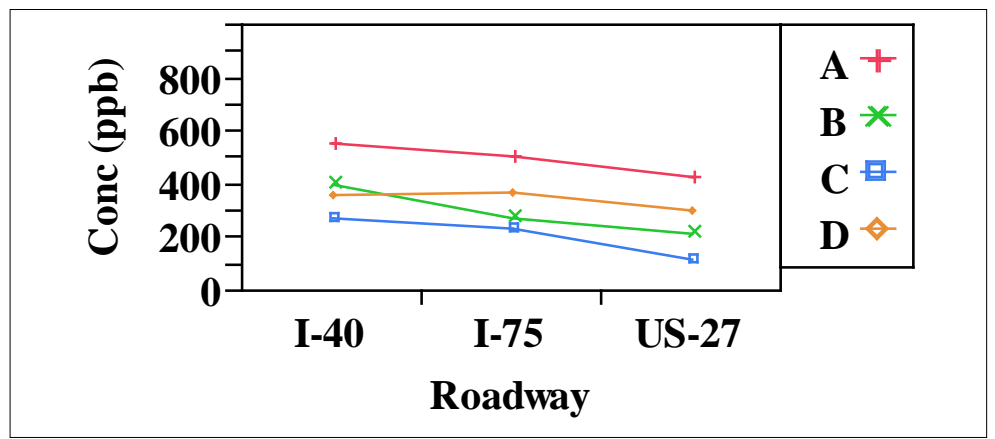

Figure 68. Graph. LS means CO concentration vs. roadway and truck manufacturer

Graphs of the $\mathrm{NO}_{\mathrm{X}}$ concentration (LS means) for truck manufacturer, roadway, and the interaction effect of truck manufacturer and roadway are shown in Figure 69, Figure 70, and Figure 71, respectively. REML statistical analysis showed that the truck manufacturer effect was not significant. REML analysis showed that the roadway effect was significant $(p<0.0001)$. Tukey-HSD analysis of LS means differences showed that $\mathrm{NO}_{\mathrm{X}}$ concentrations for roadways I40 and I-75 were significantly different $(p=0.05)$ when pair-wise comparisons were made with US-27. REML analysis for the interaction effect between truck manufacturer and roadway were not statistically significant. 


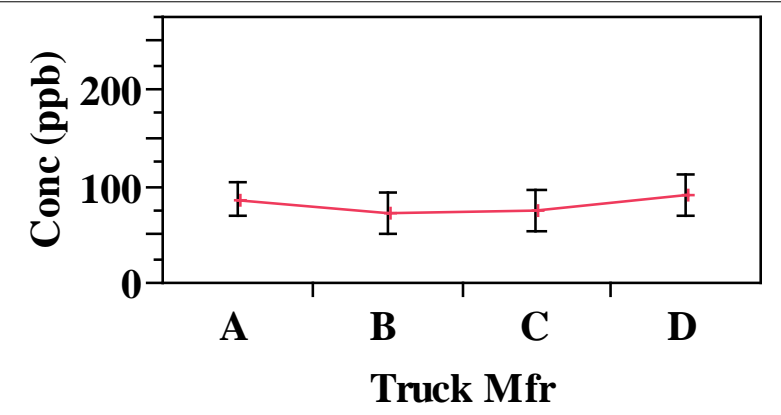

Figure 69. Graph. LS means $\mathrm{NO}_{x}$ concentration vs. truck manufacturer

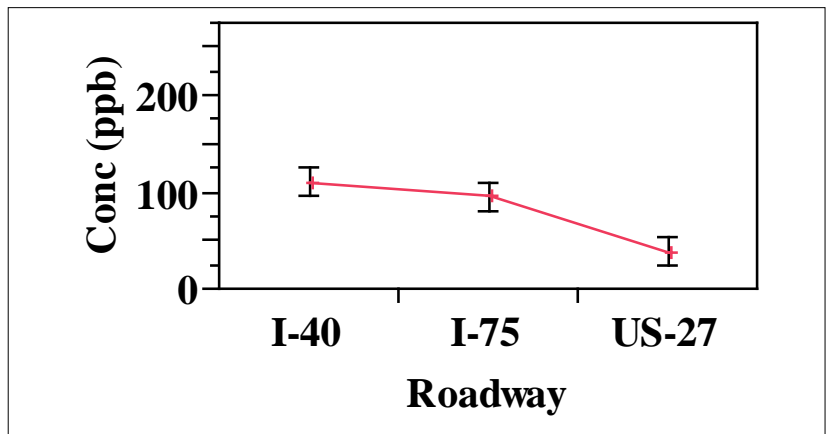

Figure 70. Graph. LS means $\mathrm{NO}_{x}$ concentration vs. roadway

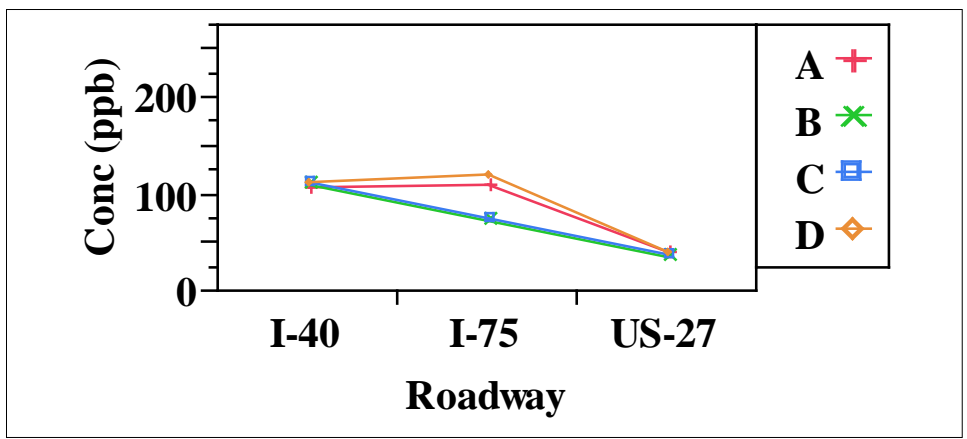

Figure 71. Graph. LS means $\mathrm{NO}_{x}$ concentration vs. roadway and truck manufacturer

Graphs of the $\mathrm{PM}_{2.5}$ (OPC) concentration (LS means) for truck manufacturer, roadway, and the interaction effect of truck manufacturer and roadway are shown in Figure 72, Figure 73, and Figure 74, respectively. REML statistical analysis showed that the truck manufacturer effect, the roadway effect, and the interaction effect between truck manufacturer and roadway were all not statistically significant. 


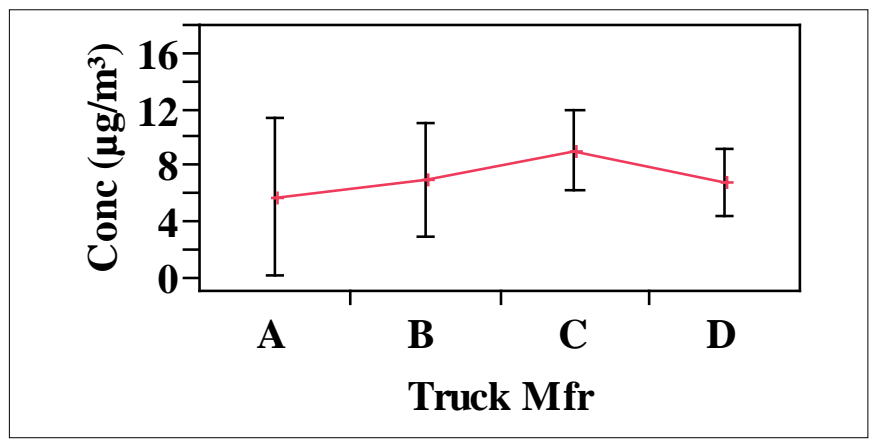

Figure 72. Graph. LS means $\mathrm{PM}_{2.5}$ (OPC) concentration vs. truck manufacturer

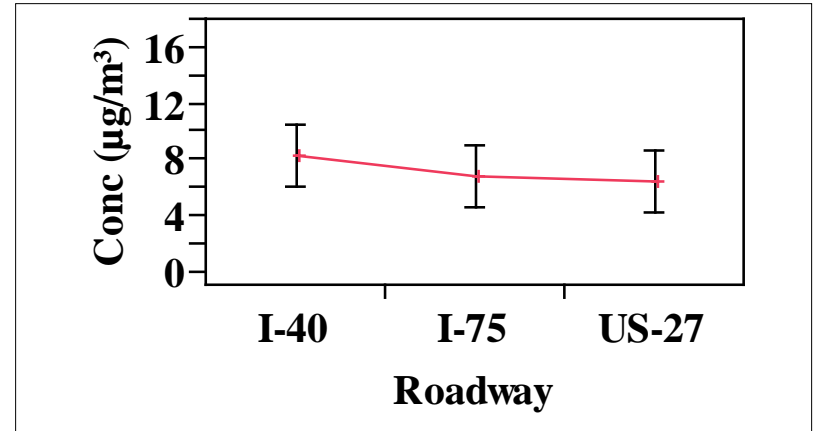

Figure 73. Graph. LS means $\mathrm{PM}_{2.5}(\mathrm{OPC})$ concentration vs. roadway

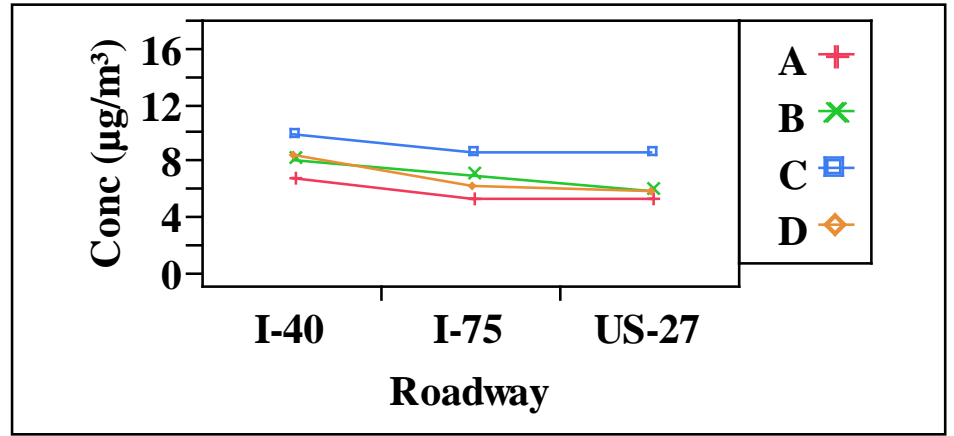

Figure 74. Graph. LS means $\mathrm{PM}_{2.5}$ (OPC) concentration vs. roadway and truck manufacturer

Graphs of the $\mathrm{PM}_{2.5}$ (DRam) concentration (LS means) for truck manufacturer, roadway, and the interaction effect of truck manufacturer and roadway are shown in Figure 75, Figure 76, and Figure 77, respectively. REML statistical analysis, like the OPC results, showed that the truck manufacturer effect, the roadway effect, and the interaction effect between truck manufacturer and roadway were all not statistically significant. 


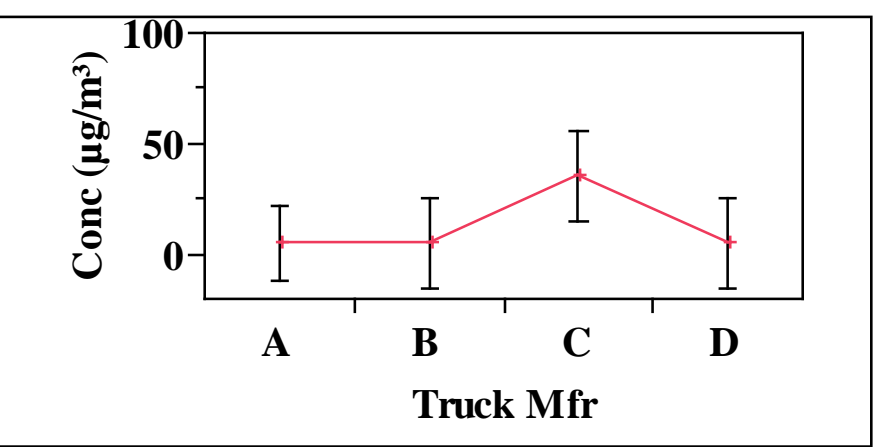

Figure 75. Graph. LS means $\mathrm{PM}_{2.5}$ (DRam) concentration vs. truck manufacturer

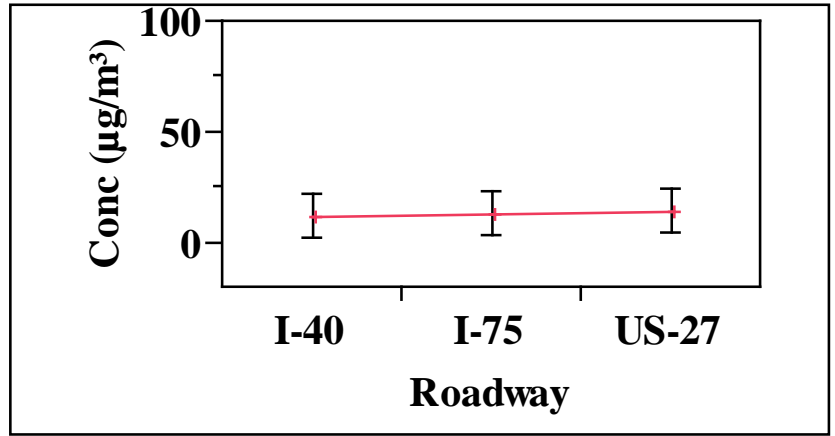

Figure 76. Graph. LS means $\mathrm{PM}_{2.5}$ (DRam) concentration vs. roadway

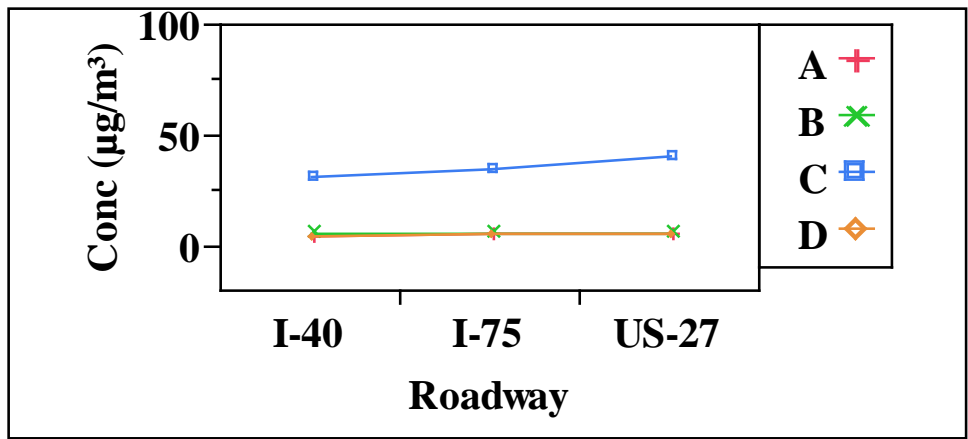

Figure 77. Graph. LS means $\mathrm{PM}_{2.5}$ (DRam) concentration vs. roadway and truck manufacturer

In summary, the in-cab $\mathrm{CO}$ and $\mathrm{NO}_{\mathrm{X}}$ concentrations were higher while driving on the interstate than while driving on the State highway. It should be noted that highway traffic was usually heavier or more dense on I-40 or I-75, and it is probably this condition that attributed to the slightly higher concentrations measured inside the cab. At any rate, the in-cab on-road CO concentrations do not appear to be a health-safety problem because even the highest $\mathrm{CO}$ concentration was less than 1 ppm, which is well below the OSHA 8-h TWA of 50 ppm. Turning next to $\mathrm{NO}_{\mathrm{X}}$ concentration, the maximum overall average was much less than $0.5 \mathrm{ppm}$. Thus, the separate concentrations of $\mathrm{NO}$ and $\mathrm{NO}_{2}$ would also be expected to be much less than the OSHA PELs of 25 ppm and 5 ppm, respectively.

The $\mathrm{PM}_{2.5}$ concentrations, in general, were relatively flat across all the trucks except for several trucks from company $\mathrm{C}$, where usually high concentrations were measured by the DRam, and 
with higher variability between the trucks from company A. At this juncture, it is strongly felt that these values are outliers caused by the vibrating environment of the truck because the DRam uses a cyclonic separation device to divert the less than $2.5 \mu \mathrm{m}$ sized particles to the analyzer away from the total size range of particles that initially enters the sampling head. Average $\mathrm{PM}_{2.5}$ measured by the DRam and OPC were 12.2 and $7.4 \mu \mathrm{g} / \mathrm{m} 3$, respectively. The correlation coefficient (or the R-value) between the DRam and the OPC using the average 15-min $\mathrm{PM}_{2.5}$ data was approximately $0.65(p<0.0001)$.

\subsubsection{In-Cab Air Filters}

Outside air enters the HVAC system of the cab by way of a vent between the engine hood and the glass windshield along the passenger side of the vehicle. The outside air passes a pre-filter located in the engine compartment on the right front side of the cab. Almost all sleeper cabs today are also equipped with an auxiliary air handling system for recirculating air in the cab. This auxiliary system is either located behind the passenger seat under the bunk in the luggage storage compartment or in the front of the cab directly beneath the passenger seat. Again, there is an air filter for the auxiliary system. Truck manufacturers recommend that these filters be inspected, cleaned, and/or replaced after 70,000 mi under normal conditions, and as often as every 20,000 mi in dusty conditions. In general, regular replacement of dirty air filters may reduce in-cab dust and allergens, and it extends the efficiency and life of the air handling system. Several photographs showing the general condition of the in-cab air filters and air handling systems of the test trucks are shown in Figure 78-Figure 81. As revealed in the photographs, good housekeeping maintenance practices were not generally followed.

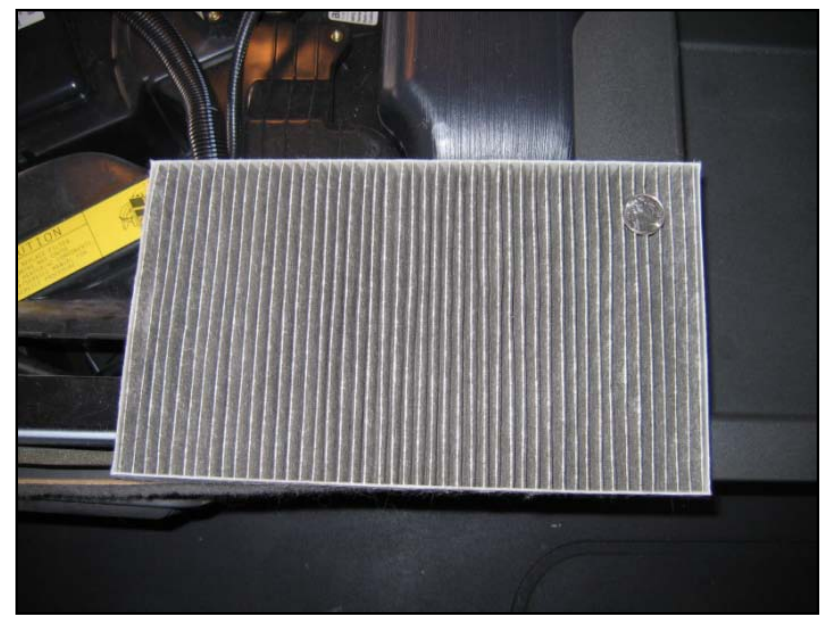

Figure 78. Photo. Outside HVAC pre-filter accessible from the engine compartment 


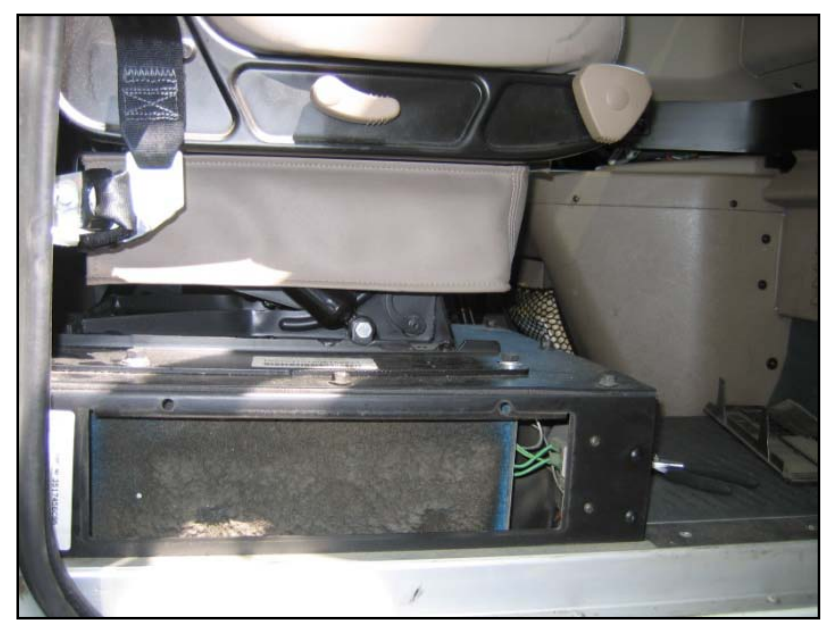

Figure 79. Photo. Auxiliary air filtration system located under passenger seat

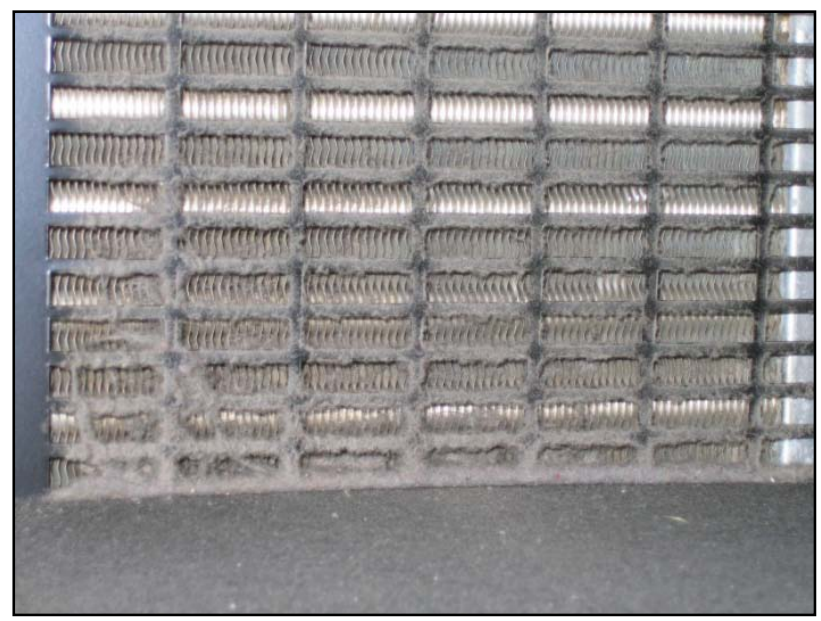

Figure 80. Photo. Auxiliary HVAC system located under sleeper berth not filtered

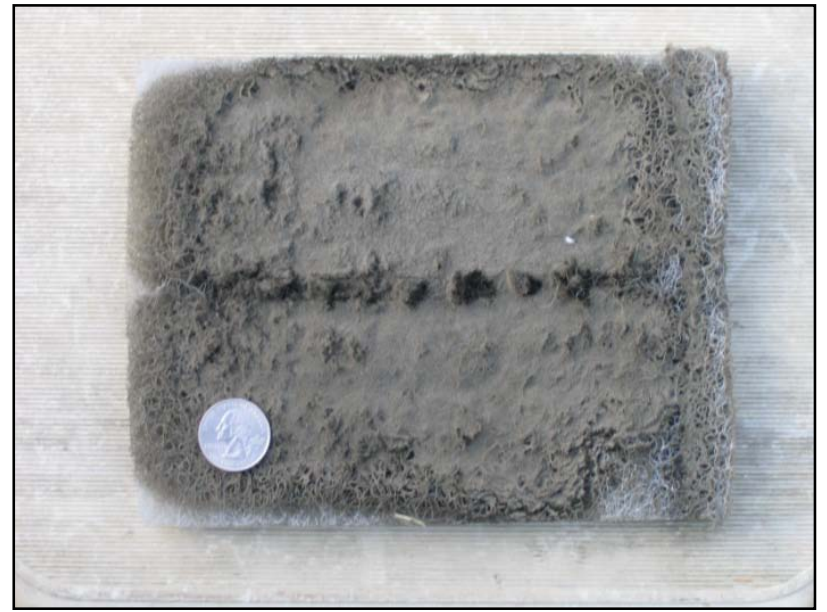

Figure 81. Photo. Internal air-filter removed from auxiliary HVAC unit. 


\subsubsection{Chemical Analysis of Particulate Matter}

Two fiber filter samples from the EBam analyzers containing PM were sent to a laboratory for general chemical evaluation. The filters from the EBam were used because they were the only ones available from the study and were considered to most closely characterize a representative sample of total particulate matter (TPM) from the cabin environment. One sample respectively was collected during the park-idling and on-road tests. The idling filter had heavy deposits of very fine, dark particulate in the filtered area. The on-road filter showed similar deposits, as well as a number of silvery metallic flakes. Small sections of each filter were sonicated in filtered ethanol to remove particulate and the samples of sonicate were spotted onto TEM (transmission electron microscopy) grids and allowed to dry. Several of the silvery metallic flakes observed the on-road filter were also mounted for elemental analysis by scanning electron microscopy with energy dispersive X-ray spectrometry (SEM/EDS).

\subsubsection{Parked-Idling Filter}

The TEM examination of the particulate from this filter showed abundant aciniform clusters, with the characteristic morphology of soot. Individual soot particles ranged from approximately 10 to 50 nanometers $(\mathrm{nm})$ in size, with an average size of approximately $10-15 \mathrm{~nm}$. The soot appeared to be amorphous, and contained traces of sodium and oxygen, along with bulk carbon. A representative TEM micrograph is included in Figure 82. Higher magnification of this area is shown in Figure 83. Note that some short sections of glass fibers from the filter are visible in the images. In addition to the soot, small particles rich in barium, sulfur, and oxygen, and calcium or sodium, were also seen, presumably representing various sulfate salts. Zinc was also detected in various areas, but its association with the other elements was not clear.

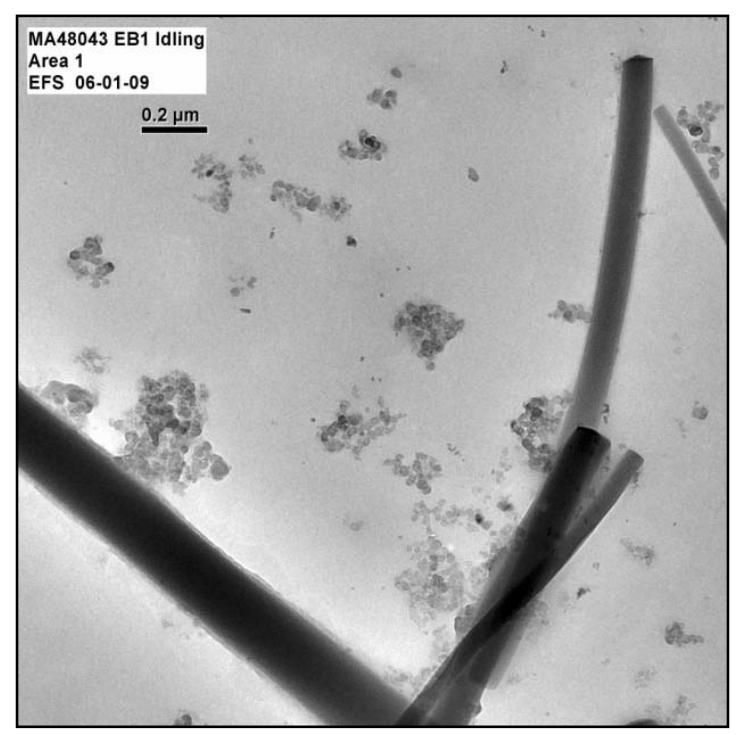

Figure 82. Photo. TEM micrograph of PM during parked-idling test $(0.2-\mu \mathrm{m}$ scale) 


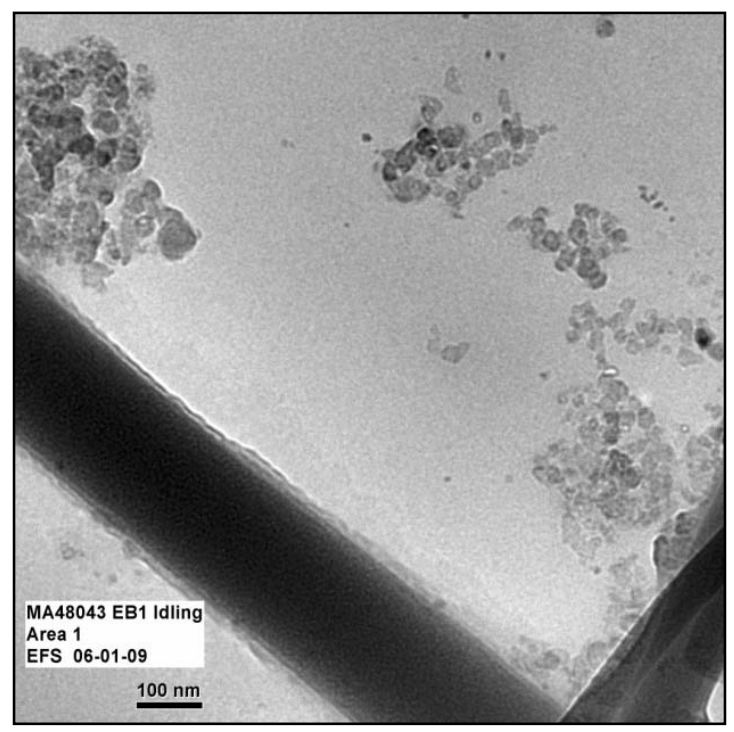

Figure 83. Photo. TEM micrograph of PM during parked-idling test (0.1- $\mu \mathrm{m}$ scale)

\subsubsection{On-Road Filter}

This filter also showed predominantly aciniform clusters of sub-micron soot, although they were not as well formed as those on the idling filter. Individual spherical particles were not as easily discernible as in the other sample; those that could be measured were about 25-30 nm in diameter. In addition to carbon, traces of other elements including oxygen, sodium, sulfur, chlorine, and silicon were detected in the soot agglomerates. Representative TEM micrographs are shown in Figure 84 and Figure 85. Small particles with primarily aluminum silicate chemistries were also seen, as well as aluminum oxide particles. The SEM/EDS analysis of the larger metal flakes showed that they were an aluminum alloy, with small amounts of magnesium, silicon, iron, and copper. The smaller aluminum oxide particles are most likely related to these elements.

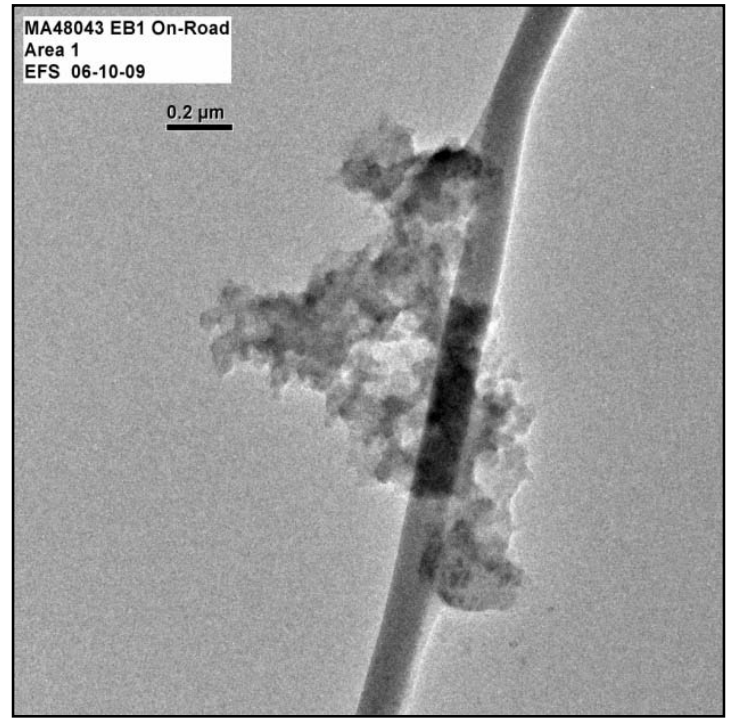

Figure 84. Photo. TEM micrograph of PM during on-road test (0.2- $\mu \mathrm{m}$ scale) 


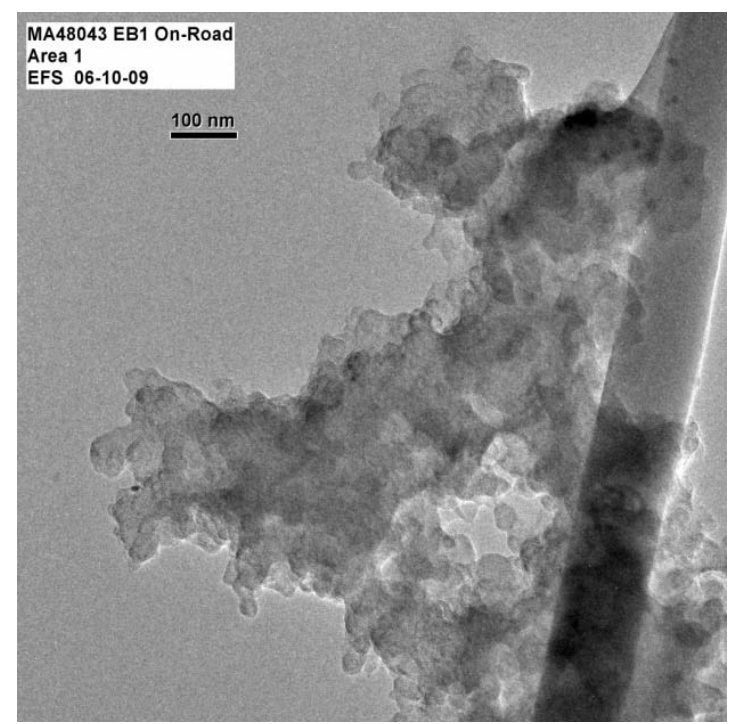

Figure 85. Photo. TEM micrograph of PM during on-road test (0.1- $\mu \mathrm{m}$ scale) 
[This page intentionally left blank.] 



\section{CONCLUSIONS}

A clear limit to the scope of this study was the small sample size of the test vehicles given that the heavy-duty diesel truck population in the U.S. varies greatly by manufacturer and model configuration. In this study, only six trucks, each from four different manufacturers were represented. A certain evenness of model configuration was achieved however because the truck leasing companies that provided the vehicles usually had only the standard model from a single manufacturer. On the other hand, none of the test vehicles actually came directly from a commercial freight hauling company. So the population of trucks in this sample only represented trucks from the rental fleet of trucks. Likewise the sample size of the air cushion seats that were represented in the study was small. A single seating supply company represented more than 90 percent of the seats that were in the vehicles.

\subsection{NOISE LEVEL}

Slight differences in noise level were observed between truck manufacturers, but for the most part, noise-level conditions were quite similar for all the trucks tested in this study. Higher noise averages were generally observed while the trucks were driven on interstates relative to State highways. It is thought that noise from tires, engine rpm, and wind impacting the cab at higher road speeds contributed to the elevated noise levels measured during interstate travel because higher vehicle speeds are permitted on the interstates. Yet, peak and maximum noise levels were generally higher on I-40 and US-27 and lower on I-75 which may be due to the fact that the I-75 terrain was relatively flat compared to I-40 or US-27. Nonetheless, the PEL values from OSHA and/or NIOSH were not exceeded by any test truck for the 8-h work standard. Also the action limit (AL) was not reached in any tested vehicle. A projection made to the current 11-h driving time limit using the worst case truck showed that the estimated dose percent was still below the AL. This study tended to show overall noise levels to be somewhat lower than those reported in historical studies, which generally revealed noise levels closer but below the PEL and greater than the AL. However, it should be noted that in several of the historical studies, the truck windows were open and noise levels were measured during the entire driving shift, which could include certain warehouse activities like the loading and unloading of freight. In the present study the windows were always closed on the test trucks and noise levels were measured only while the trucks were driven at a regular cruising speed on the interstate or State highway.

\subsection{WHOLE-BODY VIBRATION}

Differences between truck manufacturers with respect to vibration were somewhat more pronounced than the noise-level differences observed between truck manufacturers. Overall however, the vibrations from the driver and passenger seats were generally well below the European Union (EU) exposure action value (EAV) for an 8-h driving day. Several isolated incidents occurred in which the exposure limit value (ELV) was exceeded, but for the most part, these occurred while the trucks were being driven over poorer road pavement conditions. Generally, the interstate roads are better maintained than most State highways; but variability in roadway maintenance exists from region to region, even on the interstate system. 
When projections were made to the current 11-h driving time limit, seven trucks were actually over the EAV, but these occurrences were always in the y-axis, which is side-to-side vibration, rather than in the z-axis, which is up-and-down vibration. It must be mentioned again that a much higher health risk to the lumbar spine region from WBV in the z-axis exists for the seated person than from vibration in the y-axis. Finally, the comfort index of the seats, by and large these indicators fell within the "a little uncomfortable" region —one step removed from the best possible index, which is the "not uncomfortable" region. One needs to be aware that this is a relative category scale resulting from extensive research conducted mainly in Europe over the past several decades, but since the comfort index of these seats did not fall below the optimal level, some possibility however still exists for future improvement in the comfort level of the seats.

\subsection{AIR QUALITY}

\subsubsection{Parked-Idling Test}

Overall $\mathrm{CO}, \mathrm{NO}_{\mathrm{X}}$, and $\mathrm{PM}_{2.5}$ concentrations were relatively low inside the cab when both the engine and HVAC were in off modes. Highest $\mathrm{CO}$ and $\mathrm{NO}_{\mathrm{X}}$ concentrations occurred during engine-on and HVAC-recirculation modes; high $\mathrm{PM}_{2.5}$ concentrations occurred during engine-on and HVAC-fresh-air modes and during engine-on and fan-off modes. These results suggest that long-haul trucks have a tendency to self-pollute the cab during extended periods of parked idling. Self-pollution occurs when a percentage of the vehicle's own exhaust enters the cab. It is believed that this problem and the close proximity of many trucks idling at the same time in the truck-stop rest areas create the conditions for diesel exhaust to enter the cab via the HVAC system or naturally from air infiltration around window and door seals and from other areas.

These results were in line with a similar study that measured in-cab concentrations during several parked-engine-idling conditions at another truck-stop rest area.

The measured concentrations of $\mathrm{CO}$ and $\mathrm{NO}_{\mathrm{X}}$ for all of the engine/HVAC modes of operation were well below the OSHA 8-h TWA and should not pose health problems for drivers sleeping in the cabs during rest periods. However, measured concentrations of $\mathrm{PM}_{2.5}$, which is known to cause certain respiratory and other health problems, were around the limits set by the EPA for the NAAQS for the 24-h and annual averages. It should be noted that these EPA standards are ambient air monitoring standards that were set to protect general public health, including the health of sensitive populations such as asthmatics, children, and the elderly and were used only for comparison purposes in this study because industrial or workplace $\mathrm{PM}_{2.5}$ limits have not been established by OSHA. Primary and secondary NAAQS exist for CO, lead, nitrogen dioxide, particulate matter, ozone, and sulfur dioxide. Areas not meeting these NAAQS are required to create an implementation plan to meet the standards within a certain time period. The regulatory language is framed in terms of attainment levels, and the averaging times for the NAAQS are different from typical workplace averaging times. Also, some doubt exists as to whether the sleeper berth area of HDDVs and the workplace setting are in fact identical environments.

\subsubsection{On-Road Test}

The $\mathrm{CO}, \mathrm{NO}_{\mathrm{x}}$, and $\mathrm{PM}_{2.5}$ concentrations were relatively low inside the cab while driving on the roadways, which suggests that under those conditions, there was much less likelihood of trucks 
self-polluting the cabin areas. In comparison, the overall average concentrations during parked idling were approximately 1.5, 7.1, and 3.0 times greater, respectively, than the overall average on-road concentrations. The in-cab concentrations were usually higher, however, while driving on interstates than while driving on the State highways, even though the overall concentrations were low. This is believed to be caused by the higher vehicle densities prevalent on the interstate system, as a result of which more pollutants enter the vehicle via the HVAC system. These results suggest that the highway environment, rather than the truck itself, is the cause of the air pollution exposure for the truck driver. 
[This page intentionally left blank.] 


\section{RECOMMENDATIONS}

Results of this study suggests that two main areas of concern are the comfort level of the seats and the high $\mathrm{PM}_{2.5}$ concentrations measured in the cab during periods of extended engine idling. Although the noise levels inside the cabs were reasonably low, this condition was likely the result of furnishings by the manufacturer, such as wall padding, privacy curtains, floor carpeting, and engine firewall insulation which have the combined effect of attenuating sound.

Seating: Nearly all of the seats in the test vehicles came from a single seating manufacturer. In addition, the vehicles were lease- or rental- trucks, so it was likely that the standard (not the optional) seats had been furnished in the trucks because of cost. Even though, the seats in these test vehicles were adequate in reducing WBV, opportunity still exists for improvement in the comfort index, since the levels reported in this study were not optimal ones. Past questionnairetype studies have also indicated driver seating discomfort. Additional areas that should be investigated are potential spinal damage from vibration, and how seating vibration might be affected by fore and aft location of the fifth-wheel and/or from the usage of single-wide tires. The fifth-wheel is the coupling device used on truck-tractors to connect trailers. The location of the fifth-wheel is not fixed and can be adjusted to distribute trailer load over the drive axels, thus possibly influencing truck ride quality. Single-wide tires are slightly wider than traditional dual tires and can replace the double tires on each end of a drive or trailer axle. By reducing rolling friction, single-wide tires are a fuel savings innovation and can also possibly influence truck ride quality.

It is noteworthy to mention that the same driver drove all the test trucks and was knowledgeable in the operation of the seats. Heavy-duty trucks have pneumatically operated seats with multiple adjustments to control the cushion, lumbar (or back) support, isolator engagement, fore and aft adjustment, height adjustment, cushion angle, and armrest angle. For the most part, none of these factors were controlled or standardized to any degree in this study. Current human exposure guidelines do not reflect the relationships between poor posture and driving posture, various seat configurations (e.g., seat back/cushion reclining angle) and/or sitting postures (e.g., torso/knee angle) and possible adjustments of the seat relative to the steering wheel. Additional research is required to determine the optimal active seating adjustments which can minimize WBV. Also, it may be necessary to develop an effective strategy to train drivers in the proper use of the seating adjustments, so that they may use the seat controls to the full effect.

Air Quality: Offering a recommendation in this area is somewhat complicated because the most straightforward solution for improving the air quality in the cabin during periods of parked idling would be simply to prohibit engine idling while a driver is resting in the sleeper berth. However, to do this would severely limit the driver's use of the vehicle's heat and air conditioning, and comfort appliances such as a microwave or television, that depend on the idling engine to operate.

The idling engine self-pollutes the cab for the resting driver. In addition, numerous trucks parked and idling together in close proximity at a rest area exacerbates the air-quality problem in the cabs for the drivers, as well as for persons working at the truck-stop. Since a possible $\mathrm{PM}_{2.5}$ problem exists, it is likely that other gaseous hydrocarbon emissions, such as 1-3 butadiene, formaldehyde or acetaldehyde, may also be present in the cab during extended periods of parked 
engine idling. Several of these substances are toxic hazardous air contaminants which are regulated in the workplace by OSHA, unlike $\mathrm{PM}_{2.5}$ concentration.

A diesel particulate matter exposure limit has been established by the U.S Mine Safety and Health Administration (MSHA) for personal working in underground mines. This PEL (160 $\mu \mathrm{g} / \mathrm{m}^{3}$ ) is based on the airborne concentration of total carbon (TC) ${ }^{35}$. (TC $=\mathrm{EC}+\mathrm{OC}$ ) However, it should also be pointed out that the MSHA standard, while applicable in the mining workplace environment, does not apply to drivers who are resting in a travel center, as this is not defined at the present time as a workplace environment. Additional research is needed to better define and identify whether other diesel engine combustion hydrocarbons, including TC, are present above acceptable workplace exposure limits in the cabin during periods of extended idling.

The in-cab air quality during periods of parked-engine idling at truck-stop rest areas continues to be an issue which warrants further study. Design and testing of cabin air-filtration/purification systems are several possible areas for research. However, these systems, with typical low air flow rates may prove to be inadequate in reducing concentrations within the cabin environment because of the high cabin air exchange rates which exist in current cabs between inside and outside air, as measured and described elsewhere in this report.

External HVAC systems have also been reported to be successful in reducing in-cab pollutant concentrations These systems use a high air exchange rate, provide a mechanism for the truck engine to be off, and provide external air filtration, thus substantially reducing in-cab concentrations. Other technologies aimed at idle reduction include auxiliary power units (APU). The APU provides an alternative to the truck's main engine when power is needed for electricity or heating and cooling the cab during rest periods. They can be small diesel-fired generators or heaters, battery air conditioning units and other thermal storage systems. 


\section{APPENDIX A-EXPOSURE STANDARDS OR RECOMMENDED VALUES}

Table 9: Exposure Standards or Recommended Values

\begin{tabular}{|c|c|c|c|c|c|c|c|}
\hline Item & ACGIH (TLV) & NIOSH (REL) & OSHA (PEL) & EPA (NAAQS) & ISO/EU (RMS) & EU (VDM) & Jerk \\
\hline Noise & - & $\begin{array}{c}85 \text { dBA } \\
\text { 8-h TWA }\end{array}$ & $\begin{array}{c}90 \mathrm{dBA} \\
\text { 8-h TWA }\end{array}$ & - & - & - & \\
\hline WBV & - & - & - & - & $\begin{array}{l}\text { EAV } 0.5 \mathrm{~m} / \mathrm{s}^{2} \\
\text { ELV } 1.15 \mathrm{~m} / \mathrm{s}^{2} \\
\text { Driving } 8-\mathrm{h} \text { day }\end{array}$ & $\begin{array}{l}\text { EAV } 9.1 \mathrm{~m} / \mathrm{s}^{1.75} \\
\text { ELV } 21 \mathrm{~m} / \mathrm{s}^{1.75} \\
\text { Driving } 8-\mathrm{h} \text { day }\end{array}$ & None \\
\hline $\mathrm{CO}$ & $\begin{array}{l}50 \text { ppm } \\
\text { TWA }\end{array}$ & $\begin{array}{l}35 \text { ppm } \\
\text { TWA }\end{array}$ & $\begin{array}{l}50 \text { ppm } \\
\text { TWA }\end{array}$ & $\begin{array}{c}9 \text { ppm } \\
\text { 8-h } \text { average }^{1}\end{array}$ & - & - & - \\
\hline $\mathrm{CO}$ & $\begin{array}{l}400 \text { ppm } \\
\text { STEL }\end{array}$ & $\begin{array}{l}200 \text { ppm } \\
\text { Ceiling }\end{array}$ & $\begin{array}{l}50 \text { ppm } \\
\text { TWA }\end{array}$ & $\begin{array}{c}35 \text { ppm } \\
\text { 1-h average }\end{array}$ & - & - & - \\
\hline NO & $\begin{array}{l}25 \text { ppm } \\
\text { TWA }\end{array}$ & $\begin{array}{l}25 \text { ppm } \\
\text { TWA }\end{array}$ & $\begin{array}{l}25 \text { ppm } \\
\text { TWA }\end{array}$ & - & - & - & - \\
\hline $\mathrm{NO}_{2}$ & $\begin{array}{l}3 \text { ppm } \\
\text { TWA }\end{array}$ & $\begin{array}{l}1 \text { ppm } \\
\text { STEL }\end{array}$ & $\begin{array}{l}1 \text { ppm } \\
\text { STEL }\end{array}$ & $\begin{array}{c}0.053 \text { ppm } \mathrm{NO}_{2} \\
\text { Annual average }^{2}\end{array}$ & - & - & - \\
\hline $\mathrm{NO}_{2}$ & $\begin{array}{l}5 \text { ppm } \\
\text { STEL }\end{array}$ & $\begin{array}{l}1 \text { ppm } \\
\text { STEL }\end{array}$ & $\begin{array}{l}5 \text { ppm } \\
\text { Ceiling }\end{array}$ & $\begin{array}{c}0.053 \text { ppm } \mathrm{NO}_{2} \\
\text { Annual average }^{2}\end{array}$ & - & - & - \\
\hline $\mathrm{PM}_{2.5}$ & None & None & None & $\begin{array}{c}15 \mathrm{ug} / \mathrm{m}^{3} \\
\text { Annual average }^{2}\end{array}$ & - & - & - \\
\hline $\mathrm{PM}_{2.5}$ & None & None & None & $\begin{array}{c}35 \mathrm{ug} / \mathrm{m}^{3} \\
\text { 24-h average }\end{array}$ & - & - & - \\
\hline
\end{tabular}

Symbols: $\mathrm{AGCIH}=$ American Conference of Governmental Industrial Hygienists; $\mathrm{CO}=$ Carbon monoxide; $\mathrm{dBA}=$ Decibel (A-filter); EAV = Exposure action value; ELV =

Exposure limit value; EPA = Environmental Protection Agency; EU = European Union; ISO = International Organization for Standardization; NAAQS = National ambient air quality standards; $\mathrm{NIOSH}=$ National Industrial of Occupational Safety and Health; $\mathrm{NO}=$ Nitrogen oxide; $\mathrm{NO}_{2}=$ Nitrogen dioxide; $\mathrm{NO}=\mathrm{Oxides}$ of nitrogen; $\mathrm{OSHA}=$ Occupational Safety and Health Administration; PEL = Permissible exposure limit; $\mathrm{PM}_{2.5}=$ Particulate matter; $\mathrm{REL}=$ Recommended exposure limit; $\mathrm{RMS}=\mathrm{Root}$ mean square; STEL = Short-term exposure limit; TLV = Threshold limit value; TWA = Time weighted average; VDV = Vibration dose method; WBV = Whole-body vibration.

Footnotes: ${ }^{1}$ not to be exceeded more than once per year; ${ }^{2} 3$-yr average must not exceed this value; ${ }^{3} 3$-yr average of the 98 th percentile must not exceed this value. 
APPENDIX B-ON-ROAD IN-CAB AVERAGE NOISE LEVELS PER TRUCK

Table 10: On-Road In-Cab Average Noise Levels Per Truck Manufacturer, and OSHA and ISO Integrator Measurements

\begin{tabular}{|c|c|c|c|c|c|c|c|c|c|c|c|c|}
\hline $\begin{array}{c}\text { Truck } \\
\text { Mfr }\end{array}$ & $\begin{array}{c}\text { Truck } \\
\text { Test } \\
\text { No. }\end{array}$ & $\begin{array}{c}\text { Peak } \\
(\mathrm{dBC})\end{array}$ & $\begin{array}{c}\text { Min } \\
L_{\text {Min }} \\
(d B A)\end{array}$ & $\begin{array}{c}\text { Max } \\
L_{\text {Max }} \\
(d B A)\end{array}$ & $\begin{array}{c}\text { OSHA } \\
\text { Dose } \\
(\%)\end{array}$ & $\begin{array}{c}\text { OSHA } \\
\text { Estimated } \\
\text { Dose (\%) }\end{array}$ & $\begin{array}{c}\text { OSHA } \\
L_{\text {eq }} \\
\text { (dBA) }\end{array}$ & $\begin{array}{c}\text { OSHA 8-h } \\
\text { TWA } \\
\text { (dBA) }\end{array}$ & $\begin{array}{l}\text { ISO } \\
\text { Dose } \\
(\%)\end{array}$ & $\begin{array}{c}\text { ISO } \\
\text { Estimated } \\
\text { Dose (\%) }\end{array}$ & $\begin{array}{c}\text { ISO } \\
L_{e q} \\
\text { (dBA) }\end{array}$ & $\begin{array}{c}\text { ISO 8-h } \\
\text { TWA } \\
\text { (dBA) }\end{array}$ \\
\hline$A$ & 2 & 127.2 & 64.7 & 93.8 & 2.9 & 8.1 & 71.8 & 64.5 & 8.8 & 24.1 & 78.8 & 74.4 \\
\hline$A$ & 3 & 120.8 & 64.7 & 93.9 & 2.2 & 6.4 & 70.1 & 62.2 & 7.2 & 21.2 & 78.2 & 73.5 \\
\hline$A$ & 4 & $138.8 \dagger$ & 65.4 & 95.4 & $3.8 \dagger$ & $10.7 \dagger$ & $73.8 \dagger$ & $66.3 \dagger$ & $10.5 \dagger$ & $29.5 \dagger$ & $79.6 \dagger$ & $75.1 \dagger$ \\
\hline$A$ & 6 & 118.0 & 64.0 & $97.5 \dagger$ & 2.0 & 5.1 & 68.2 & 61.4 & 7.4 & 18.7 & 77.6 & 73.5 \\
\hline$A$ & 7 & 111.6 & 65.7 & 88.6 & 1.8 & 4.8 & 68.0 & 60.9 & 6.7 & 18.0 & 77.5 & 73.2 \\
\hline$A$ & 8 & 114.4 & 65.2 & 90.2 & 3.0 & 9.5 & 72.9 & 64.6 & 8.7 & 27.3 & 79.3 & 74.3 \\
\hline$A$ & 9 & 113.6 & 65.2 & 88.6 & 1.1 & 3.2 & 65.1 & 57.3 & 5.3 & 15.7 & 76.9 & 72.2 \\
\hline$B$ & 1 & 117.6 & 64.8 & 94.8 & 1.3 & 3.7 & 66.1 & 58.8 & 6.3 & 17.3 & 77.3 & 72.9 \\
\hline$B$ & 2 & 116.8 & 66.5 & 89.1 & $0.1^{*}$ & $0.2^{*}$ & $44.5^{*}$ & $36.6^{*}$ & 3.8 & 11.4 & 75.5 & 70.8 \\
\hline$B$ & 3 & 118.8 & 65.7 & 95.3 & 0.2 & 0.5 & 52.4 & 44.3 & 3.4 & 10.5 & 75.2 & 70.3 \\
\hline$B$ & 5 & 118.8 & 65.8 & 91.9 & 0.2 & 0.5 & 52.1 & 44.2 & 3.8 & 11.4 & 75.5 & 70.8 \\
\hline C & 1 & $111.2^{*}$ & 63.5 & $87.8^{*}$ & 0.4 & 1.2 & 58.3 & 50.7 & $3.0^{*}$ & $8.6^{*}$ & $74.3^{*}$ & $69.7^{*}$ \\
\hline C & 2 & 112.8 & 66.0 & 92.1 & 0.3 & 0.9 & 56.4 & 48.7 & 4.4 & 12.8 & 76.0 & 71.4 \\
\hline C & 3 & 116.0 & 67.7 & 95.5 & 0.3 & 0.7 & 54.5 & 47.6 & 4.9 & 13.0 & 76.1 & 71.9 \\
\hline C & 4 & 118.4 & 69.3† & 90.8 & 0.5 & 1.5 & 59.9 & 51.8 & 6.1 & 18.8 & 77.7 & 72.8 \\
\hline C & 5 & 112.8 & 66.5 & 90.8 & 0.4 & 1.2 & 57.9 & 50.1 & 4.6 & 13.5 & 76.3 & 71.5 \\
\hline $\mathrm{D}$ & 1 & 120.8 & 65.6 & 93.4 & 1.0 & 2.7 & 64.3 & 56.8 & 5.3 & 14.9 & 76.9 & 72.4 \\
\hline $\mathrm{D}$ & 2 & 116.4 & 64.9 & 93.8 & $0.1^{*}$ & 0.4 & 50.4 & 42.5 & $3.0^{*}$ & 9.0 & 74.5 & 69.8 \\
\hline$D$ & 3 & 114.8 & 65.5 & 91.5 & $0.1^{*}$ & 0.4 & 50.0 & 42.1 & 3.3 & 10.0 & 74.9 & 70.2 \\
\hline D & 4 & 115.2 & 64.6 & 93.6 & 0.9 & 2.6 & 63.6 & 55.7 & 5.4 & 16.1 & 77.0 & 72.2 \\
\hline$D$ & 5 & 115.2 & $61.3^{*}$ & 93.5 & 0.3 & 1.1 & 57.4 & 48.9 & 3.8 & 12.4 & 75.9 & 70.8 \\
\hline D & 6 & 128.0 & 63.5 & 93.8 & 1.6 & 4.7 & 67.9 & 60.2 & 6.7 & 19.5 & 77.9 & 73.2 \\
\hline
\end{tabular}

* Minimum values; † Maximum values; Dose (\%) and TWA values are not referenced over an actual or total 8-h work shift. 


\section{APPENDIX C-DRIVER SEAT CUSHION RMS VALUES PER ROADWAY}

Table 11. Driver Seat Cushion RMS Values Axis of Translation or $\mathrm{m} / \mathrm{s}^{2}$ Comfort vs. Roadway

\begin{tabular}{|c|c|c|c|c|c|c|c|c|c|c|c|c|c|}
\hline $\begin{array}{c}\text { Truck } \\
\text { Mfr. }\end{array}$ & $\begin{array}{c}\text { Truck } \\
\text { Test } \\
\text { No. }\end{array}$ & $\begin{array}{c}\text { X-axis } \\
1-40\end{array}$ & $\begin{array}{l}\text { X-axis } \\
\text { US-27 }\end{array}$ & $\begin{array}{c}\text { X-axis } \\
1-75\end{array}$ & $\begin{array}{c}\text { Y-axis } \\
\text { I-40 }\end{array}$ & $\begin{array}{l}\text { Y-axis } \\
\text { US-27 }\end{array}$ & $\begin{array}{c}\text { Y-axis } \\
\text { I-75 }\end{array}$ & $\begin{array}{c}\text { Z-axis } \\
\text { I-40 }\end{array}$ & $\begin{array}{l}\text { Z-axis } \\
\text { US-27 }\end{array}$ & $\begin{array}{c}\text { Z-axis } \\
\text { I-75 }\end{array}$ & $\Sigma$ I-40 & $\begin{array}{c}\Sigma \text { US- } \\
27\end{array}$ & $\Sigma$ I-75 \\
\hline$A$ & 5 & 0.24 & 0.24 & 0.28 & 0.25 & 0.20 & 0.28 & 0.23 & 0.26 & 0.27 & 0.34 & 0.34 & 0.39 \\
\hline$A$ & 6 & 0.25 & 0.26 & 0.31 & 0.23 & 0.24 & 0.28 & 0.25 & 0.32 & 0.31 & 0.35 & 0.41 & 0.43 \\
\hline$A$ & 7 & 0.29 & 0.31 & 0.32 & 0.24 & 0.25 & 0.29 & 0.23 & 0.29 & 0.29 & 0.36 & 0.41 & 0.43 \\
\hline$A$ & 8 & 0.24 & 0.24 & 0.24 & 0.21 & 0.23 & 0.23 & 0.24 & 0.25 & 0.26 & 0.33 & 0.35 & 0.35 \\
\hline$A$ & 9 & 0.20 & 0.19 & 0.21 & 0.33 & 0.38 & 0.35 & 0.29 & 0.32 & 0.32 & 0.40 & 0.45 & 0.43 \\
\hline B & 1 & 0.30 & 0.34 & 0.32 & 0.31 & 0.31 & 0.31 & 0.35 & 0.40 & 0.38 & 0.47 & 0.52 & 0.50 \\
\hline$B$ & 2 & 0.29 & 0.36 & 0.30 & 0.36 & 0.35 & 0.32 & 0.36 & 0.38 & 0.38 & 0.49 & 0.53 & 0.50 \\
\hline B & 3 & 0.24 & 0.28 & 0.27 & 0.31 & 0.36 & 0.33 & 0.36 & 0.40 & 0.40 & 0.45 & 0.52 & 0.50 \\
\hline B & 4 & 0.25 & 0.25 & 0.25 & 0.35 & 0.31 & 0.29 & $0.41 \dagger$ & 0.40 & 0.41 & $0.51 \dagger$ & 0.49 & 0.50 \\
\hline $\mathrm{B}$ & 5 & 0.24 & 0.29 & 0.30 & 0.36 & 0.40 & 0.39 & 0.33 & $0.42 \dagger$ & 0.40 & 0.45 & 0.54 & 0.53 \\
\hline B & 6 & 0.28 & 0.31 & 0.30 & 0.37 & $0.45 \dagger$ & $0.44 \dagger$ & 0.33 & 0.40 & 0.39 & 0.47 & $0.55 \dagger$ & $0.55 \dagger$ \\
\hline C & 1 & 0.20 & 0.25 & 0.24 & 0.22 & 0.26 & 0.27 & 0.31 & 0.37 & 0.37 & 0.37 & 0.45 & 0.45 \\
\hline C & 2 & 0.21 & 0.24 & 0.25 & 0.36 & 0.32 & 0.30 & 0.34 & 0.42 & $0.41 \dagger$ & 0.46 & 0.51 & 0.48 \\
\hline C & 3 & 0.21 & 0.25 & 0.24 & 0.25 & 0.27 & 0.26 & 0.31 & 0.38 & 0.37 & 0.39 & 0.46 & 0.45 \\
\hline C & 4 & 0.28 & $0.36 \dagger$ & $0.34 \dagger$ & 0.27 & 0.34 & 0.33 & 0.30 & 0.38 & 0.39 & 0.41 & 0.52 & 0.51 \\
\hline $\mathrm{C}$ & 5 & 0.26 & 0.31 & 0.29 & 0.34 & 0.39 & 0.37 & 0.30 & 0.38 & 0.38 & 0.43 & 0.52 & 0.51 \\
\hline C & 6 & 0.23 & 0.26 & 0.29 & 0.27 & 0.29 & 0.32 & 0.28 & 0.33 & 0.38 & 0.38 & 0.43 & 0.49 \\
\hline $\mathrm{D}$ & 1 & 0.27 & 0.28 & 0.30 & 0.36 & 0.35 & 0.31 & 0.30 & 0.32 & 0.32 & 0.44 & 0.44 & 0.44 \\
\hline D & 2 & 0.20 & 0.23 & 0.24 & 0.34 & 0.34 & 0.34 & 0.31 & 0.34 & 0.35 & 0.42 & 0.45 & 0.46 \\
\hline $\mathrm{D}$ & 3 & 0.29 & 0.28 & 0.31 & 0.28 & 0.29 & 0.29 & 0.32 & 0.31 & 0.34 & 0.42 & 0.42 & 0.46 \\
\hline $\mathrm{D}$ & 4 & 0.28 & 0.28 & 0.30 & 0.30 & 0.41 & 0.36 & 0.31 & 0.34 & 0.34 & 0.43 & 0.50 & 0.48 \\
\hline $\mathrm{D}$ & 5 & $0.35 \dagger$ & 0.33 & 0.33 & $0.37 \dagger$ & 0.37 & 0.34 & 0.31 & 0.34 & 0.32 & 0.48 & 0.49 & 0.46 \\
\hline D & 6 & 0.24 & 0.26 & 0.29 & 0.33 & 0.34 & 0.32 & 0.31 & 0.32 & 0.35 & 0.43 & 0.43 & 0.47 \\
\hline
\end{tabular}

†Maximum values; if the 8-h EAV has been exceeded, the values are underlined. 


\section{APPENDIX D-DRIVER SEAT CUSHION RMS VALUES PER ROADWAY}

Table 12. Driver Seat Cushion RMS Values Axis of Translation $\mathrm{m} / \mathrm{s}^{2}$ or Comfort vs. Roadway

\begin{tabular}{|c|c|c|c|c|c|c|c|c|c|c|c|c|c|}
\hline $\begin{array}{c}\text { Truck } \\
\text { Mfr. }\end{array}$ & $\begin{array}{c}\text { Truck } \\
\text { Test } \\
\text { No. }\end{array}$ & $\begin{array}{c}\text { X-axis } \\
1-40\end{array}$ & $\begin{array}{l}\text { X-axis } \\
\text { US-27 }\end{array}$ & $\begin{array}{c}\text { X-axis } \\
\text { I-75 }\end{array}$ & $\begin{array}{c}\text { Y-axis } \\
\text { I-40 }\end{array}$ & $\begin{array}{l}\text { Y-axis } \\
\text { US-27 }\end{array}$ & $\begin{array}{c}\text { Y-axis } \\
\text { I-75 }\end{array}$ & $\begin{array}{c}\text { Z-axis } \\
\text { I-40 }\end{array}$ & $\begin{array}{l}\text { Z-axis } \\
\text { US-27 }\end{array}$ & $\begin{array}{c}\text { Z-axis } \\
\text { I-75 }\end{array}$ & $\Sigma$ I-40 & $\begin{array}{c}\Sigma \text { US- } \\
27\end{array}$ & $\Sigma I-75$ \\
\hline$A$ & 3 & 0.17 & 0.21 & 0.20 & 0.21 & 0.23 & 0.23 & 0.18 & 0.24 & 0.21 & 0.27 & 0.33 & 0.30 \\
\hline$A$ & 4 & 0.22 & 0.23 & 0.23 & 0.22 & 0.21 & 0.23 & 0.20 & 0.22 & 0.21 & 0.30 & 0.31 & 0.32 \\
\hline$A$ & 5 & 0.20 & 0.22 & 0.20 & 0.21 & 0.21 & 0.23 & 0.21 & 0.22 & 0.23 & 0.30 & 0.31 & 0.31 \\
\hline$A$ & 6 & 0.20 & 0.24 & 0.23 & 0.20 & 0.22 & 0.23 & 0.20 & 0.21 & 0.22 & 0.29 & 0.31 & 0.31 \\
\hline$A$ & 7 & 0.20 & 0.22 & 0.24 & 0.22 & 0.24 & 0.24 & 0.25 & 0.27 & 0.29 & 0.33 & 0.35 & 0.38 \\
\hline$A$ & 8 & 0.16 & 0.18 & 0.17 & 0.21 & 0.22 & 0.21 & 0.23 & 0.23 & 0.23 & 0.30 & 0.31 & 0.30 \\
\hline$A$ & 9 & 0.16 & 0.18 & 0.17 & 0.39 & $\underline{0.53}$ & 0.43 & 0.23 & 0.24 & 0.25 & 0.38 & 0.46 & 0.42 \\
\hline$B$ & 2 & $0.23 \dagger$ & $0.42 \dagger$ & $0.35 \dagger$ & 0.37 & 0.40 & 0.35 & 0.31 & 0.34 & 0.34 & 0.44 & 0.54 & 0.49 \\
\hline$B$ & 3 & 0.20 & 0.23 & 0.22 & 0.36 & 0.41 & 0.38 & 0.31 & 0.32 & 0.35 & 0.43 & 0.47 & 0.47 \\
\hline B & 4 & 0.19 & 0.22 & 0.20 & 0.39 & 0.38 & 0.33 & $0.35 \dagger$ & 0.36 & 0.39 & 0.47 & 0.48 & 0.48 \\
\hline B & 5 & 0.20 & 0.24 & 0.24 & 0.41 & 0.44 & 0.42 & 0.30 & 0.35 & 0.38 & 0.44 & 0.50 & 0.51 \\
\hline B & 6 & 0.21 & 0.26 & 0.23 & 0.38 & $\underline{0.50}$ & 0.45 & 0.31 & 0.36 & 0.36 & 0.44 & 0.54 & 0.52 \\
\hline $\mathrm{C}$ & 1 & 0.20 & 0.26 & 0.24 & 0.29 & 0.35 & 0.34 & 0.23 & 0.27 & 0.27 & 0.35 & 0.41 & 0.40 \\
\hline$C$ & 2 & 0.17 & 0.20 & 0.22 & $0.49 \dagger$ & 0.41 & 0.38 & 0.30 & 0.35 & 0.37 & 0.48 & 0.48 & 0.48 \\
\hline $\mathrm{C}$ & 3 & 0.17 & 0.21 & 0.21 & 0.31 & 0.31 & 0.29 & 0.26 & 0.32 & 0.32 & 0.36 & 0.41 & 0.41 \\
\hline$C$ & 4 & 0.18 & 0.23 & 0.21 & 0.30 & 0.39 & 0.35 & 0.32 & $0.37 \dagger$ & $0.39 \dagger$ & 0.40 & 0.49 & 0.49 \\
\hline$C$ & 5 & 0.23 & 0.27 & 0.26 & 0.45 & $\underline{0.55}{ }^{\dagger}$ & $\underline{0.56}{ }^{\dagger}$ & 0.34 & 0.35 & 0.34 & $0.50 \dagger$ & $0.56 \dagger$ & $0.56 \dagger$ \\
\hline C & 6 & 0.21 & 0.24 & 0.23 & 0.30 & 0.31 & 0.31 & 0.26 & 0.30 & 0.33 & 0.37 & 0.41 & 0.43 \\
\hline $\mathrm{D}$ & 1 & 0.21 & 0.25 & 0.23 & 0.40 & 0.40 & 0.34 & 0.27 & 0.31 & 0.31 & 0.42 & 0.46 & 0.42 \\
\hline$D$ & 2 & 0.16 & 0.20 & 0.20 & 0.42 & 0.37 & 0.34 & 0.27 & 0.30 & 0.31 & 0.42 & 0.43 & 0.42 \\
\hline $\mathrm{D}$ & 3 & 0.19 & 0.20 & 0.21 & 0.30 & 0.29 & 0.29 & 0.29 & 0.29 & 0.32 & 0.38 & 0.38 & 0.41 \\
\hline$D$ & 4 & 0.19 & 0.22 & 0.21 & 0.35 & $\underline{0.52}$ & 0.41 & 0.26 & 0.29 & 0.29 & 0.39 & 0.50 & 0.43 \\
\hline$D$ & 5 & 0.21 & 0.24 & 0.22 & 0.30 & 0.30 & 0.29 & 0.24 & 0.27 & 0.27 & 0.36 & 0.39 & 0.37 \\
\hline$D$ & 6 & 0.18 & 0.20 & 0.21 & 0.43 & 0.43 & 0.37 & 0.28 & 0.30 & 0.32 & 0.44 & 0.45 & 0.44 \\
\hline
\end{tabular}

†Maximum values and/or if the 8-h EAV has been exceeded, the values are underlined. 


\section{APPENDIX E-DRIVER BACK REST RMS VALUES PER ROADWAY}

Table 13. Driver Back Rest RMS Values Axis of Translation $\mathrm{m} / \mathrm{s}^{2}$ or Comfort vs. Roadway

\begin{tabular}{|c|c|c|c|c|c|c|c|c|c|c|c|c|c|}
\hline $\begin{array}{c}\text { Truck } \\
\text { Mfr. }\end{array}$ & $\begin{array}{c}\text { Truck } \\
\text { Test } \\
\text { No. }\end{array}$ & $\begin{array}{c}\text { X-axis } \\
1-40\end{array}$ & $\begin{array}{l}\text { X-axis } \\
\text { US-27 }\end{array}$ & $\begin{array}{c}\text { X-axis } \\
\text { I-75 }\end{array}$ & $\begin{array}{c}Y \text {-axis } \\
1-40\end{array}$ & $\begin{array}{l}\text { Y-axis } \\
\text { US-27 }\end{array}$ & $\begin{array}{c}\text { Y-axis } \\
\text { I-75 }\end{array}$ & $\begin{array}{c}\text { Z-axis } \\
\mathrm{I}-40\end{array}$ & $\begin{array}{l}\text { Z-axis } \\
\text { US-27 }\end{array}$ & $\begin{array}{c}\text { Z-axis } \\
\text { I-75 }\end{array}$ & $\Sigma \mathrm{I}-40$ & $\begin{array}{c}\Sigma \text { US- } \\
27\end{array}$ & $\Sigma$ I-75 \\
\hline$A$ & 3 & 0.23 & 0.30 & 0.29 & 0.22 & 0.23 & 0.25 & 0.22 & 0.27 & 0.25 & 0.32 & 0.38 & 0.37 \\
\hline$A$ & 4 & 0.26 & 0.29 & 0.28 & 0.23 & 0.23 & 0.25 & 0.23 & 0.25 & 0.24 & 0.34 & 0.37 & 0.36 \\
\hline$A$ & 5 & 0.23 & 0.27 & 0.26 & 0.22 & 0.23 & 0.27 & 0.26 & 0.26 & 0.27 & 0.35 & 0.37 & 0.38 \\
\hline$A$ & 6 & 0.27 & 0.28 & 0.30 & 0.21 & 0.22 & 0.25 & 0.23 & 0.24 & 0.26 & 0.34 & 0.35 & 0.38 \\
\hline$A$ & 7 & 0.23 & 0.25 & 0.27 & 0.23 & 0.23 & 0.24 & 0.33 & 0.32 & 0.33 & 0.40 & 0.41 & 0.42 \\
\hline$A$ & 8 & 0.21 & 0.23 & 0.22 & 0.23 & 0.21 & 0.21 & 0.32 & 0.31 & 0.30 & 0.39 & 0.38 & 0.37 \\
\hline$A$ & 9 & 0.21 & 0.23 & 0.24 & 0.22 & 0.21 & 0.24 & 0.23 & 0.22 & 0.24 & 0.31 & 0.31 & 0.34 \\
\hline$B$ & 2 & 0.24 & 0.27 & 0.26 & 0.24 & 0.23 & 0.23 & 0.33 & 0.33 & 0.35 & 0.41 & 0.42 & 0.43 \\
\hline B & 3 & 0.25 & 0.29 & 0.29 & 0.23 & 0.23 & 0.24 & 0.30 & 0.29 & 0.32 & 0.39 & 0.39 & 0.42 \\
\hline B & 4 & 0.25 & 0.28 & 0.26 & 0.22 & 0.23 & 0.25 & 0.32 & 0.31 & 0.35 & 0.40 & 0.40 & 0.44 \\
\hline B & 5 & 0.25 & 0.29 & 0.30 & 0.23 & 0.24 & 0.27 & 0.34 & 0.36 & 0.42 & 0.42 & 0.45 & 0.51 \\
\hline$B$ & 6 & 0.22 & 0.27 & 0.26 & 0.23 & 0.24 & 0.23 & $0.37 \dagger$ & 0.35 & 0.39 & $0.44 \dagger$ & 0.43 & 0.46 \\
\hline C & 1 & 0.25 & $0.31 \dagger$ & 0.29 & 0.21 & 0.23 & 0.23 & 0.20 & 0.24 & 0.23 & 0.31 & 0.36 & 0.35 \\
\hline C & 2 & 0.24 & 0.27 & 0.30 & 0.26 & 0.25 & 0.30 & 0.27 & 0.29 & 0.33 & 0.37 & 0.39 & 0.45 \\
\hline C & 3 & 0.23 & 0.27 & 0.28 & 0.23 & 0.24 & 0.27 & 0.22 & 0.28 & 0.29 & 0.32 & 0.39 & 0.40 \\
\hline C & 4 & 0.22 & 0.29 & 0.26 & 0.19 & 0.22 & 0.24 & 0.35 & $0.39 \dagger$ & $0.45 \dagger$ & 0.41 & $0.47^{* *}$ & $0.52^{* *}$ \\
\hline C & 5 & 0.24 & 0.29 & 0.29 & 0.27 & 0.25 & $0.31 \dagger$ & 0.30 & 0.36 & 0.37 & 0.40 & 0.45 & 0.48 \\
\hline$C$ & 6 & 0.22 & 0.25 & 0.25 & 0.25 & 0.24 & 0.27 & 0.28 & 0.30 & 0.33 & 0.37 & 0.39 & 0.42 \\
\hline D & 1 & 0.25 & 0.28 & 0.30 & $0.31 \dagger$ & 0.25 & 0.25 & 0.29 & 0.33 & 0.32 & 0.41 & 0.42 & 0.42 \\
\hline $\mathrm{D}$ & 2 & 0.20 & 0.24 & 0.23 & 0.27 & 0.23 & 0.26 & 0.31 & 0.33 & 0.34 & 0.40 & 0.41 & 0.43 \\
\hline $\mathrm{D}$ & 3 & 0.24 & 0.27 & 0.28 & 0.23 & 0.21 & 0.24 & 0.33 & 0.32 & 0.37 & 0.41 & 0.40 & 0.46 \\
\hline $\mathrm{D}$ & 4 & 0.24 & 0.30 & 0.29 & 0.23 & 0.24 & 0.25 & 0.32 & 0.35 & 0.36 & 0.40 & 0.45 & 0.45 \\
\hline D & 5 & 0.22 & 0.28 & 0.27 & 0.26 & $0.26 \dagger$ & 0.28 & 0.32 & 0.34 & 0.36 & 0.41 & 0.44 & 0.45 \\
\hline$D$ & 6 & $0.28 \dagger$ & 0.29 & $0.33 \dagger$ & 0.27 & 0.23 & 0.25 & 0.31 & 0.32 & 0.35 & 0.42 & 0.41 & 0.46 \\
\hline
\end{tabular}

† Maximum values and/or if the 8-h EAV has been exceeded, the values are underlined. 


\section{APPENDIX F-PASSENGER SEAT CUSHION RMS VALUES PER ROADWAY}

Table 14. Passenger Seat Cushion RMS Values Axis of Translation $\mathrm{m} / \mathrm{s}^{2}$ or Comfort vs. Roadway

\begin{tabular}{|c|c|c|c|c|c|c|c|c|c|c|c|c|c|}
\hline $\begin{array}{c}\text { Truck } \\
\text { Mfr. }\end{array}$ & $\begin{array}{c}\text { Truck } \\
\text { Test } \\
\text { No. }\end{array}$ & $\begin{array}{c}\text { X-axis } \\
1-40\end{array}$ & $\begin{array}{l}\text { X-axis } \\
\text { US-27 }\end{array}$ & $\begin{array}{c}\text { X-axis } \\
\text { I-75 }\end{array}$ & $\begin{array}{c}\text { Y-axis } \\
\text { I-40 }\end{array}$ & $\begin{array}{l}\text { Y-axis } \\
\text { US-27 }\end{array}$ & $\begin{array}{c}\text { Y-axis } \\
\text { I-75 }\end{array}$ & $\begin{array}{c}\text { Z-axis } \\
\text { I-40 }\end{array}$ & $\begin{array}{l}\text { Z-axis } \\
\text { US-27 }\end{array}$ & $\begin{array}{c}\text { Z-axis } \\
\text { I-75 }\end{array}$ & $\Sigma$ I-40 & $\begin{array}{c}\Sigma \text { US- } \\
27\end{array}$ & $\Sigma$ I-75 \\
\hline \multirow[t]{7}{*}{$A$} & 3 & 0.17 & 0.23 & 0.22 & 0.21 & 0.23 & 0.23 & 0.18 & 0.23 & 0.21 & 0.32 & 0.40 & 0.38 \\
\hline & 4 & 0.17 & 0.17 & 0.19 & 0.23 & 0.24 & 0.26 & 0.26 & 0.28 & 0.25 & 0.39 & 0.41 & 0.41 \\
\hline & 5 & 0.16 & 0.20 & 0.18 & 0.22 & 0.25 & 0.24 & 0.24 & 0.24 & 0.25 & 0.37 & 0.40 & 0.39 \\
\hline & 6 & 0.15 & 0.21 & 0.18 & 0.22 & 0.25 & 0.23 & 0.26 & 0.25 & 0.27 & 0.37 & 0.41 & 0.40 \\
\hline & 7 & 0.15 & 0.17 & 0.18 & 0.20 & 0.20 & 0.20 & 0.30 & 0.30 & 0.33 & 0.39 & 0.40 & 0.43 \\
\hline & 8 & 0.15 & 0.17 & 0.17 & 0.20 & 0.19 & 0.18 & 0.26 & 0.27 & 0.26 & 0.36 & 0.37 & 0.36 \\
\hline & 9 & 0.18 & 0.19 & 0.19 & 0.21 & 0.21 & 0.22 & 0.28 & 0.27 & 0.30 & 0.40 & 0.39 & 0.42 \\
\hline \multirow[t]{5}{*}{$B$} & 2 & 0.24 & 0.32 & 0.27 & 0.25 & $0.30 \dagger$ & 0.26 & 0.31 & 0.35 & 0.35 & 0.46 & 0.56 & 0.51 \\
\hline & 3 & 0.21 & 0.22 & 0.23 & 0.21 & 0.21 & 0.21 & 0.28 & 0.29 & 0.32 & 0.41 & 0.43 & 0.45 \\
\hline & 4 & 0.22 & 0.21 & 0.20 & 0.19 & 0.20 & 0.20 & 0.28 & 0.31 & 0.35 & 0.40 & 0.43 & 0.45 \\
\hline & 5 & $0.29 \dagger$ & $0.32 \dagger$ & $0.37 \dagger$ & 0.20 & 0.21 & 0.23 & 0.30 & 0.34 & 0.37 & 0.47 & 0.51 & 0.57 \\
\hline & 6 & 0.18 & 0.20 & 0.20 & 0.21 & 0.21 & 0.21 & 0.32 & 0.33 & 0.36 & 0.42 & 0.44 & 0.46 \\
\hline \multirow[t]{6}{*}{ C } & 1 & 0.16 & 0.21 & 0.19 & 0.20 & 0.23 & 0.21 & 0.19 & 0.22 & 0.20 & 0.32 & 0.38 & 0.35 \\
\hline & 2 & 0.23 & 0.27 & 0.33 & 0.24 & 0.23 & 0.27 & 0.31 & 0.31 & 0.39 & 0.46 & 0.48 & 0.57 \\
\hline & 3 & 0.18 & 0.21 & 0.21 & 0.21 & 0.23 & 0.24 & 0.25 & 0.31 & 0.34 & 0.37 & 0.44 & 0.46 \\
\hline & 4 & 0.19 & 0.23 & 0.24 & 0.19 & 0.21 & 0.21 & $0.39 \dagger$ & $0.43 \dagger$ & $\underline{0.51 \dagger}$ & 0.47 & 0.53 & 0.61 \\
\hline & 5 & 0.21 & 0.24 & 0.25 & 0.25 & 0.23 & $0.27 \dagger$ & 0.36 & 0.37 & 0.38 & 0.48 & 0.50 & 0.53 \\
\hline & 6 & 0.18 & 0.20 & 0.23 & 0.24 & 0.22 & 0.24 & 0.31 & 0.32 & 0.38 & 0.43 & 0.44 & 0.50 \\
\hline \multirow[t]{6}{*}{$\mathrm{D}$} & 1 & 0.16 & 0.19 & 0.19 & $0.26 \dagger$ & 0.22 & 0.21 & 0.29 & 0.33 & 0.32 & 0.42 & 0.44 & 0.43 \\
\hline & 2 & 0.17 & 0.21 & 0.19 & 0.25 & 0.23 & 0.25 & 0.26 & 0.29 & 0.29 & 0.40 & 0.43 & 0.43 \\
\hline & 3 & 0.16 & 0.19 & 0.19 & 0.20 & 0.22 & 0.22 & 0.29 & 0.32 & 0.34 & 0.39 & 0.43 & 0.45 \\
\hline & 4 & 0.16 & 0.20 & 0.19 & 0.21 & 0.22 & 0.22 & 0.29 & 0.32 & 0.34 & 0.39 & 0.44 & 0.45 \\
\hline & 5 & 0.16 & 0.19 & 0.18 & 0.25 & 0.25 & 0.26 & 0.30 & 0.32 & 0.33 & 0.42 & 0.45 & 0.46 \\
\hline & 6 & 0.17 & 0.19 & 0.20 & 0.24 & 0.21 & 0.22 & 0.28 & 0.30 & 0.34 & 0.41 & 0.41 & 0.46 \\
\hline
\end{tabular}

†Maximum values; if the 8-h EAV has been exceeded, the values are underlined. 


\section{APPENDIX G-DRIVER SEAT CUSHION VDV PER ROADWAY}

Table 15. Driver Seat Cushion VDV Axis of Translation $\mathrm{m} / \mathrm{s}^{2}$ or Comfort vs. Roadway

\begin{tabular}{|c|c|c|c|c|c|c|c|c|c|c|}
\hline Truck Mfr. & $\begin{array}{c}\text { Truck } \\
\text { Test No. }\end{array}$ & $\begin{array}{c}\text { X-axis } \\
\text { I-40 }\end{array}$ & $\begin{array}{c}\text { X-axis US- } \\
27\end{array}$ & $\begin{array}{c}\text { X-axis } \\
\text { I-75 }\end{array}$ & $\begin{array}{c}Y \text {-axis } \\
\text { I-40 }\end{array}$ & $\begin{array}{l}Y \text {-axis } \\
\text { US-27 }\end{array}$ & $\begin{array}{l}\text { Y-axis } \\
\text { I-75 }\end{array}$ & $\begin{array}{l}\text { Z-axis } \\
\text { I-40 }\end{array}$ & $\begin{array}{l}\text { Z-axis } \\
\text { US-27 }\end{array}$ & $\begin{array}{c}\text { Z-axis } \\
\text { I-75 }\end{array}$ \\
\hline$A$ & 3 & 2.9 & 3.3 & 3.1 & 3.2 & 3.4 & 3.4 & 3.7 & 4.9 & 4.0 \\
\hline$A$ & 4 & 3.7 & 3.7 & 3.6 & 3.2 & 3.1 & 3.5 & 4.1 & 4.3 & 4.5 \\
\hline$A$ & 5 & 3.3 & 3.3 & 3.0 & 3.2 & 3.2 & 3.2 & 3.9 & 4.5 & 4.1 \\
\hline$A$ & 6 & 3.3 & $\underline{23.7 \dagger}$ & 3.6 & 3.2 & $\underline{11.6}$ & 3.4 & 3.8 & 4.2 & 4.3 \\
\hline$A$ & 7 & 3.2 & 3.3 & 3.5 & 3.0 & 3.3 & 3.4 & 4.7 & 5.3 & 6.0 \\
\hline$A$ & 8 & 2.9 & 3.1 & 2.6 & 2.9 & 3.1 & 3.0 & 4.3 & 4.6 & 4.5 \\
\hline$A$ & 9 & 2.6 & 2.8 & 2.5 & 6.9 & 8.8 & 7.2 & 4.7 & 4.9 & 4.8 \\
\hline$B$ & 2 & 3.9 & $\underline{14.8 \dagger}$ & $12.7 \dagger$ & 5.4 & 6.9 & 6.0 & 6.1 & $7.7 \dagger$ & 7.5 \\
\hline$B$ & 3 & 3.7 & 3.5 & 3.4 & 5.6 & 6.4 & 5.7 & 6.4 & 6.6 & 7.0 \\
\hline$B$ & 4 & 3.7 & 3.4 & 3.1 & 5.9 & 5.8 & 4.7 & $6.9 \dagger$ & 7.4 & 7.6 \\
\hline$B$ & 5 & 3.4 & 3.5 & 3.5 & 6.8 & 6.9 & 6.4 & 6.3 & 7.0 & 7.4 \\
\hline$B$ & 6 & 3.4 & 3.8 & 3.4 & 6.0 & 7.8 & 6.7 & 6.5 & 7.2 & 7.2 \\
\hline C & 1 & 4.0 & 4.2 & 4.1 & 4.3 & 5.0 & 4.7 & 4.5 & 5.3 & 4.9 \\
\hline C & 2 & 3.0 & 3.3 & 3.7 & $8.1 \dagger$ & 6.7 & 5.6 & 6.2 & 7.0 & 7.4 \\
\hline$C$ & 3 & 3.5 & 3.6 & 3.8 & 4.5 & 4.5 & 4.1 & 5.2 & 6.5 & 6.3 \\
\hline$C$ & 4 & 2.8 & 3.5 & 3.1 & 4.9 & 6.6 & 5.6 & 6.4 & 7.2 & $8.0 \dagger$ \\
\hline$C$ & 5 & $4.1 \dagger$ & 4.4 & 5.0 & 7.3 & 8.8 & $8.5 \dagger$ & 6.4 & 6.3 & 6.4 \\
\hline$C$ & 6 & 3.8 & 4.1 & 3.8 & 4.6 & 4.7 & 4.4 & 5.3 & 6.1 & 6.4 \\
\hline $\mathrm{D}$ & 1 & 3.7 & 4.1 & 3.6 & 5.8 & 6.3 & 4.9 & 5.5 & 6.7 & 6.1 \\
\hline$D$ & 2 & 2.9 & 3.4 & 3.2 & 7.0 & 6.0 & 4.8 & 5.5 & 6.1 & 6.0 \\
\hline$D$ & 3 & 3.0 & 3.0 & 3.2 & 4.7 & 4.5 & 4.3 & 6.0 & 5.5 & 6.1 \\
\hline$D$ & 4 & 3.0 & 3.4 & 3.1 & 5.7 & 8.5 & 6.7 & 5.4 & 5.8 & 5.8 \\
\hline $\mathrm{D}$ & 5 & 3.9 & 4.2 & 3.5 & 4.5 & 4.2 & 3.9 & 4.8 & 5.6 & 5.1 \\
\hline$D$ & 6 & 3.1 & 3.3 & 3.1 & 7.4 & 7.1 & 6.2 & 5.8 & 6.3 & 6.1 \\
\hline
\end{tabular}

†Maximum values; if the 8-h EAV has been exceeded, the values are underlined. 



\section{APPENDIX H-DRIVER BACK REST VDV PER ROADWAY}

Table 16. Driver Back Rest VDV Axis of Translation $\mathrm{m} / \mathrm{s}^{1.75}$ and Roadway

\begin{tabular}{|c|c|c|c|c|c|c|c|c|c|c|}
\hline $\begin{array}{c}\text { Truck } \\
\text { Mfr. }\end{array}$ & $\begin{array}{c}\text { Truck } \\
\text { Test No. }\end{array}$ & $\begin{array}{c}\text { X-axis } \\
\text { I-40 }\end{array}$ & $\begin{array}{l}\text { X-axis } \\
\text { US-27 }\end{array}$ & $\begin{array}{c}\text { X-axis } \\
\text { I-75 }\end{array}$ & $\begin{array}{c}Y \text {-axis } \\
\text { I-40 }\end{array}$ & $\begin{array}{l}\text { Y-axis } \\
\text { US-27 }\end{array}$ & $\begin{array}{c}Y \text {-axis } \\
\text { I-75 }\end{array}$ & $\begin{array}{c}\text { Z-axis } \\
\text { I-40 }\end{array}$ & $\begin{array}{l}\text { Z-axis } \\
\text { US-27 }\end{array}$ & $\begin{array}{c}\text { Z-axis } \\
\text { I-75 }\end{array}$ \\
\hline$A$ & 3 & 4.0 & 4.8 & 4.5 & 3.1 & 3.3 & 3.5 & 4.2 & 5.1 & 4.7 \\
\hline$A$ & 4 & 4.8 & 4.8 & 4.6 & 3.2 & 3.4 & 3.8 & 4.7 & 5.1 & 4.9 \\
\hline$A$ & 5 & 3.8 & 4.2 & 4.1 & 3.0 & 3.2 & 3.7 & 4.8 & 5.2 & 4.9 \\
\hline$A$ & 6 & 4.4 & 4.2 & 4.7 & 2.9 & 3.2 & 3.5 & 4.6 & 4.8 & 5.0 \\
\hline$A$ & 7 & 4.0 & 3.8 & 4.3 & 3.1 & 3.3 & 3.4 & 6.0 & 6.0 & 6.4 \\
\hline$A$ & 8 & 3.7 & 3.8 & 3.4 & 3.2 & 3.1 & 3.0 & 5.8 & 5.7 & 5.5 \\
\hline$A$ & 9 & 3.6 & 3.6 & 3.7 & 3.0 & 3.1 & 3.2 & 4.4 & 4.6 & 4.4 \\
\hline B & 2 & 4.1 & 4.1 & 4.0 & 3.6 & 3.3 & 3.6 & 6.3 & 6.8 & 7.0 \\
\hline$B$ & 3 & 4.2 & 4.1 & 4.3 & 3.1 & 3.5 & 3.4 & 5.8 & 6.0 & 6.5 \\
\hline$B$ & 4 & 4.7 & 4.4 & 4.1 & 3.2 & 3.5 & 3.6 & 6.4 & 6.6 & 7.2 \\
\hline B & 5 & 4.2 & 4.3 & 4.5 & 3.2 & 3.4 & 4.0 & 6.7 & 7.2 & 8.2 \\
\hline$B$ & 6 & 3.7 & 4.0 & 3.8 & 3.1 & 3.4 & 3.0 & 7.0 & 7.1 & 7.4 \\
\hline$C$ & 1 & 4.7 & 4.9 & 4.7 & 2.9 & 3.3 & 3.4 & 4.0 & 4.7 & 4.4 \\
\hline$C$ & 2 & 4.2 & 4.4 & 5.0 & 3.5 & 3.5 & 4.2 & 5.7 & 6.0 & 7.0 \\
\hline $\mathrm{C}$ & 3 & 4.3 & 4.7 & 5.1 & 3.3 & 3.5 & 3.9 & 4.5 & 5.8 & 6.0 \\
\hline$C$ & 4 & 3.5 & 4.2 & 4.0 & 3.1 & 3.2 & 3.7 & $7.3 \dagger$ & $8.1 \dagger$ & $\underline{10.5}{ }^{\dagger}$ \\
\hline $\mathrm{C}$ & 5 & 4.4 & 4.6 & $5.7 \dagger$ & 3.5 & 3.5 & $4.4 \dagger$ & 6.2 & 6.9 & 7.6 \\
\hline$C$ & 6 & 3.9 & 4.0 & 4.1 & 3.5 & 3.6 & 3.9 & 5.4 & 6.0 & 6.9 \\
\hline$D$ & 1 & 4.3 & $4.9 \dagger$ & 4.7 & $4.0 \dagger$ & $3.7 \dagger$ & 3.5 & 6.0 & 6.6 & 6.5 \\
\hline$D$ & 2 & 3.6 & 4.0 & 3.5 & 3.6 & 3.2 & 3.4 & 6.4 & 6.6 & 7.2 \\
\hline$D$ & 3 & 3.8 & 4.0 & 4.1 & 3.0 & 3.1 & 3.2 & 7.1 & 6.2 & 7.3 \\
\hline $\mathrm{D}$ & 4 & 4.1 & 4.7 & 4.4 & 3.2 & 3.4 & 3.4 & 6.4 & 7.2 & 7.6 \\
\hline $\mathrm{D}$ & 5 & 4.0 & 4.8 & 4.2 & 3.6 & 3.5 & 3.6 & 6.1 & 6.7 & 6.6 \\
\hline $\mathrm{D}$ & 6 & $4.8 \dagger$ & 4.8 & 5.0 & 3.7 & 3.3 & 3.4 & 6.7 & 6.4 & 6.7 \\
\hline
\end{tabular}

†Maximum values; if the 8-h EAV has been exceeded, the values are underlined. 



\section{APPENDIX I—PASSENGER SEAT CUSHION VDV PER ROADWAY}

Table 17. Passenger Seat Cushion VDV Axis of Translation $\mathrm{m} / \mathrm{s}^{1.75}$ and Roadway

\begin{tabular}{|c|c|c|c|c|c|c|c|c|c|c|}
\hline Truck Mfr. & $\begin{array}{c}\text { Truck } \\
\text { Test No. }\end{array}$ & $\begin{array}{c}\text { X-axis } \\
\text { I-40 }\end{array}$ & $\begin{array}{l}\text { X-axis } \\
\text { US-27 }\end{array}$ & $\begin{array}{c}\text { X-axis } \\
\text { I-75 }\end{array}$ & $\begin{array}{c}\text { Y-axis } \\
\text { I-40 }\end{array}$ & $\begin{array}{l}\text { Y-axis } \\
\text { US-27 }\end{array}$ & $\begin{array}{c}\text { Y-axis } \\
\text { I-75 }\end{array}$ & $\begin{array}{c}\text { Z-axis } \\
\text { I-40 }\end{array}$ & $\begin{array}{l}\text { Z-axis } \\
\text { US-27 }\end{array}$ & $\begin{array}{c}\text { Z-axis } \\
\text { I-75 }\end{array}$ \\
\hline$A$ & 3 & 3.4 & 4.0 & 3.8 & 3.0 & 3.4 & 3.1 & 3.7 & 4.7 & 4.1 \\
\hline$A$ & 4 & 2.9 & 2.6 & 3.1 & 3.3 & 3.5 & 3.7 & 5.1 & 5.5 & 6.0 \\
\hline$A$ & 5 & 2.9 & 3.2 & 3.1 & 3.1 & 3.6 & 3.3 & 4.7 & 4.8 & 4.7 \\
\hline$A$ & 6 & 2.3 & 3.4 & 2.8 & 3.0 & 4.1 & 3.0 & 5.2 & 5.3 & 5.7 \\
\hline$A$ & 7 & 2.4 & 2.7 & 2.8 & 2.7 & 2.8 & 2.8 & 6.2 & 6.7 & 8.5 \\
\hline$A$ & 8 & 2.6 & 2.8 & 2.6 & 3.0 & 2.6 & 2.6 & 6.2 & 5.9 & 6.1 \\
\hline$A$ & 9 & 2.7 & 3.0 & 2.8 & 2.8 & 3.0 & 3.0 & 5.0 & 5.1 & 5.5 \\
\hline B & 2 & 4.3 & $7.3 \dagger$ & $6.6 \dagger$ & $3.9 \dagger$ & $6.5 \dagger$ & $5.8 \dagger$ & 6.1 & $\underline{9.2 \dagger}$ & $\underline{9.5}{ }^{\dagger}$ \\
\hline$B$ & 3 & 3.6 & 3.3 & 3.7 & 2.8 & 3.2 & 3.0 & 5.7 & 6.0 & 6.7 \\
\hline$B$ & 4 & 3.6 & 3.5 & 3.2 & 2.8 & 3.0 & 2.8 & 5.5 & 6.3 & 7.0 \\
\hline$B$ & 5 & $5.7 \dagger$ & 5.2 & 6.3 & 2.8 & 3.0 & 3.5 & 5.9 & 6.4 & 7.2 \\
\hline$B$ & 6 & 3.2 & 3.1 & 3.1 & 2.7 & 3.0 & 2.7 & 6.0 & 6.4 & 6.5 \\
\hline$C$ & 1 & 2.7 & 3.4 & 2.9 & 2.8 & 3.4 & 3.1 & 4.0 & 4.4 & 3.8 \\
\hline$C$ & 2 & 5.1 & 5.1 & 6.0 & 3.3 & 3.3 & 3.8 & 7.1 & 7.0 & 8.4 \\
\hline C & 3 & 3.7 & 3.7 & 3.7 & 2.9 & 3.3 & 3.4 & 6.1 & 6.8 & 7.7 \\
\hline $\mathrm{C}$ & 4 & 3.1 & 4.0 & 3.8 & 2.9 & 2.9 & 3.2 & $7.7 \dagger$ & 8.7 & $\underline{10.8}{ }^{\dagger}$ \\
\hline$C$ & 5 & 4.1 & 4.3 & 4.3 & 3.3 & 3.2 & 4.0 & 7.3 & 7.4 & 8.0 \\
\hline C & 6 & 3.3 & 3.6 & 3.9 & 3.4 & 3.4 & 3.4 & 6.4 & 6.8 & 7.8 \\
\hline$D$ & 1 & 2.7 & 3.4 & 3.0 & 3.4 & 3.2 & 3.0 & 5.8 & 6.7 & 6.4 \\
\hline$D$ & 2 & 3.3 & 3.9 & 3.2 & 3.4 & 3.1 & 3.3 & 5.3 & 5.8 & 6.0 \\
\hline $\mathrm{D}$ & 3 & 2.5 & 3.3 & 3.1 & 2.7 & 3.0 & 3.0 & 6.1 & 6.4 & 7.0 \\
\hline $\mathrm{D}$ & 4 & 2.6 & 3.3 & 3.0 & 2.8 & 3.1 & 3.0 & 6.0 & 6.6 & 7.0 \\
\hline $\mathrm{D}$ & 5 & 2.7 & 3.3 & 2.9 & 3.3 & 3.5 & 3.4 & 6.1 & 6.5 & 6.5 \\
\hline$D$ & 6 & 2.9 & 3.5 & 3.1 & 3.3 & 3.0 & 3.1 & 6.2 & 6.6 & 7.1 \\
\hline
\end{tabular}

†Maximum values if the 8-h EAV has been exceeded, the values are underlined. 
[This page intentionally left blank.] 


\section{REFERENCES}

1. U.S. Department of Transportation, Federal Motor Carrier Safety Administration, Code of Federal Regulations: Title 49, Part 395, Hours of Service of Drivers. October 2008.

2. Karwowski, W., \& Marras, W.S. (eds.). The Occupational Ergonomics Handbook. CRC Press, Boca Raton, FL. 1999.

3. U.S. Department of Labor, Occupational Safety and Health Administration, Code of Federal Regulations: Title 29, Part 1910.95, Occupational Noise Exposure. July 2007.

4. U.S. Department of Health and Human Services, Occupational Noise Exposure. National Institute for Occupational Safety and Health, Cincinnati, OH. June 1998.

5. Robinson, G.S., Casali, J.G., \& Lee, S.E. Role of Driver Hearing in Commercial Motor Vehicle Operation: An Evaluation of the FHWA Hearing Requirement. (National Technical Information Service Order Number: PB98-114606). Federal Highway Administration, Office of Motor Carrier Research and Standards, Washington, DC. 1997.

6. Hessel, P.A., Heck, M.M., \& McJilton, C. Noise levels in over-the-road tractors. American Industrial Hygiene Association Journal; Vol. 43(4): 261-264. 1982.

7. Van den Heever, D.J. \& Roets, F.J. Noise exposure of truck drivers: A comparative study. American Industrial Hygiene Association Journal; Vol. 57: 564-566. 1996.

8. Seshagiri, B. Occupational Noise Exposure of Operators of Heavy Trucks. American Industrial Hygiene Association Journal; Vol. 59(3): 205-213. 1998.

9. Lee, S.E. Role of Driver Hearing in Commercial Motor Vehicle Operation: An Evaluation of the FHWA Hearing Requirement. A PhD Dissertation submitted to the Faculty of the Virginia Polytechnic Institute and State University. 1998.

10. Griffin, M.J. Handbook of Human Vibration. Elsevier Academic Press, San Diego, CA. 1990.

11. International Organization for Standardization (ISO), Mechanical Vibration and ShockEvaluation of Human Exposure to Whole-body Vibration, Part 1: General Requirements; Ref Document No. 2631-1; Geneva, Switzerland. 1997.

12. Paschold, H.W., \& Sergeev, A.V. Whole-body Vibration Knowledge Survey of U.S. Occupational Safety and Health Professionals. Journal of Safety Research; Vol. 40, 171176. 2009.

13. European Commission: Directive 2002/44/EC of the European Parliament and of the Council of 25 June 2002 on the Minimum Health and Safety Requirements Regarding the Exposure of Workers to the Risks arising from Physical Agents (Vibration); Article 16(1) of Directive 89/291/EEC. Official Journal of the European Communities, L177. 2002.

14. Health and Safety Executive: Whole-body Vibration - the Control of Vibration at Work. HSE Book ISBN 071766126 1, Her Majesty’s Stationery Office, Colegate, Norwich, UK. 2005.

15. Dupuis, H., \& Zerlett, G. The Effects of Whole-Body Vibration. Springer-Verlag, New York, NY. 1986. 
16. Boshuizen, H.C., \& Bongers, P.M. and Hulshof, C.T.J. Back Disorders and Whole-body Vibration. International Journal of Industrial Ergonomics; Vol. 6, 55-59. 1990.

17. Seidel, H. Selected Health Risks Caused by Long-term Whole-body Vibration. American Journal of Industrial Medicine; Vol. 23: 589-604. 1993.

18. Miyamoto, M., Shirai, Y., Nakayama, Y., Gembun, Y., \& Kaneda, K. An Epidemiologic Study of Occupational Low Back Pain in Truck Drivers. Journal of Nippon Medical School; Vol. 67(3): 186-190. 2000.

19. Bovenzi, M., Rui, F., Negro, C., D’Agostin, F., Angotzi, G., Bianchi, S., et al.. An Epidemiological Study of Low Back Pain in Professional Drivers. Journal of Sound and Vibration; Vol. 298: 514-539. 2006.

20. Cann, A.P., Salmoni, A.W., \& Eger, T.R. Predictors of Whole-body Vibration Exposure Experienced by Highway Transport Truck Operators. Ergonomics; Vol. 47(13): 14321453. 2004.

21. Health Effects Institute, Diesel Emissions and Lung Cancer: Epidemiology and Quantitative Risk Assessment, A Special Report of the Institute's Diesel Epidemiology Expert Panel; Special Report. Flagship Press, N. Andover, MA. 1999.

22. U.S. Environmental Protection Agency, Health Assessment Document for Diesel Engine Exhaust. National Center for Environmental Assessment, Office of Research and Development; Publication No. EPA/600/8-90/057F. 2002.

23. Doraiswamy, P., Davis, W.T., Miller, T.L., \& Lam, N. Air Quality Measurements Inside Diesel Truck Cabs During Long Term Idling. Transportation Research Record: Journal of the Transportation Research Board; Vol. 1987: 82-91. 2005.

24. Sabina, L.D., Kozawaa, K., Behrentza, E., Winera, A.M., Fitzc, D.R., Pankratzc, D.V., et al. Analysis of Real-Time Variables Affecting Children's Exposure to Diesel-Related Pollutants during School Bus Commutes in Los Angeles. Atmospheric Environment; Vol. 39: 5243-54. 2005.

25. Davis, M.E., Smith, T.J., Laden, L., Hart, J.E., Blicharz, A.P., Reaser, P., et al. Driver Exposure to Combustion Particle in the U.S. Trucking Industry. Journal of Occupational and Environmental Hygiene; Vol. 4: 848-854. 2007.

26. Laden, F., Hart, J.E., Smith, T.J., Davis, M.E. \& Garshick, E. Cause-Specific Mortality in the Unionized U.S. Trucking Industry. Environmental Health Perspectives; Vol. 115(8): 1192-1196. 2007.

27. U.S. Department of Labor, Occupational Safety and Health Administration. Code of Federal Regulations, Title 29, Part 1910.1000, Air Contaminants. July 2008.

28. Heywood, J.B. Internal Combustion Engine Fundamentals. McGraw-Hill Book Co.; New York, NY. 1988.

29. U.S. Environmental Protection Agency. Air Program, Code of Federal Regulations, Title 40, Part 50, National Primary and Secondary Ambient Air Quality Standards. July 2009. 
30. World Health Organization (WHO) Air Quality Guidelines for Particulate Matter, Ozone, Nitrogen Dioxide and Sulfur Dioxide. No.: WHO/SDE/PHE/OEH/06.02. WHO Press, Geneva, Switzerland. 2006.

31. U.S. Environmental Protection Agency. User's Guide to MOBILE6.1 and MOBILE6.2: Mobile Source Emission Factor Model. EPA420-R-02-028. Office of Transportation and Air Quality; Ann Arbor, MI. October 2002.

32. Lodge, J.P. (ed.). Methods of Air Sampling and Analysis (3rd Edition). Lewis Publishers: CRC Press, Inc. Boca Raton, FL. 1988.

33. Winberry, W.T. (ed.). Methods for Determination of Indoor Air Pollutants: EPA Methods. Noyes Data Corp; Park Ridge, NJ. 1993.

34. Montgomery, D.D. Design and Analysis of Experiments (5th Edition). John Wiley and Sons, Inc; New York, NY. 2001.

35. U.S. Mine Safety and Health Administration Department of Labor, Code of Federal Regulations, Title 30, Part 57.5060, Limit on exposure to diesel particulate matter. July 2009. 